Technical University of Madrid

School of Civil Engineering

\title{
FUNICULARITY AND EQUILIBRIUM FOR High-Performance Conceptual Structural Design
}

\section{LEONARDo TODISCO}

THIS DISSERTATION IS SUBMITTED FOR THE DEGREE OF

DOCTOR OF PHILOSOPHY IN

Engineering of Structures, Materials and Foundations

2016 

Leonardo Todisco

PhD Dissertation, (C) 2016

SUPERVISOR:

Professor Hugo Corres Peiretti

LOCATION:

MADRID, SPAIN 



\section{Abstract}

Curved structures are characterized by the critical relationship between their geometry and structural behaviour, and selecting an appropriate shape in the conceptual design of such structures is important for achieving materialefficiency. However, the set of bending-free geometries are limited and, often, non-structural design criteria (e.g., usability, architectural needs, aesthetics) prohibit the selection of purely funicular or antifunicular shapes.

In response to this issue, this thesis studies the possibility of achieving an axial-only behaviour even if the geometry departs from the ideally bending-free shape.

This dissertation presents a new design approach, based on graphic statics that shows how bending moments in a two-dimensional geometry can be eliminated by adding forces through an external post-tensioning system. This results in bending-free structures that provide innovative answers to combined demands on versatility and material optimization.

The graphical procedure has been implemented in a free-downloadable design-driven software (EXOEQUILIBRIUM) where structural performance evaluations and geometric variation are embedded within an interactive and parametric working environment. This provides greater versatility in finding new efficient structural configurations during the first design stages, bridging the gap between architectural shaping and structural analysis.

The thesis includes the application of the developed graphical procedure to shapes with random curvature and distribution of loads. Furthermore, the effect of different design criteria on the internal force distribution has been analyzed. 
Finally, the construction of reduced- and large-scale models provides further physical validation of the method and insights about the structural behaviour of these structures.

In summary, this work strongly expands the range of possible forms that exhibit a bending-free behaviour and, de facto, opens up new possibilities for designs that combine high-performing solutions with architectural freedom. 


\section{Resumen}

Las estructuras que trabajan por forma se caracterizan por la íntima e indisociable relación entre geometría y comportamiento estructural. Por consiguiente, la elección de una apropiada geometría es el paso previo indispensable en el diseño conceptual de dichas estructuras.

En esa tarea, la selección de las posibles geometrías antifuniculares para las distribuciones de cargas permanentes más habituales son más bien limitadas $y$, muchas veces, son criterios no estructurales (adaptabilidad funcional, estética, proceso constructivo, etc.) los que no permiten la utilización de dichas geometrías que garantizarían el máximo aprovechamiento del material.

En este contexto, esta tesis estudia la posibilidad de obtener una estructura sin momentos flectores incluso si la geometría no es antifunicular para sus cargas permanentes.

En efecto, esta tesis presenta un procedimiento, basado en la estática gráfica, que demuestra cómo un conjunto de cargas adicionales, introducidas a través de un sistema de pretensado exterior con elementos post-tesos, puede eliminar los momentos flectores debidos a cargas permanentes en cualquier geometría plana. Esto se traduce en una estructura antifunicular que proporciona respuestas innovadoras a demandas conjuntas de versatilidad arquitectónica y optimización del material.

Dicha metodología gráfica ha sido implementada en un software distribuido libremente (EXOEQUILIBRIUM), donde el análisis estructural y la variación geométrica están incluidos en el mismo entorno interactivo y paramétrico. La utilización de estas herramientas permite más versatilidad en la búsqueda de 
nuevas formas eficientes, lo cual tiene gran importancia en el diseño conceptual de estructuras, liberando al ingeniero de la limitación del propio cálculo y de la incomprensión del comportamiento estructural, facilitando extraordinariamente el hecho creativo a la luz de una metodología de este estilo.

Esta tesis incluye la aplicación de estos procedimientos a estructuras de cualquier geometría y distribución inicial de cargas, así como el estudio de diferentes posibles criterios de diseño para optimizar la posición del sistema de post-tesado. Además, la metodología ha sido empleada en el proyecto de maquetas a escala reducida y en la construcción de un pabellón hecho enteramente de cartón, lo que ha permitido obtener una validación física del procedimiento desarrollado.

En definitiva, esta tesis expande de manera relevante el rango de posibles geometrías antifuniculares y abre enormes posibilidades para el diseño de estructuras que combinan eficiencia estructural y flexibilidad arquitectónica. 


\section{Acknowledgments}

I wish to thank my supervisor, Professor Hugo Corres Peiretti, for inspiring and guiding my research. I appreciated his infinite insistence on intellectual clarity and the opportunity of conducting research on such fascinating topic. Furthermore, I truly enjoyed the possibility of assisting him with the course of "Conceptual Design of Structures" at UPM during the last four years. His endless desire to understand how structures work, probably, is the most important learning which I have inherited over the last years. I wish to thank the Structural Concrete (HE) Research Group for offering me a scholarship to carry out this dissertation.

Furthermore, I would like to express my gratitude to other members of the HE Research Group: Professor Javier León, Professor Alejandro Pérez Caldentey and Professor José Romo Martín. From Professor León I received a constant encouragement as well as valuable help due to his formidable knowledge of History. He is responsible of my incessant desire of studying the past to conceive a better future. Furthermore, I truly enjoyed the opportunity of assisting him with the course of "Maintenance and assessment of historic structures". I wish to thank Professor Pérez for his personal assistance and advices at various stages in my research, and for sharing his extraordinary expertise in structural design and analysis. Finally, I am grateful to Professor Romo for supporting my research with his few, but essential, insights into the current cutting-edge practice of structural design within the office of Fhecor Consulting Engineers. 
A very important part of this research has been carried out at the Massachusetts Institute of Technology. I wish to thank Professor John Ochsendorf for welcoming me as a visiting researcher in the Department of Architecture, and Professor Caitlin Mueller for being an inspiring and motivating advisor during my stay at Cambridge. Professor Mueller offered her valuable knowledge on design and computation as well as a constant encouragement during my stay at MIT. This thesis would not have been possible without her expertise. In addition, I wish to thank Professor Corentin Fivet for welcoming me to the world of graphic statics and for providing important feedback on my research. I am extremely grateful for his assistance and friendship. I wish to thank Juney Lee for his help regarding graphics, and Professor Jerome Connor for discussing future directions of my research. I extend my thanks also to the entire Structural Design Lab and Digital Structures Group for offering ideas and support during my stay. Finally, I am grateful to Francesca Liuni, a master student of architecture at MIT, for sharing an infinite number of discussions and delicious muffins during the cold Bostonian winter.

This thesis would not have been possible without the assistance of the archivists of the Library of our School. I wish to thank Concepción García and her team for their extraordinary aid in satisfying my infinite requests for sources. I am grateful to students who worked with me during these years: Albéric Trancart "the president", Borja Regúlez, Angela Addante, Marco Dore, Antonio Landolfa "Cip", Marco Pepe "Ciop", Alberto Sanchez and Bastian Ninino. Thanks, I have learnt something from each one of you. I also wish to thank my colleagues Alejandro Giraldo, Francesco Marchetto, Freddy Ariñez, Giancarlo Groli, Rodrigo Martínez, Miguel Ángel Peña and Isidro García. A warm thanks to Beatriz Gutiérrez for her kindness and sweetness.

I am truly grateful to Javier Monsalvo and Luis Carlos Mayoral for being my family in Spain. Most of all, I would like to thank my family for their endless support and encouragement. Finally, I would like to thank Giusy for her enduring support. Her encouragement, enthusiasm and smiles made this thesis possible. 


\section{Publications}

The author, together with other colleagues, has published a number of peerreviewed papers dealing with aspects of the work herein:

- Todisco, L.; Corres, H.; Mueller, C.; (2015) "Funicularity through External Post-Tensioning: Design Philosophy and Computational Tool," Journal of Structural Engineering (ASCE), Vol. 142, No. 2.

- Todisco, L.; Fivet, C.; Corres, H.; Mueller, C.; (2015) "Design and Optimization of Externally Post-Tensioned Structures using Graphic Statics," In Proceedings of IASS Symposium, Amsterdam.

- Todisco, L.; Fivet, C.; Corres, H.; Mueller, C.; (2015) "Design and Optimization of Externally Post-Tensioned Structures using Graphic Statics," Journal of the IASS, Vol. 56, No. 4, 249-258.

- Todisco, L.; Corres, H.; (2016) "Il concetto di funicolarità. Lapplicazione per il conceptual design di strutture efficienti e versatili," Structural, Vol. 201, No. 1.

- Todisco, L.; Mueller, C.; (2016) "Externally post-tensioned structures: validation through physical models," Proc. of the ICSA Symposium, Guimarães (accepted).

Finally, the author of this dissertation, with the paper submitted to the IASS Symposium 2015, has been awarded with the Hangai Prize [50]. 


\section{Contents}

I State of the Art 9

1 INTRODUCTION 11

1.1 Introduction .................... 11

1.2 Research Significance . . . . . . . . . ..... 14

1.3 Dissertation Outline .............. 16

2 Literature REVIEW 19

2.1 Introduction ................. 19

2.2 The concept of funicularity ............. 20

2.2.1 Brief historical analysis ...........2 20

2.2.2 The funicular curve ............ 28

2.2.3 Effects of material and load variation . . . . . . 29

2.2.4 An alternative design approach ......... 31

2.2.5 Final comments ............. 32

2.3 Design methods ............... 33

2.3.1 Introduction ............... 33

2.3.2 Physical methods .............. 33

2.3.3 Graphical methods ............ 37

2.3.4 Computational methods ............ 43

2.3.5 Final comments ............ . 45

2.4 Computational tools ................... 48

2.4.1 Introduction .............. 48 
2.4.2 Geometry-based tools . . . . . . . . . . . . 48

2.4 .3 Analysis-based tools . . . . . . . . . . . 50

2.4.4 Design-oriented tools ............. 50

2.4.5 Final comments ............. 53

2.5 Summary ...................... 55

II Post-Tensioned Antifunicular Structures $\quad 57$

3 BACKground $\quad 59$

3.1 Introduction $\ldots \ldots \ldots \ldots \ldots \ldots$

3.2 Background .................. 60

3.3 Organization of the Part II . . . . . . . . . . 65

3.4 Summary ........................ 66

4 METHODOLOGY AND IMPLEMENTATION

4.1 Methodology . . . . . . . . . . . . . . . . 67

4.1 .1 Introduction . . . . . . . . . . . 67

4.1.2 Graphical construction ........... 71

4.1.3 Managing indeterminacies .......... 78

4.2 Implementation . . . . . . . . . . . . . . . 83

4.3 Summary ....................... 85

5 Applications and Design Criteria $\quad 8_{7}$

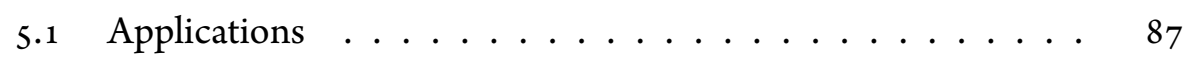

5.1.1 Random geometries ............ 87

5.1.2 Extension to non-uniform distribution of loads . . . 92

5.1.3 Extension to twisted $2 \mathrm{~d}$ geometries ......... 92

5.1.4 Behaviour for additional uniform load . . . . . . . 94

5.1.5 Material-efficiency of the system . . . . . . . . . 95

5.2 Design criteria $\ldots \ldots \ldots \ldots \ldots$

5.2 .1 Introduction $\ldots \ldots \ldots \ldots \ldots$

$5.2 .2 \quad$ Notations . . . . . . . . . . . . . . 99

5.2 .3 Design criteria . . . . . . . . . . . 99 
5.2.4 Parametric analysis and implementation . . . . . 102

$5.2 .5 \quad$ Results . . . . . . . . . . . . . . 103

5.3 Summary ...................... 117

6 REDUCED- AND LARGE-SCALE PHYSICAL MODELS 119

6.1 Reduced-scale physical models . . . . . . . . . . . . . . 119

6.1 .1 Introduction . . . . . . . . . . . . . 119

6.1.2 Review of physical models . . . . . . . . . . 120

6.1.3 Manufacturing process . . . . . . . . . . 121

6.1.4 Experimental results . . . . . . . . . . . 124

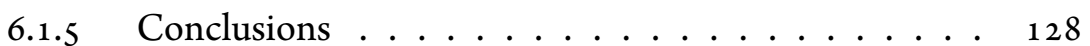

6.2 Pavilion at the 2015 IASS Symposium $\ldots \ldots \ldots \ldots \ldots$

6.2 .1 Introduction . . . . . . . . . . . 128

6.2.2 Project specifications . . . . . . . . . . . . 129

6.2 .3 Material . . . . . . . . . . . . . 129

6.2 .4 Design . . . . . . . . . . . . 130

6.2.5 Fabrication and construction process ....... 136

6.2.6 Acknowledgments to the Project Team . . . . . . . 136

6.2 .7 Conclusions . . . . . . . . . . . . 140

6.3 Summary ...................... 140

III Conclusions 143

7 CONCLUSIONS AND FUTURE STUdIES $\quad 145$

7.1 Summary of results . . . . . . . . . . . . . . 145

7.2 Future studies . . . . . . . . . . . . . . 147

7.3 Final remarks . . . . . . . . . . . . . 152

$\begin{array}{lll}\text { A Appendix 1 } & 153\end{array}$

A.1 Timeline ..................... 153

$\begin{array}{ll}\text { REFERENCES } & 164\end{array}$ 



\section{List of figures}

1.1 U.S. Energy consumption by sector . . . . . . . . . . . 12

$\mathbf{1 . 2}$ Bridges resulting of improper design approach . . . . . . . 14

1.3 Structures satisfying various requirements ........ 15

2.1 Examples of primordial axial-only structures . . . . . . . 21

$\mathbf{2 . 2}$ Thrust lines under different load conditions ........ 22

2.3 Mausoleum of Centcelles .............. 24

2.4 Actio=Rectio principle ............... 25

2.5 Catenaries and parabolas ............. . 27

2.6 Bending-free shapes for three sets of loads . . . . . . . . 29

2.7 Design of St. Paul's Cathedral, London . . . . . . . . . . . 34

2.8 Poleni's safety assessment of San Peter's dome . . . . . . . 34

2.9 Physical models used by Gaudí and Isler . . . . . . . . . 35

2.10 Physical models of the Musmeci's bridge . . . . . . . . 36

2.11 Funicular polygons by Varignon ............ 38

2.12 Reciprocal relationship between form and force polygons . . . 39

2.13 Application of graphic statics to buildings . . . . . . . 41

2.14 Application of graphic statics to bridges . . . . . . . . . 42

2.15 Comparison of design methods . . . . . . . . . . 46

2.16 Front view and cross section of the Tiemblo bridge . . . . . 49

2.17 Graphic statics applied to the Tiemblo bridge. . . . . . . . 49

2.18 Resulting antifunicular arches for curved decks . . . . . . 54

3.1 Photo of the Façade of the Pavilion of the Future. . . . . . 60 
3.2 Façade of the Pavilion of the Future. . . . . . . . . 62

3.3 Externally post-tensioned bridge . . . . . . . . . . 64

4.1 Graphical construction for finding the point loads. . . . . . . . 69

4.2 Graphical construction for generating the point loads. . . . . 70

4.3 Graphical construction $(1$ of 2$) . \ldots \ldots \ldots 74$

4.4 Graphical construction $(2$ of 2$) . \ldots \ldots \ldots 75$

4.5 Reactions with $H_{2} \neq 0 \ldots \ldots \ldots \ldots$. . . . . . . 77

4.6 Reactions with $H_{2}=0 \ldots \ldots \ldots \ldots$. . . . . . . 77

4.7 Examples of different tendon layouts for a circular arch. . . . 79

4.8 Examples of different tendon layouts for an elliptical shape. . . 80

4.9 Solutions with same prestress at one end. . . . . . . . 82

4.10 Algorithm of the tool implemented in Grasshopper. . . . . . . 84

5.1 Antifunicular three-pointed arch with vertical struts. . . . . . 88

5.2 Resulting post-tensioned forms for arbitrary geometries ( $\left(\begin{array}{lll}1 \text { of } 3 & \end{array}\right)$

5.3 Resulting post-tensioned forms for arbitrary geometries ( 2 of 3 ). 90

5.4 Resulting post-tensioned forms for arbitrary geometries ( 3 of 3 ) 91

5.5 Design for non-uniform load distribution . . . . . . . 93

5.6 Design of a footbridge with Y-shape in plan $\ldots \ldots \ldots$

5.7 Behaviour for additional distributed loads. . . . . . . . . 95

5.8 Comparison between bending and post-tensioned solutions . . 97

5.9 Notations . . . . . . . . . . . . . . . . . . . . 100

5.10 Application of DC to a circular arch $($ offset $=5 \%) \ldots \ldots 105$

5.11 Application of DC to a circular $\operatorname{arch}($ offset $=10 \%) \ldots \ldots 106$

5.12 Application of DC to a circular arch (offset=15\%) . . . . . 107

5.13 Application of DC to a basket arch (offset=5\%) . . . . . . 108

5.14 Application of DC to a basket arch (offset=10\%) . . . . . . . 109

5.15 Application of DC to a basket arch (offset=15\%) . . . . . 110

5.16 Application of DC to a free-form shape (offset=4\%) . . . . 111

5.17 Application of DC to a free-form shape (offset=6\%) . . . . 112

5.18 Application of DC to a free-form shape (offset=8\%) . . . . 113

5.19 Indeterminacies vs strain energy (perspective view) . . . . 115 
5.20 Indeterminacies vs strain energy (lateral views) $\ldots \ldots \ldots 116$

6.1 Connection details for compressive and tensioned elements . . 123

6.2 Collapse sequence of a free-form asymmetrical shape $\ldots \ldots .125$

6.3 Collapse sequence of a basket arch . . . . . . . . 126

6.4 Collapse sequence of a circular arch . . . . . . . . . 127

6.5 Materials employed for building the pavilion . . . . . . . 130

6.6 Design proposal . . . . . . . . . . . . . . . 131

6.7 Graphical construction $\left(1\right.$ of $\left._{3}\right) \ldots \ldots \ldots \ldots . \ldots \ldots$

6.8 Graphical construction $(2$ of 3$) \ldots \ldots \ldots . \ldots . \ldots 134$

6.9 Graphical construction $(3$ of 3$) \ldots \ldots \ldots \ldots$

6.10 Fabrication Process . . . . . . . . . . . . . . . 137

6.11 Construction Process . . . . . . . . . . . . . . 138

6.12 After construction . . . . . . . . . . . . . 139

7.1 Optimal shapes for symmetrical and asymmetrical loading . . 149

7.2 Graphical overview of the process .......... 150 



\section{Part I}

State of the Art 



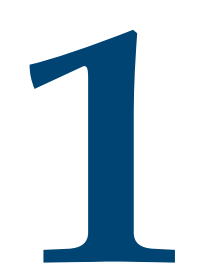

Introduction

\subsection{INTRODUCTION}

"Globally, more people live in urban areas than in rural areas, with 54\% of the world's population residing in urban areas in 2014. In 1950, 30\% of the world's population was urban, and by 2050, 66\% of the world's population is projected to be urban"

$$
\text { [114]. }
$$

With this premise, buildings and civil infrastructures are going to play a strategic role in the urbanization process during the incoming decades. Buildings, referred to the whole construction sector, already represent the major resource consumer among different sectors (Figure 1.1). In this context, they are expected to have an increasing impact on resources consumption during the next decades. 


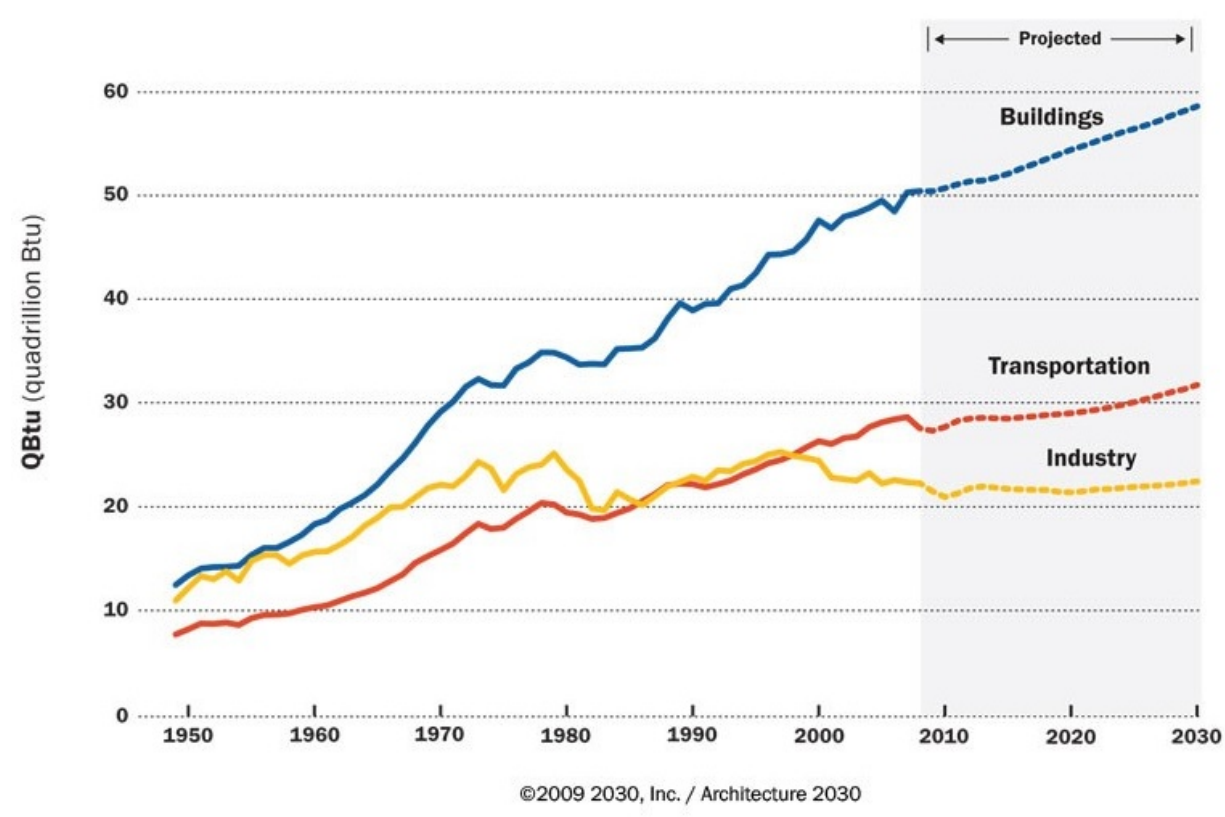

Figure 1.1: U.S. energy Consumption by sector.

Building energy consumption can be considered as the sum of operational and embodied energy. A recent study [6] estimates that $24 \%$ of a typical building embodied energy is related to the structure; this value reaches almost $100 \%$ for a bridge. Part of this embodied energy is associated to the construction materials; thus, a structure can be sustainable, in the true spirit of the word, if it satisfies the guiding principle of reducing use of natural resources [22]. In other words, an essential part of the energy reduction can be achieved through sound structural conceptual design aimed at minimizing the use of material $[27,28]$. This can be accomplished, for example, by designing a structural shape where bending moments are minimum, guaranteeing a maximum exploitation of the material.

Shapes without bending moments are defined as funicular or antifunicular curves if, respectively, only tension or compression forces act. The words "bending-free", "no-bending" and "axial-only" are used to generally identify structures where there are only axial forces, without specifying if the structural 
members work in compression or in tension.

The simple concept of funicularity has been scientifically defined between the $\mathrm{XV}$ and the XVII century and the use of bending-free shapes has been a common adopted design approach throughout the ages. It consists in defining the overall form of the structure as one no-bending shape corresponding, generally, to the permanent loads, and then to determine its thickness based on the variation of the funicular shapes related to the variable loads.

However, a bending-free curve often is not employed because of the low technical knowledge of the designer about equilibrium, or when non-structural design criteria (such as function, program, and aesthetics) prohibit the selection of purely axial-only shapes.

The first case is described by the two bridges shown in Figures 1.2a and 1.2c, respectively located in Germany and Australia. Both of these structures are characterized by an inappropriate structural behaviour. In fact, despite their curved shape these bridges cannot be referred as antifunicular arch bridges because axial forces in the curved structural members are not predominant with respect to bending moments. Figures $1.2 \mathrm{~b}$ and $1.2 \mathrm{~d}$ illustrate the expected antifunicular geometries of these structures, if the arch weight is neglected. The previous examples point out that: $\mathrm{i}$ ) architectural processes (form-finding) are sometimes disconnected from structural evaluations, and ii) the concept of funicularity and its implications are often ignored or not employed in a proper way.

The second case, luckily more frequent than the first, occurs when other important requirements (from aesthetics, to usability, to environmental issues) do not allow the employment of a bending-free curve. The following examples better illustrate this concept. Figure 1.3 shows: (a) the Alcántara Bridge, a Roman semi-circular arch bridge built at Alcántara (Spain) more than 2000 years ago; (b) an ellipsoid-shaped roof employed to cover a new mall in Chiasso (Switzerland); (c) an asymmetrical roof covering the train station of Waterloo (UK); (d) the Zentrum Paul Klee, a museum dedicated to the artist Paul Klee, located in Bern (Switzerland) which roof geometry takes inspiration from the 


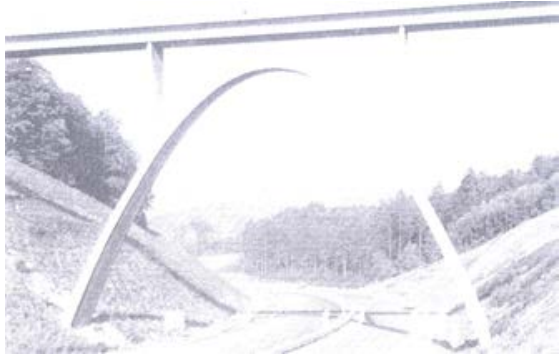

(a)

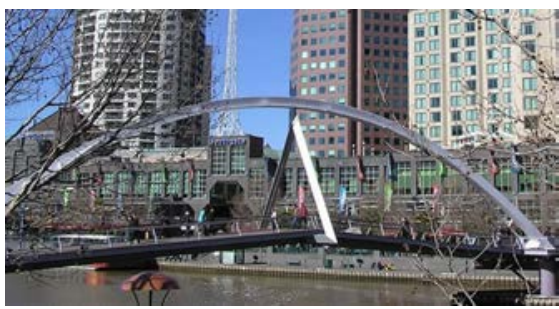

(c)

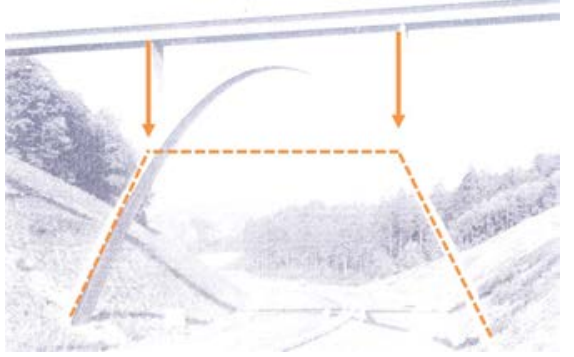

(b)

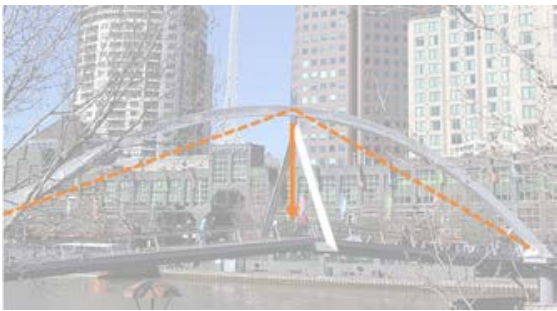

(d)

Figure 1.2: Bridges resulting of improper design approach.

complex nature of the shapes and articulations of the body of work of the artist.

All the structures illustrated in Figure 1.3, that according to the author represent great example of structural engineering, have a shape that depart from the antifunicular one for the self-weight, but that has been chosen to satisfy other important requirements.

In summary, the set of bending-free geometries are limited and, often, nonstructural design criteria (usability, architectural needs, image, etc...) prohibit the selection of purely funicular or antifunicular shapes. In response to this issue, this thesis studies the possibility of achieving an antifunicular behaviour even if the geometry departs from the antifunicular one.

\subsection{Research SignificAnCE}

The current study aims to develop a new method for designing versatile and material-efficient structures where non-structural design criteria prohibit the selection of purely bending-free shapes. 


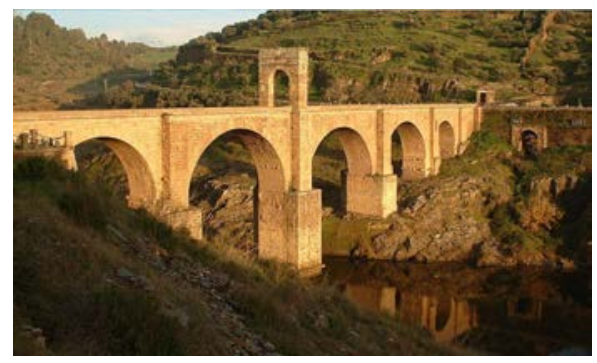

(a)

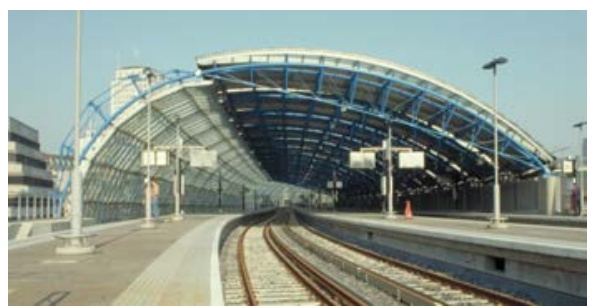

(c)

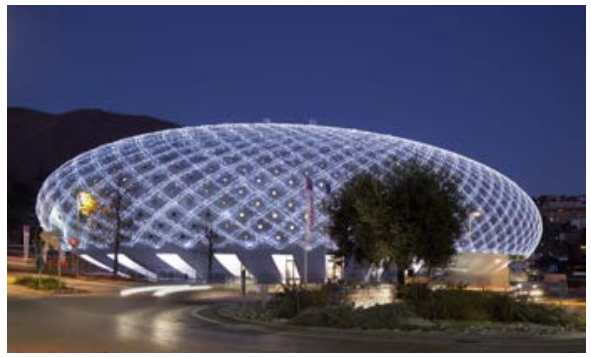

(b)

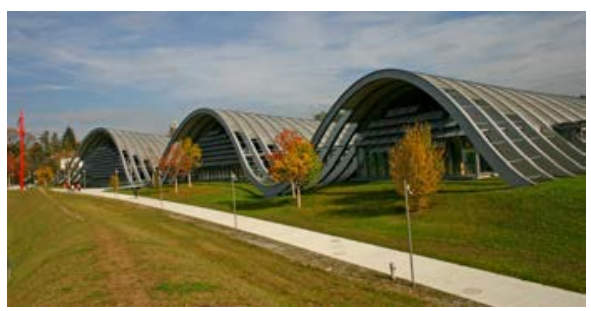

(d)

Figure 1.3: Structures satisfying various requirements.

The proposed approach consists in changing the internal force distribution instead of the structural shape, for achieving the required axial-only behaviour. This can be accomplished by using a hybrid structure that combines rigid compressive members, prestressed members and connection elements. This solution allows to maintain the starting shape and, at the same time, to achieve material-efficiency.

In addition to a graphical methodology developed for solving the described problem, this study includes the implementation of a new design-oriented software which goes beyond the limit of the traditional tools, by bridging the gap between architectural shaping and structural analysis. This software, named EXOEQUILIBRIUM, works in an interactive and parametric framework, which combines geometric alteration with structural predictions. These features makes it suitable for being used during the conceptual design stage because facilitate the exploration of axial-only design alternatives. Furthermore, the implemented tool can be freely downloaded from author's website [4]. 
In summary, this thesis presents a research aimed at achieving an axial-only behaviour when a bending-free shape cannot be adopted. This is achieved by using an hybrid structure that through prestressing modifies the internal force distribution. Although they are not object of this work, it is important to remind that many other requirements (e.g., geometric limitations, robustness, constructability, resiliency, long-term behaviour), over the material-efficiency, have to be considered during the early stage design of a structure.

\subsection{Dissertation Outline}

This dissertation presents a novel procedure that takes advantage of the principle of funicularity to design versatile and material-efficient structures within a design-oriented environment. It is organized as described in the following.

\section{Part I. State of the Art}

The first part of this thesis includes the statement of the problem and research significance (Chapter 1), and literature review (Chapter 2). The latter is divided in three sections:

1. The concept of funicularity (Section 2.2). In the first section the concept of funicularity is presented, focusing on its historical development and on the main features of funicular and antifunicular curves. Next, the effects of material properties and load variation on structural behaviour are briefly described. The concepts, here illustrated, are valid for the design of new structures and for the safety assessment of the existing ones.

2. Design methods (Section 2.3). The second section focuses on the existing procedures aimed at finding bending-free shapes. Methodologies, more or less contemporary, are illustrated and critically analysed.

3. Computational tools (Section 2.4). The third section analyses software in which the described procedures can be implemented. These computational tools, depending on their features, are divided into three main groups: geometry-based, analysis-based and design-oriented tools. 


\section{Part II. Post-Tensioned Antifunicular Structures}

Part II of this work illustrates the application of the antifunicularity concept to structures whose shapes, due to several circumstances, have a non-antifunicular geometry for permanent loads. A new design approach, based on graphic statics, is presented. It shows how bending moments in any two-dimensional curved geometry can be eliminated by adding forces through an external post-tensioning system. An interactive parametric tool (EXOEQUILIBRIUM) is introduced for finding the layout of a post-tensioning system for any structural geometry (Chapter 4 ). The versatility and the potential of the proposed procedure are illustrated with many new design proposals (Chapter 5). In addition, the methodology has been employed for the construction of reduced physical models (Section 6.1). Finally, the design and the construction process of a Pavilion, adopting the developed approach, is in-depth illustrated in Section 6.2. The contents of this Part have been published in several peer-reviewed papers [108-112].

\section{Part III. Conclusions}

The third part of the dissertation remarks general conclusions and specific contributions of this work (Section 7.1). Additionally, important directions for future studies are illustrated in Section 7.2. 

The resistant virtues of the structure that we make depend on

their form; it is through their form that they are stable and not

because of an awkward accumulation of materials. There is

nothing more noble and elegant from an intellectual viewpoint

than this; resistance through form.

Eladio Dieste

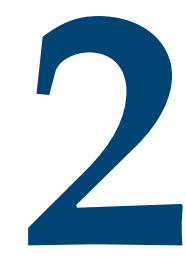

Literature Review

\subsection{INTRODUCTION}

The literature review presented in Chapter 2 is divided in three main sections:

1. The concept of funicularity (Section 2.2). This section presents the definition of the concept of funicularity and its implications on the internal force distribution. Furthermore, a review of the historical development of this concept is described.

2. Design methods (Section 2.3). In this section the most important methodologies to find bending-free shapes are illustrated. These procedures are organized in three main groups: methods based on physical models, graphical techniques and numerical procedures. These methodologies are critically reviewed and, for each one of them, benefits and disadvantages are pointed out. 
3. Computational tools (Section 2.4). This section presents an overview of the existing software aimed at performing form-finding analysis. Depending on their different features, they can be classified in: analysis-based tools, geometry-based tools and design-oriented tools. The section also touches upon the limitations when using these software to the early design stage and the possibility of using tools more oriented to the first stages of design.

\subsection{THE CONCEPT OF FUNICULARITY}

\subsubsection{BRIEF HISTORICAL ANALYSIS}

Before the $15^{\text {th }}$ century the use of funicular and antifunicular structures was based on the empirical acceptation of their good structural performance without an explicit analytical formulation of their mechanical behaviour. Stability was ensured by following geometrical and numerical rules obtained by previous experiences from similar structures $[7,49]$.

Primordial examples of funicular and antifunicular structures are represented, respectively, by suspended bridges (Figure 2.1a [101]) and corbelled domes (Figure $2.1 \mathrm{~b}[2 \mathrm{O}]$ ). Funicular shapes frequently were adopted to cross long valleys, while antifunicular geometries were generally employed as shelters from weather.

Roman constructions (typically arch bridges and domes) were based on a circular shape, which is not a funicular curve for its self-weight. However, Roman builders applied different techniques (e.g., filler materials, step-rings, concrete with graded density) for changing the load distribution, and indirectly to achieve a better structural stability. Today, there is no knowledge about the mathematical and/or the physical models employed by Romans, but the author believes that there was something more than intuition. The following examples aim at better explaining this concept.

The Pantheon of Rome (Figure 2.2a), the building dedicated to all the gods, represents the peak of the architectural and structural revolution promoted by 


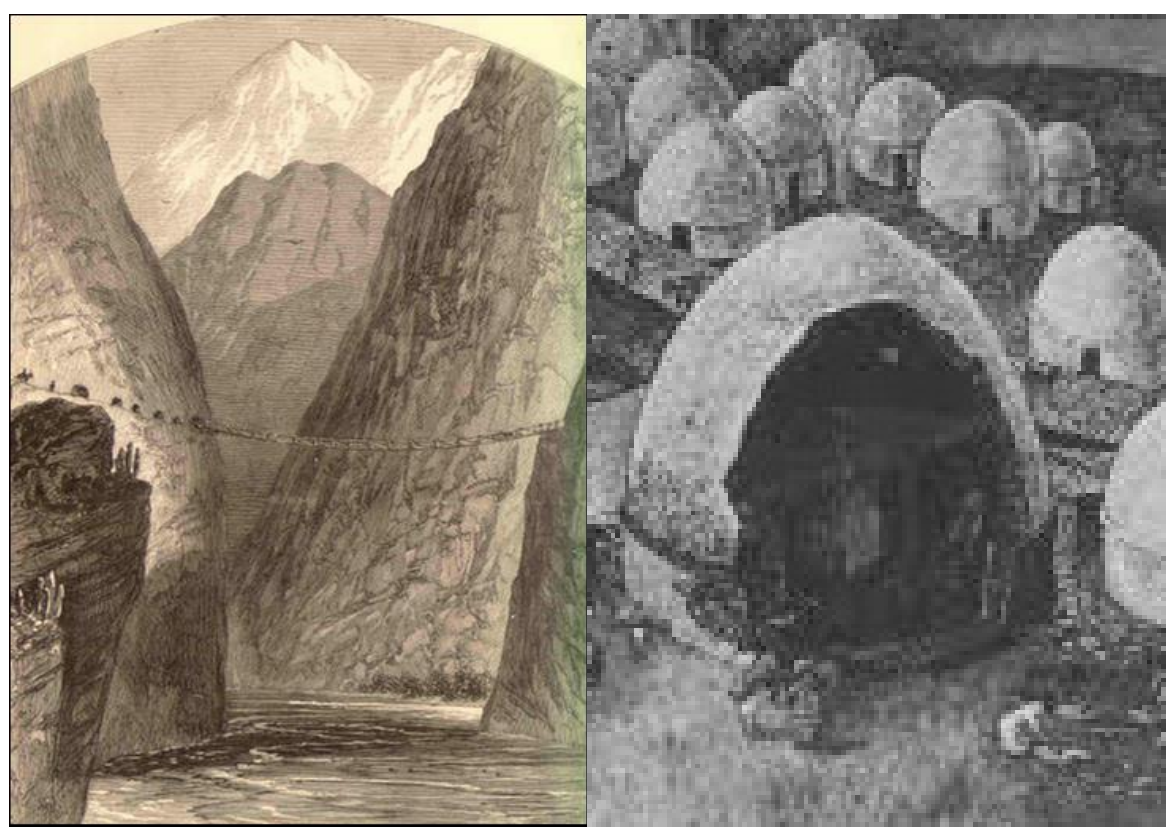

(a)

(b)

Figure 2.1: Examples of primordial axial-only structures.

Romans. It was reconstructed, after a fire, with a de sign of Ap ollodorus of Damascus during a period that ranges from $118 \mathrm{AD}$ to $128 \mathrm{AD}$. This building has been for different reasons a revolutionary c onstruction: among others, the use of concrete (opus caementicium), the dimension of the dome (with 43.3 meter it is still the world's largest unreinforced concrete dome) and the employment of concrete with different $\mathrm{d}$ ensity. The distribution of the dead load is influenced by the variable density of the concrete (as shown in Figure $2.2 \mathrm{~b}$, it ranges from $13.5 \mathrm{kN} / \mathrm{m}^{3}$ in the upper part of the dome to $16 \mathrm{kN} / \mathrm{m}^{3}$ in the lower part of the dome and in the abutments) and by a series of step-rings placed at the bottom of the dome.

Lancaster [62] developed an interesting comparative analysis of the Pantheon that aimed at evaluating the influence of different load distributions on the thrust lines and their corresponding Rankine Safety Factors. The Rankine Safety Factor is a geometrical safety factor calculated by dividing the width of the abutment by twice the distance of the thrust line from the centerline of the abutment. Low values of the Rankine Safety Factors correspond to lower levels of safety and a 
factor of 1 indicates the collapse point of the structure.

The analysis was carried out by dividing the dome in slices of $45^{\circ}$, with variable depth, as shown in Figure 2.2a. This hypothesis neglects the existence of hoop forces and it is representative of the actual state of the dome that appears cracked along meridians [94]. Furthermore, as there are infinite possible load paths of the compression forces within the thickness of the dome, the chosen thrust line is obtained by minimizing the horizontal thrust.

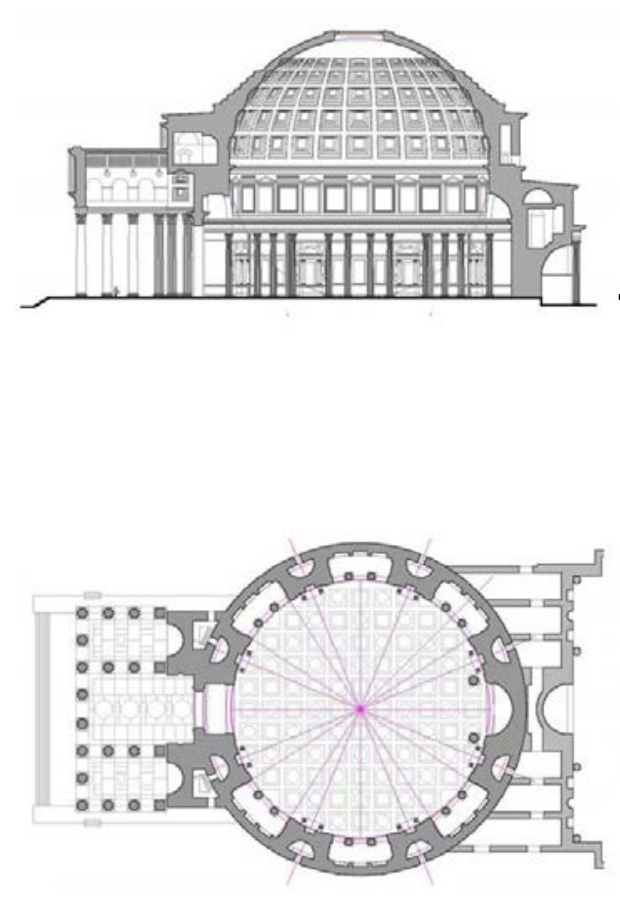

(a)

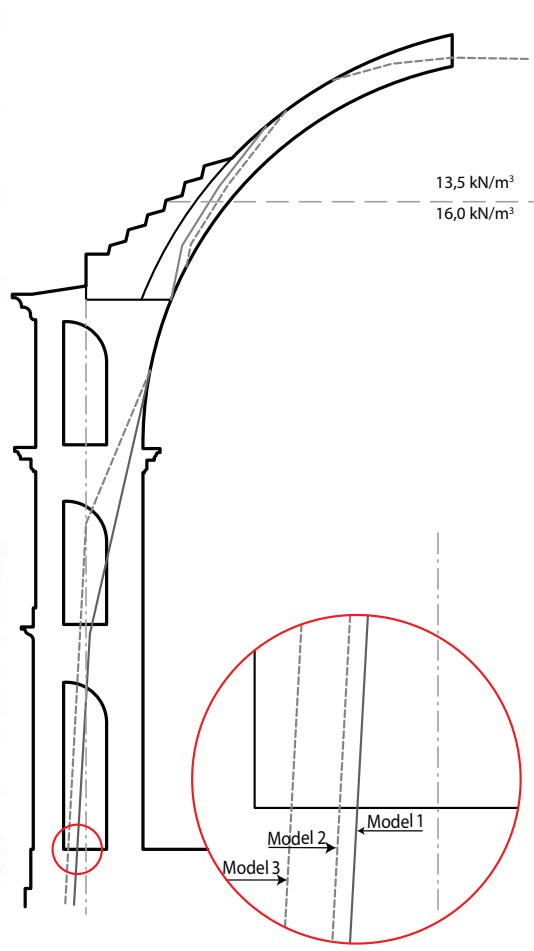

(b)

Figure 2.2: Thrust lines under different load conditions.

The aim of these analysis was to examine the effects of the graded concrete and the step-rings on the Rankine Safety Factor. This was achieved by studying three different load conditions:

- Model 1: it takes into account the real distribution of loads and the existence of step-rings. This leads to a Rankine Safety Factor of 4.23 . 
- Model 2: it considers a constant density of $16 \mathrm{kN} / \mathrm{m}^{3}$ of the concrete in the dome and the existence of step-rings. This leads to a Rankine Safety Factor of 3.60 .

- Model 3: it takes into account a constant density of $16 \mathrm{kN} / \mathrm{m}^{3}$ of the concrete in the dome and neglects the existence of step-rings. In this case the Rankine Safety Factor decreases to 2.60.

The three thrust lines, under different load conditions, are represented in Figure 2.2b. This simplified analysis reveals the importance of the load distribution on the structural stability and the great efficiency of employing step-rings that, similar to pinnacles, verticalize the thrust line and contribute to increase the stability of the building.

Another example of Roman construction is represented by the Mausoleum of Centcelles, at Constanti, Tarragona (Spain). This building probably was a tomb of a person belonged to a high level political, social or religious class during the Roman presence in Spain. The supposed period of construction ranges from the I to the IV century. The building is composed by a big chamber with a circular plan and a spherical masonry dome which spans $11 \mathrm{~m}$ (see Figure 2.3a).

A simplified analysis was developed by Ramos [21] for estimating the influence of different heights of the backfill on the thrust lines and their corresponding Rankine Safety Factors. As in the previous example, the simplification of no-hoop forces was employed and, among infinite thrust lines, the load path corresponding to the minimum horizontal thrust was selected. The analysis, shown in Figure 2.3b, studies the influence of tho different backfill positions on the thrust line and corresponding Rankine Safety Factor:

- Model 1: it discards the existence of backfill. This lies to a Rankine Safety Factor of 2.82 .

- Model 2: it takes into account a backfill with a height corresponding to the $50 \%$ of the rise. This lies to a Rankine Safety Factor of 3.51 . 


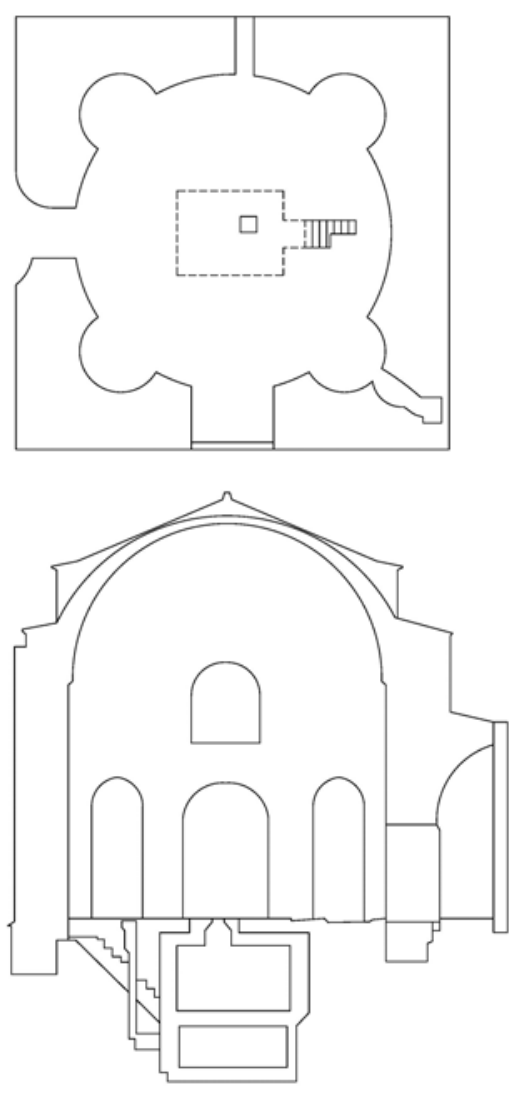

(a)

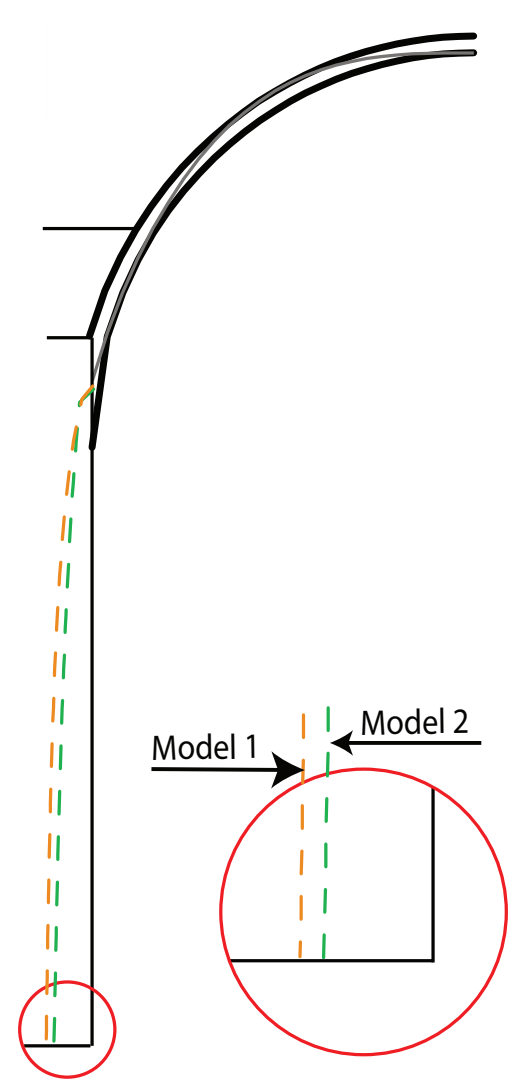

(b)

Figure 2.3: Mausoleum of Centcelles. 
This results point out the fact that backfill, common employed by Romans in their construction, plays a key role for increasing the stability of the building.

The analysis of the previous two examples clearly illustrate that Roman builders had a great experience in the construction of circular arch and domes and they were aware of the great importance of adding more weight on the lower part of the structure to get a better structural behaviour. The arrangement of external weight above elements addressed to receive horizontal thrusts with the goal of verticalize the thrust line is an example of prestress. The main difference, with the modern prestressed system, is that in the latter case the system is auto-equilibrated, while the in first case the reaction are increased.

During the high and late medieval period, pointed arches were spreadly adopted by combining two circular arches. At that time, a singular contribute was provided by Villard de Honnecourt who anticipated the Newtonian concept of Actio=Rectio with an empirical analogy with fighters [45] (Figure 2.4), that require mutual thrusts to maintain equilibrium.

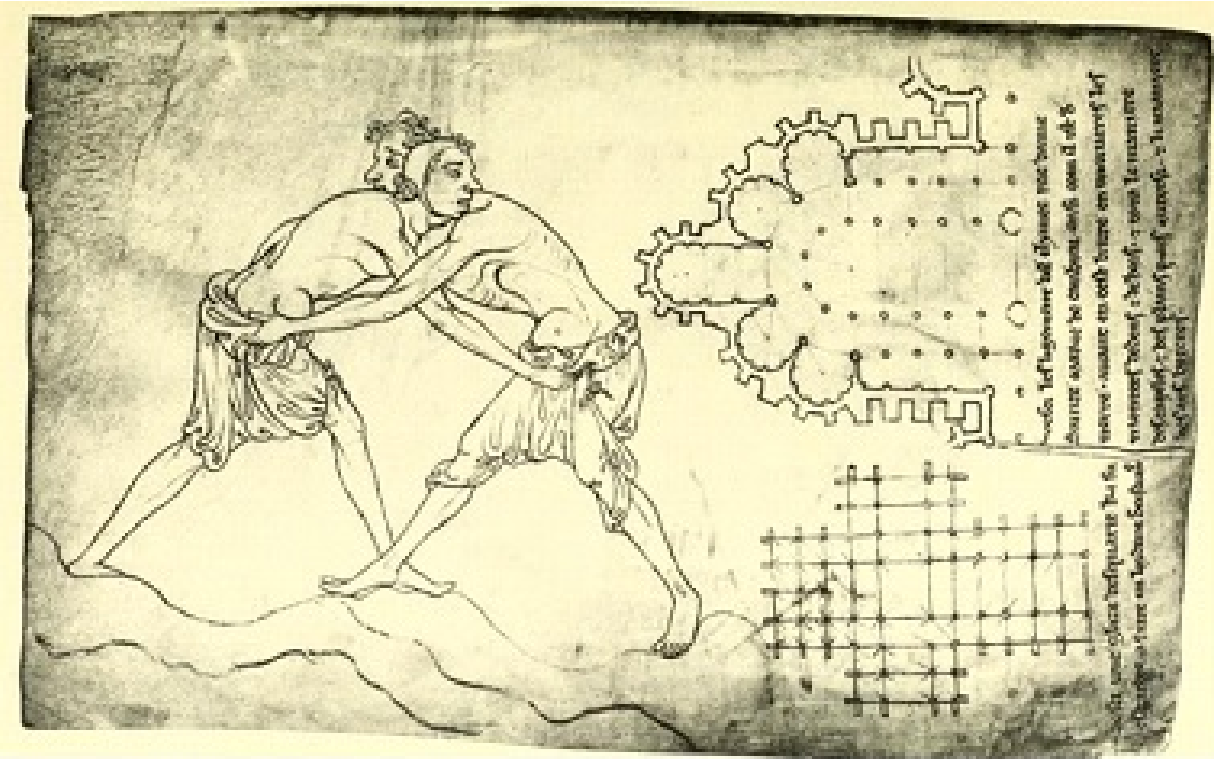

Figure 2.4: Actio=Rectio principle [45] 
Starting from the $15^{\text {th }}$ century, the first documents on investigations about the structural mechanics behind the behaviour of chains and arches arise: a theoretical approximation began to combine the experimental evidence. The first attempts defining the structural behaviour of curved structures resulted to the studies of Leon Battista Alberti (1404-1472), Andrea Palladio (1508-1580) and Leonardo da Vinci (1452-1519). Da Vinci established the basis of the scientific analysis attempting to develop a theory with the concept of statics and realized the foundation of the arch mechanics stating:

"The arch is nothing else than a force originated by two weaknesses, for the arch in buildings is composed of two segments of a circle, each of which being very weak in itself tends to fall; but as each opposes this tendency in the other, the two weaknesses combine to form one strength" (Leonardo da Vinci [3o]).

Depending on the span-to-rise ratio, the difference between a catenary and a parabola, respectively, the funicular shape associated to self-weight (constant load per unit length) and the funicular shape associated to a uniform horizontal distributed load, could be very small: Galileo Galilei (1564-1642) confused one for another in his writing'Dialogues Concerning Two New Sciences" [38], where he stated that the funicular geometry of a chain was a parabola. As shown in Figure 2.5, the two curves are almost identical when the span-to-rise ratio, $\lambda$, is quite high and their slope is low. The difference between the two curves was demonstrated and published by Jungius (1587-1657) after his death.

The key idea to use the inversion principle to find the ideal compression-only geometry for a rigid arch starting from the hanging shape of a rope was published by Robert Hooke (1635-1703) in his famous anagram [46], which solution, published posthumously, is:

"Ut pendet continuum flexile sic stabit contiguum rigidum inversum", which translate in "As hangs the flexible line, so but inverted will stand the rigid arch."

After Hooke, several scientists studied the problem (Bernoulli, Leibniz, and Huygens) but they were reticent to share their results [44]. Differently, David Gregory (1659-1708) published a crucial essay on the subject where the catenary geometry was mathematically described $[42]$ and it was stated: 


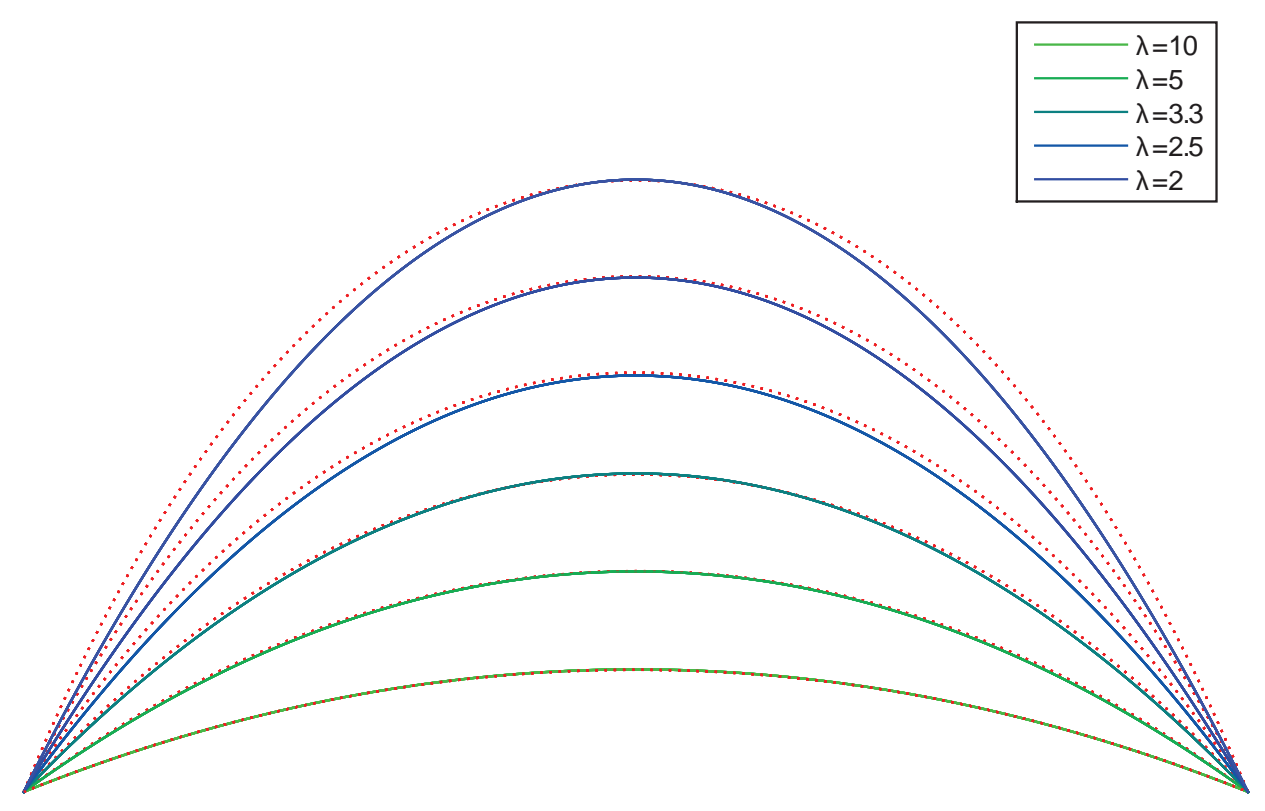

Figure 2.5: Catenaries (dotted line) and parabolas (solid lines). 
"...when an arch of any other figure is supported, it is because in its thickness some catenaria is included..." (Translation from Latin)

Despite this statement is not literally correct (the word "catenaria" should be replaced with "thrust line" as the theoretical line representing the path of the resultants of the forces through an existing estructure [11]), it represents the basic concept behind the structural assessment of masonry arches and it appears in most essays on the subject until the $19^{\text {th }}$ century [7]. As in depth shown in Section 2.3.2, the first application of Gregory's statement can be found in the stability assessment of St. Peter's Dome in Rome. The extraordinary intuition of Gregory, together with the theory of plasticity developed in the $20^{\text {th }}$ century, laid the basis for the common adopted procedures for the structural assessment of masonry. The historical analysis of the concepts of equilibrium, funicularity, thrust line, etc... is extremely fascinating. In this section a very quick overview has been presented, readers more interested in the historical analysis can refer to Kurrer [57], Heyman [44], Timoshenko [105] and Addis [8]. Additionally, together with the information collected in Section 2.3, a timeline with the historical analysis of the funicularity concept and its most prominent employers, from the $15^{\text {th }}$ century to nowadays, is illustrated in Appendix A.

\subsubsection{THE FUNICULAR CURVE}

As described in Chapter 1, in this study, the word "funicular" identifies a geometry in which, for a determinate distribution of loads, only tension forces act. On the contrary, the word "antifunicular" defines a shape in which, for a determinate distribution of loads, only compressive forces act. The terms "bending-free", "no-bending" and "axial-only" are employed to generally identify, both, funicular and antifunicular curves. After defining the acting loads, an infinite number of funicular shapes can be found. By changing the horizontal reactions, or the related, rise of the shape, or the curve length, it is possible to explore the family of all tension-only geometries corresponding to one set of loads. The identical concept is valid for antifunicular structures which exhibit only compression forces $[11,18,48,119]$. Example of families of bending-free 

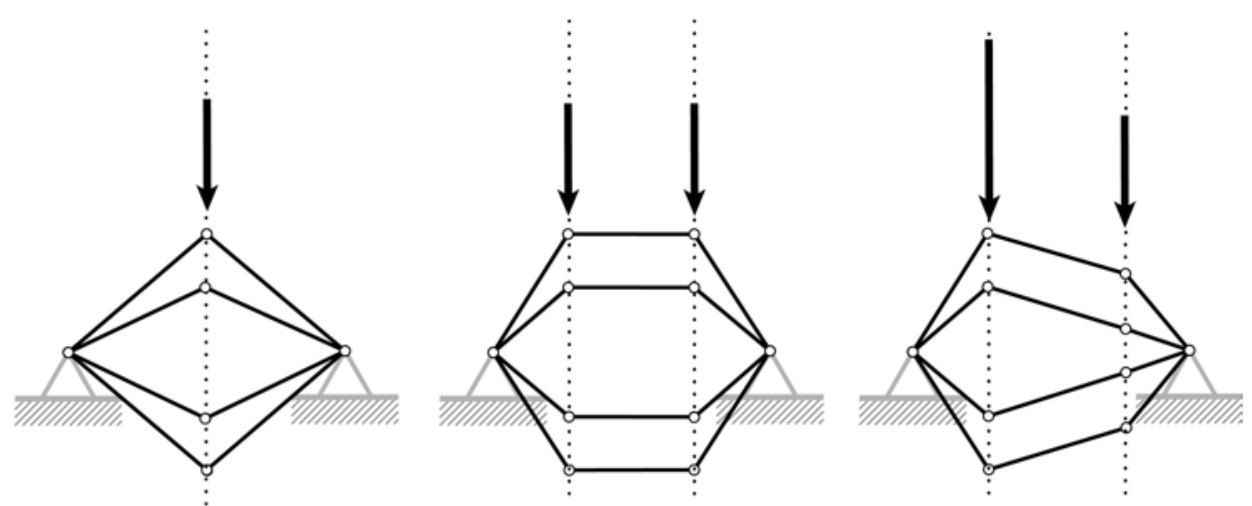

Figure 2.6: Bending-free shapes for three sets of loads.

shapes for three determinate sets of loads are shown in Figure 2.6.

\subsubsection{EFFECTS OF MATERIAL AND LOAD VARIATION}

According to the definition, the funicular (or antifunicular) behaviour is a temporary and an ideal one, because shape and loads inevitably change during the structure life-time. The discrepancy between antifunicular shape (or thrust line) and line of centroids can generates different effects within the structure, depending on its bending stiffness and support typology.

In the following, effects on the structures due to load variation and non-ideal material properties are described separately.

\section{Effects related to permanent loads}

Deformations related to shortening or elongations due to permanent loads can be easily eliminated by employing elements with, respectively, shorter or longer lengths than the theoretical ones [82]. Another alternative consists in employing temporary hinges during decentering and then to remove those after the shortening due to permanent loads is completed [106].

\section{Effects related to increase of permanent loads (after construction)}

An increase of permanent loads, after completing the construction, produces a growth of internal forces within the structure and consequent deformations, which cannot be eliminated making the structure shorter or longer because it 
has been already constructed. These internal forces inevitably produce vertical displacements. Effects consequent to an increase of permanent loads depend on the flexural stiffness of the structure and its degree of indeterminacy. This statement is better explained in the following.

Structures with negligible flexural stiffness (e.g., cables), after an increase of permanent loads continue to be funicular with a geometry similar to the starting one but higher rise, because it is the only way to be in equilibrium.

Structures with no-negligible flexural stiffness (e.g., arches) behave differently depending on support conditions and their degree of indeterminacy. Arches hinged at the supports and at the crown (statically determinate) are not affected by a linear increase of permanent loads, and if the starting geometry has an antifunicular shape, the bending moments still remain null after the increase of permanent loads [33]. Differently, in case of two hinged arches (one degree of indeterminacy), bending moments arise in order to satisfy the condition of compatibility and the thrust line is always above the line of centroids [71].

Finally, if the arch is fully restrained, in addition to the previous described bending moments, other bending moments appear in proximity of supports. Ultimately, effects related to the increase of permanent loads grow with high degree of structural indeterminacy.

In order to decrease the deformations resultant from the growth of permanent loads, two main expedients can be employed to mitigate the problem. The first consists in designing the arch taking into account the deformations due to the increase of axial deformation: this implies that the arch is not funicular for its starting permanent loads. The second, invented by Freyssinet, and adopted in several notable bridges, consists in inducing external forces in the arch crown by employing jacks to neutralize the deformations due to shortening.

\section{Effects related to temperature variation and rheological properties}

The effects derived from a lowering of the temperature or shrinkage of the material are similar to the consequences produced by an increase of permanent loads, in fact, both, produce shortening of the axis of the arch [106]. The previous described conclusions for increasing permanent loads are still valid. 


\section{Effects related to variable loads}

All the distributions of loads that differ from which has been used to find the bending-free geometry inevitably generate bending moments in structures with no-negligible bending stiffness. If the structure is made of discrete elements (e.g., masonry structures) its thickness has to be sized in order to contain the envelope of thrust lines related to all the possible load combinations. On the other hand, if the structure has bending capacity, the thickness of the arch can be reduced. Structures with negligible bending stiffness result in a different geometry because it represents the only way to be in equilibrium.

\subsubsection{AN ALTERNATIVE DESIGN APPROACH}

The previous section has pointed out that the coincidence between line of centroids and antifunicular shape is impossible to be guaranteed continually during the life time of real structures where material properties and variable loads affect the structure. Construction process contributes to make the choice more complicated. Despite several efforts have been carried out to find the optimal geometry of an arch, the question is still open.

An interesting procedure has been adopted for the construction of the Tilos' Arch in the Canary Island of La Palma, Spain, where the shape of the reinforced concrete arch has been designed to be antifunicular for permanent loads after 10 years the conclusion of the construction [87]. A decade represents a range of time necessary to complete great part of the processes of shrinkage and creep. Generally all procedures adopted for finding the most convenient geometry are based on the use of the permanent loads as loads to find the shape of the arch $[71,76]$.

An alternative procedure has been studied by the author together with Ninino [84]. It consists in investigating alternative distributions of loads, which differ from the common adopted one, for finding a more material-efficient shape of the arch. This concept follows an intuition of Fernández Casado, who stated that the most material-efficient arch shape should be found within the envelope of all antifunicular shapes obtained employing all the combinations between 
permanent and live loads [33]. This procedure would change the classical design approach, which consists in $[82]$ :

1. to find the overall form based on the antifunicular of permanent loads,

2. to determine the thickness based on the variation of the funicular shapes related to variable loads.

Preliminary results demonstrate the existence of even more efficient shapes than the antifunicular found for permanent loads, de facto confirming the intuition of Fernández Casado. The gap between the antifunicular curve for permanent loads and the optimal shape found after a complex optimization procedure increases for higher differences, in magnitude and in distribution, between permanent and variable loads. Nevertheless, if a comparison in terms of material is performed, the differences result relatively small. In fact, the maximum vertical distance between the two curves is around $2 \%$ of the rise, and this result, for practical applications, can be negligible.

\subsubsection{Final COMMENTS}

In this section the basic concepts of funicularity and antifunicularity have been described, and the effects on the structure due to variable material characteristic and loads have been briefly illustrated. It has been pointed out that, if the structure has bending stiffness, the bending-free behaviour is temporary. Furthermore, a new approach for designing more material-efficient arches has been proposed. Next section is focused on describing and critically reviewing classical and more recent methodologies for finding axial-only shapes. 


\subsection{Design Methods}

\subsubsection{INTRODUCTION}

The aim of this section is to present a brief overview of different methodologies for finding bending-free shapes in two and three dimensions. The search of axialonly curves can follow principally three approaches. The first is based on the use of physical hanging models in which elements without bending stiffness are free to find an equilibrated shape in the space (Section 2.3.2). The second approach is founded on the use of graphical techniques for exploring bending-free forms, mainly in 2-D (Section 2.3.3). Finally, the third approach is the most recent one, and it is based on the application of numerical form-finding techniques (Section 2.3.4). For each procedure advantages and limits are briefly illustrated.

\subsubsection{PhysicAl METHODS}

As mentioned in Section 2.2.1, the idea of employing the inversion principle to find a compression-only geometry was proposed for the first time by Robert Hooke in 1676 . As stated by Huerta [47], it has been one of the most brilliant ideas in the history of structural analysis. Hooke suggested to Christopher Wren, architect of the St. Paul's Cathedral in London, to design the shape of the dome using a chain model loaded with the corresponding weights at the respective centres of gravity [44]. Figure 2.7 illustrates, on the left, the first sketches of the architect and, on the right, the coincidence between the shape of the interior dome and the catenary.

Around sixty years later, in the 1740 s, a hanging physical reduced model was employed by Poleni for assessing the stability of St. Peter's dome in Rome (Figure 2.8). Differently from Hooke, Poleni used different weights along the curve. In this structural assessment, Poleni employed the slicing techniques which allows to analyse a tree-dimensional dome by dividing it in slices (simple arches). In the case of the St. Peter's Dome it was divided in 50 segments. As reported in Huerta [47], after the intuition of Poleni, the use of hanging models for safety assessments was not used frequently in the following centuries. 

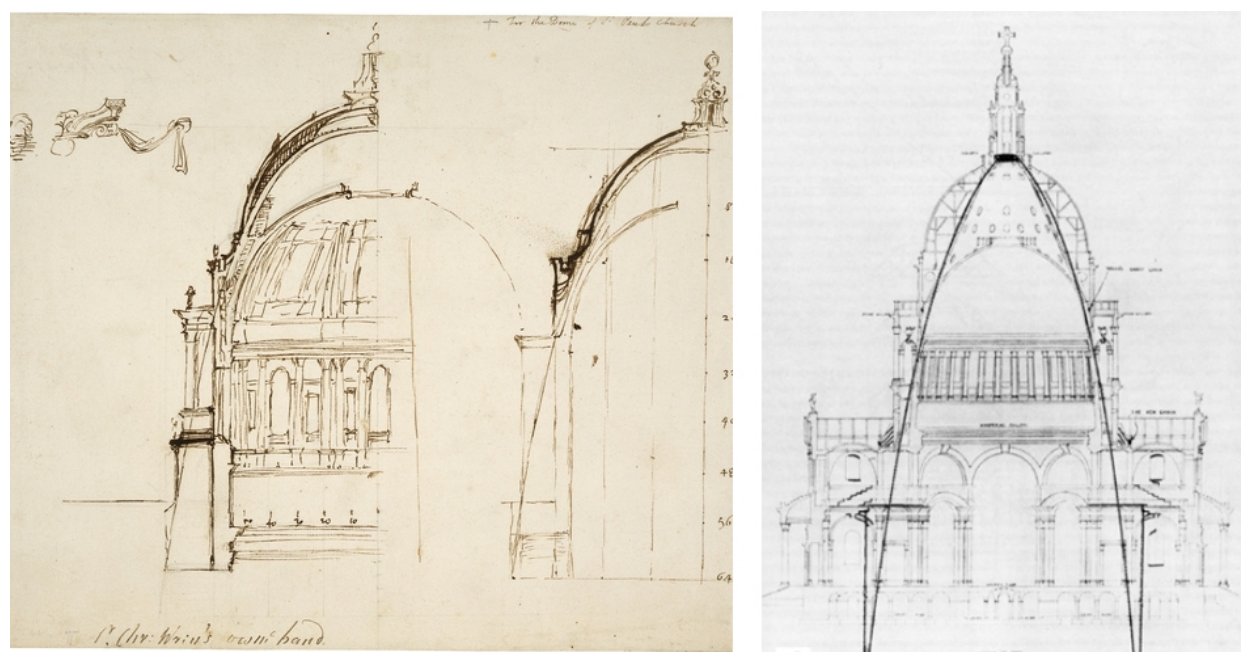

Figure 2.7: Wren's free-hand drawing (on the left); catenary shape of the dome (on the right)
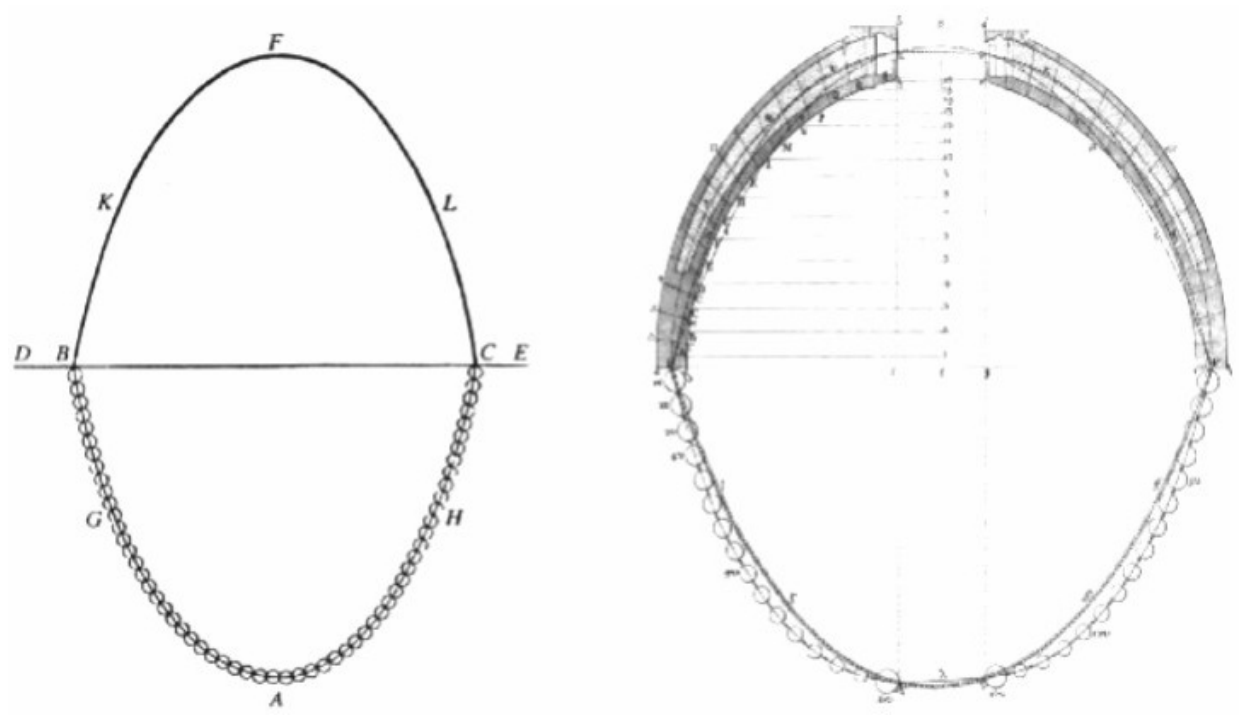

Figure 2.8: Poleni's safety assessment of San Peter's dome 
In 1837 , Hübsch adopted the same Hook's principle for designing a dome in Kassel, Germany, and, several decades later, Ungewitter strongly recommended the use of physical models for the design of cathedrals [113]. With the exception of few cases (Hübsch and Young) physical hanging models were not used for two centuries until the $20^{\text {th }}$ century, when Gaudí and Isler employed complex web of chains and sheets of cloth, respectively, to find the shape of their well-known buildings. As stated by Isler:

"The model has an answer to (nearly) everything" (Heinz Isler)

Figure 2.9 shows the photos of the models employed by Gaudí for finding the shape of the Sagrada Familia in Barcelona, and by Isler for designing ultra-thin shells in Switzerland. Gaudís experimental methods were based on models in which a set of loads were suspended to a network of wires. Differently, Isler employed sheet clothes which were frozen and then inverted in order to obtain antifunicular shells [63]. The Gaudi's choice of using wires, instead of surfaces, represents an implicit application of the slicing technique to the threedimensional hanging models [47].
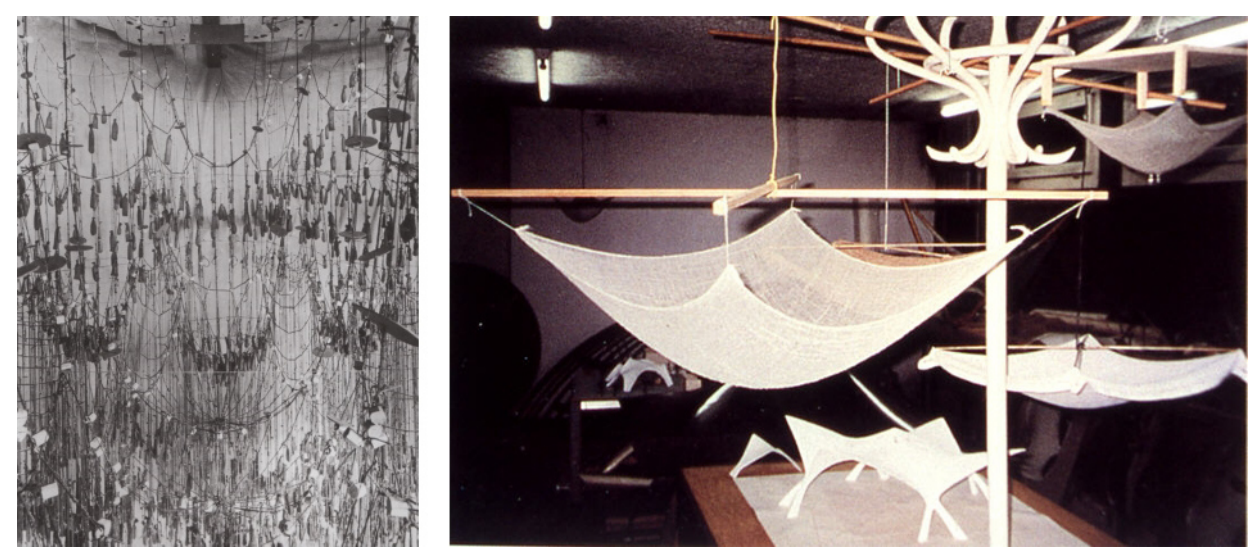

Figure 2.9: Physical models used by Gaudí and Isler

Both the designers rejected the idea of using shapes designed according to a determinate architectural style and they employed hanging models as design method for finding material-efficient shapes. In addition to Gaudí and Isler, several European engineers worked with physical models. One of the most 
relevant employer of that technique was Frei Otto (1925-2015) who used soap films for finding minimal surfaces [86].

\section{"Structures cannot be designed arbitrary" (Frei Otto)}

With the goal of carrying this long design tradition of experimental methods to the education field, several universities (e.g., Cornell University, John Hopkins University, University of Manitoba, Eindhoven University of Technology and MIT among others) have organized workshops focused on designing and building structural ice shells with the goal of reproducing Isler's experiments [1]. The author of this dissertation, in an attempt to reproduce the well-known Musmeci's bridge over the Basento River (Potenza, Italy) has constructed a reduced-scale physical model made of frozen water and soaked fabric (Figure 2.10).

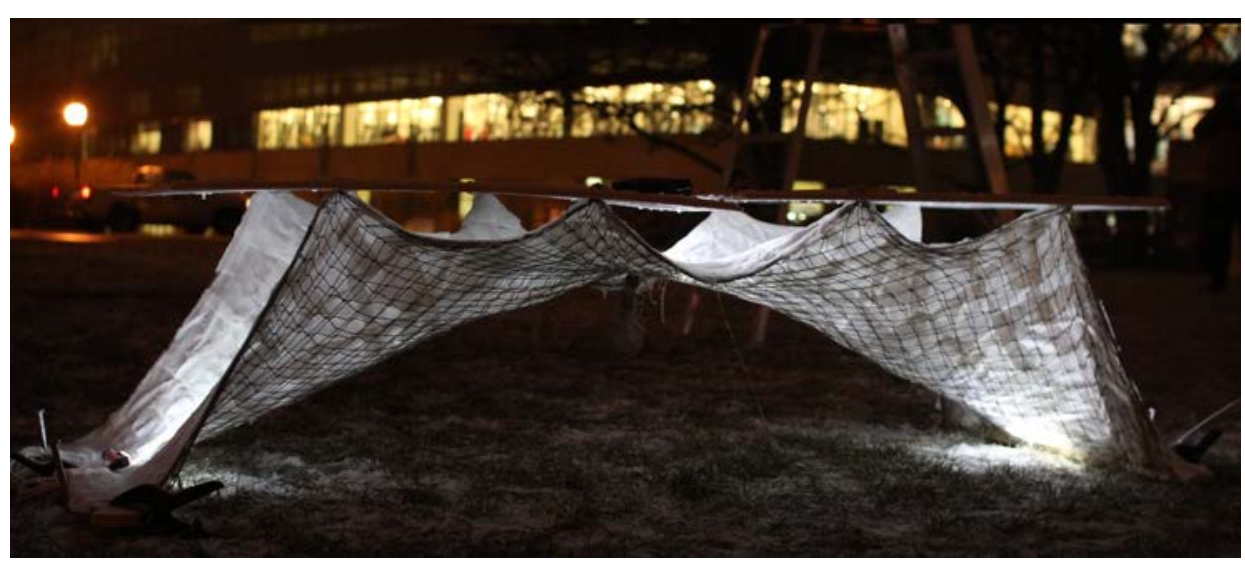

Figure 2.1 o: Physical models of the Musmeci's bridge over the Basento River.

It is important to evidence that the shape of a hanging chain is independent of scale, as the static equilibrium of structures in compression [9], so hanging reduced models can be defined as scale-independent. Hanging models provide immediate feedback to variation of loads and support position. This allows a good control of the designed shape in two and three dimensions.

The main disadvantages of experimental methods are represented by the difficult to take into account variable thickness and loads different from the vertical ones. Furthermore, it is pretty difficult to obtain values of stresses and 
strains in different point of the hanging geometry. Additionally, materials used to build the physical models are different from real building materials, and the obtained three-dimensional shapes depend on the warpage of fabric. Finally, the construction of physical models can be very time consuming.

\subsubsection{GRAPHICAL METHODS}

The most well-known graphical method is graphic statics, which relates structural geometry and internal forces through dual polygons, defined as funicular and force polygons. The dualism concept between the funicular polygon (also known as Cremona or Cremona-Maxwell diagram) and the force polygon was introduced by Varignon [116] (Figure 2.11).

Based on this principle, a new graphical technique was presented by Culmann in 1864 in order:

"to solve engineering tasks that are accessible to geometric treatment with the aid of the new geometry" [29]

Important contributions were provided by Maxwell, who developed the theory of reciprocal diagrams $[12,72,73]$ and by Ritter, who employed graphic statics for the study of statically determinate structures [92, 93]. Furthermore, Rankine developed the Theorems of Transformation of Structures. As stated by Bauschinger in the preface of his well-known book [14]:

"Graphical statics is so crucial to the study of engineering sciences and the practicing engineer that we hope to see it spread widely, and this will be the case to some extent.

Perhaps my book can help proliferate this knowledge further because it is not necessary to be familiar with the so-called newer geometry. I did not plan it that way, it happened by itself"

The reciprocal relationship between form and force polygons ensures that the structures are always in equilibrium (Figure 2.12).

The method is graphical in the sense that forces are geometrically calculated from the force polygon. In addition, the clarity of graphical approaches have 


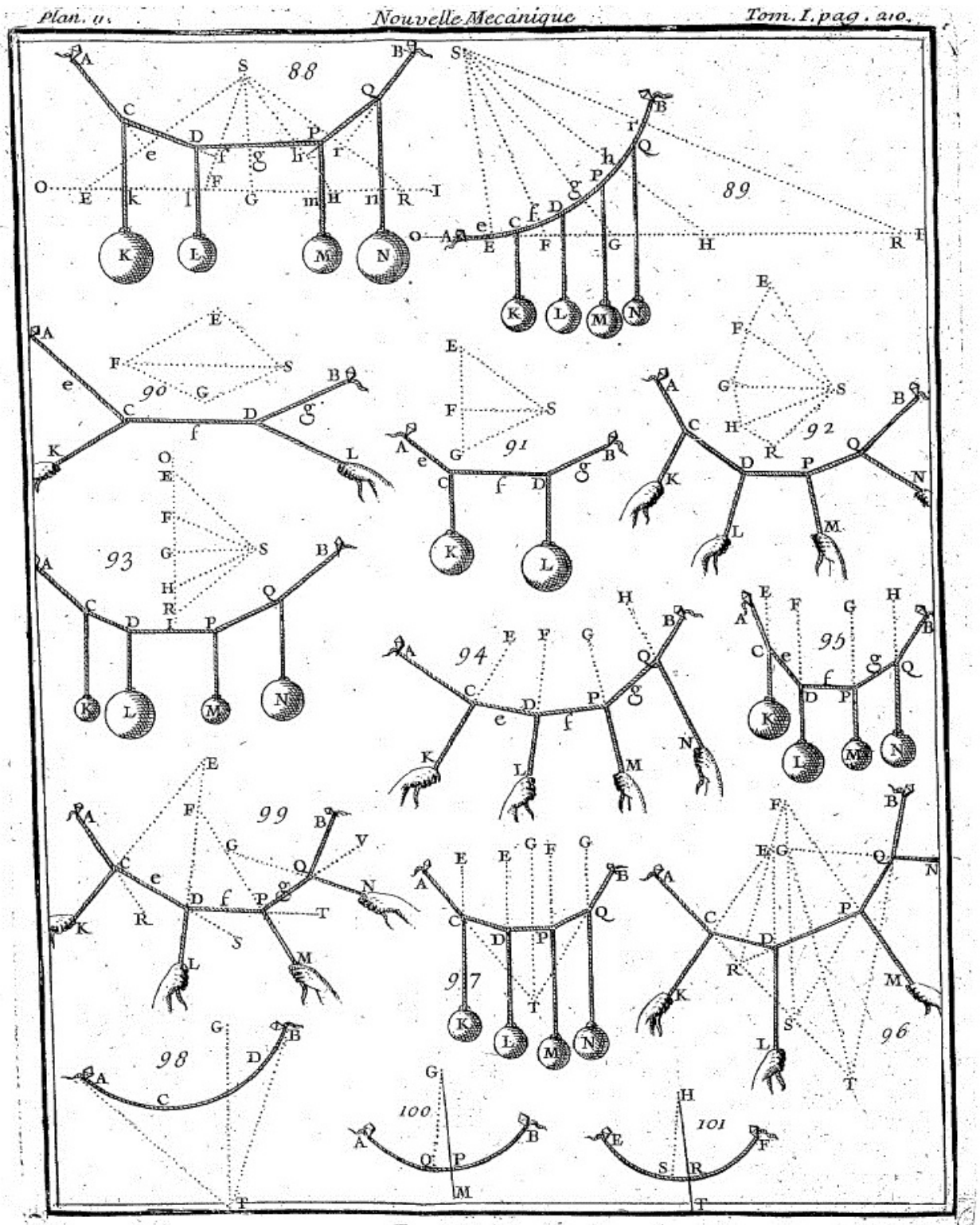

Figure 2.1 1: Funicular polygons by Varignon. 


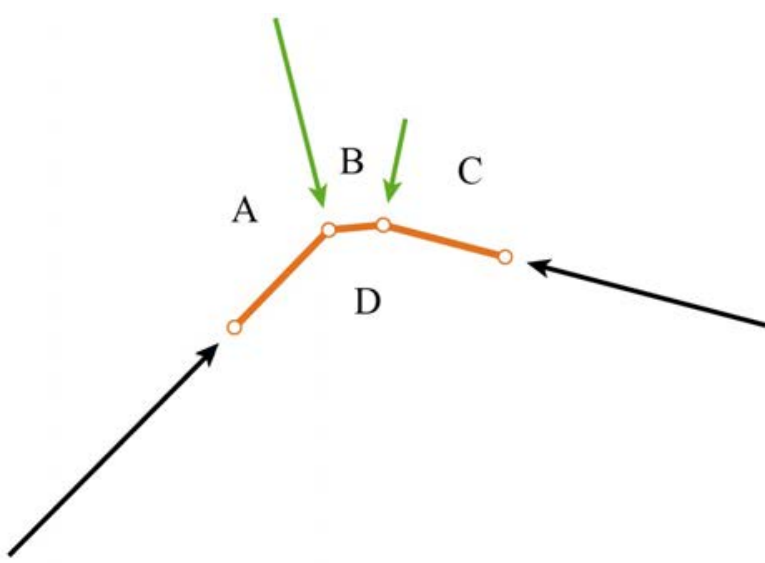

Form Polygon

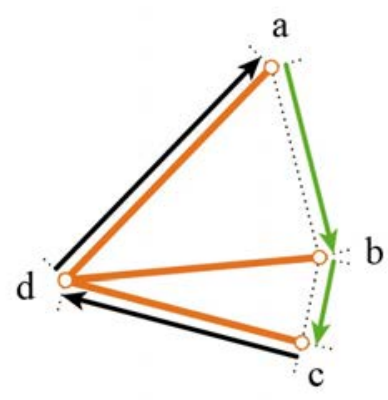

Force Polygon

Figure 2.1 2: Reciprocal relationship between form and force polygons.

a high didactic value since relations between form and forces can be clearly expressed.

During one century (1850-1950) graphic statics has been the most taught and employed design method. Figures 2.13 and 2.14 show several examples of buildings and bridges, respectively, in which graphic statics has been employed. Pictures on the left side describe the graphical analysis, while pictures on the right side illustrate photos of the building object of study.

Figure 2.13 (first row) illustrates an original drawing by Luis Moya Blanco (1904-1990) who employed graphical methods for the design of the church of St. Agustín in Madrid. Moya took advantage of graphical methods to efficiently design arches whose horizontal thrusts are equilibrated by an elliptical shape in plan. Figure 2.13 (second row) shows the graphical construction done by Rafael Guastavino for the design of the dome of St. Francis de Sales Church in Philadelphia in 1909 [85]. Figure 2.13 (third row) illustrates the graphical study done by Rubió i Bellver in 1912 for understanding the structural behaviour of the Palma de Mallorca Cathedral which main feature is the incredible slenderness of the columns [49].

As mentioned before, Figure 2.14 describes existing bridges in which graphic statics have been employed as design method. Figure 2.14 (first row) shows the graphical construction adopted by Robert Maillart in 1929 for the Salginatobel 
Bridge, a 132 meter span concrete bridge hinged at the springing lines and the crown. There is a perfect match between the thrust line and the axis of the bridge close to springing lines, while when the two lines do not fit perfectly, such as at the middle half of the span, bending moments arise and the corresponding crosssection is bigger [35]. Figure 2.14 (second and third row) shows the graphical construction provided by Théophile Seyrig for the Maria Pia Bridge located in Oporto [104]. Finally, Figure 2.13 (fourth row) illustrates a recent example provided by Conzett for the design of the Traversina bridge [26]. 

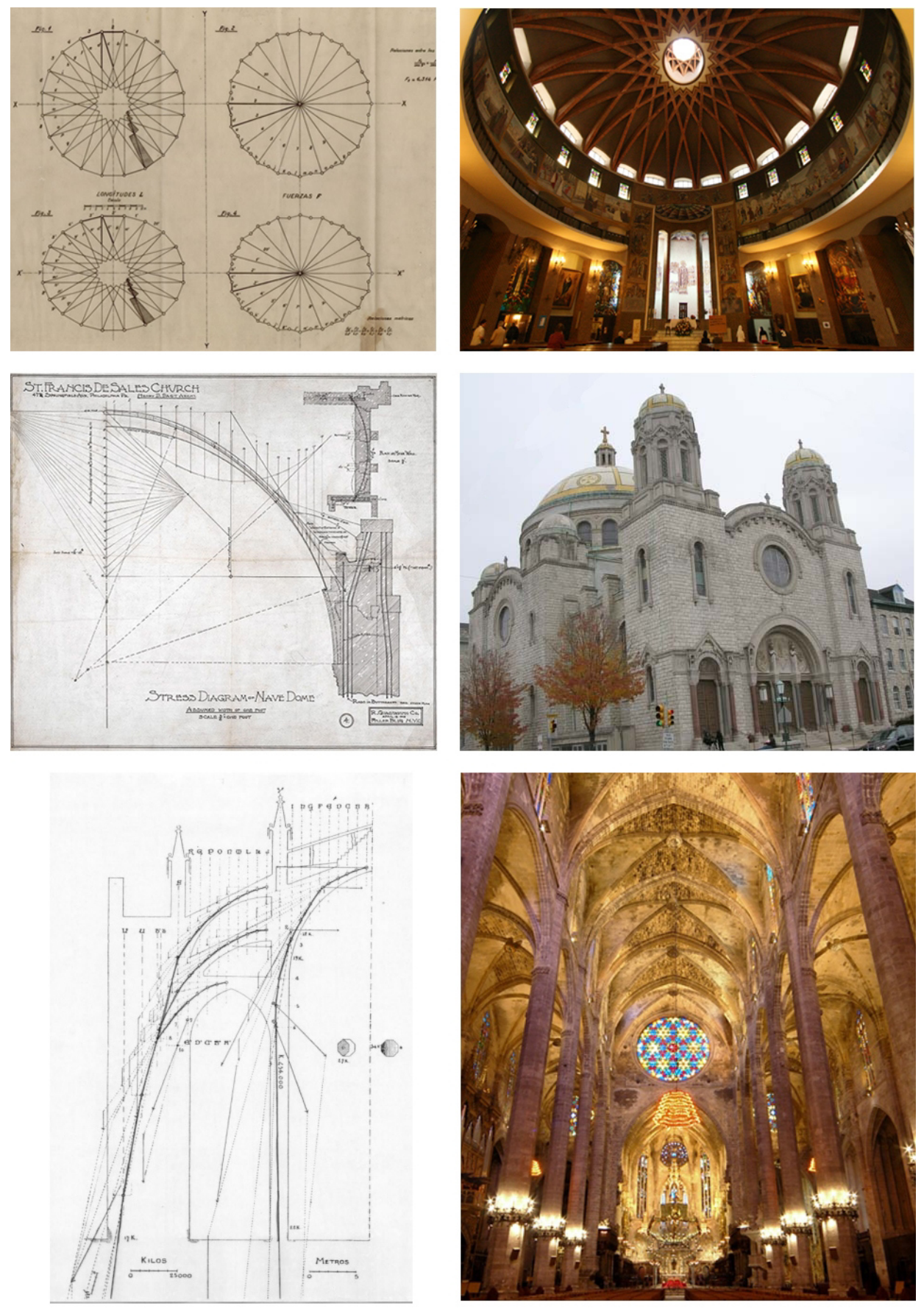

Figure 2.13: Application of graphic statics to buildings. 



Figure 2.14: Application of graphic statics to bridges. 


\subsubsection{COMPUTATIONAL METHODS}

\section{Method based on bending distribution}

Considering an infinitesimal element of a rope, $d x$, loaded with a set of vertical loads, $q(x)$, the horizontal component, $H$, of the axial force, $N$, is constant along the curve because only vertical loads act. The differential equation of the family of funicular curves can be expressed as:

$$
\frac{d^{2} y}{d x^{2}}=-\frac{q(x)}{H}
$$

Equation 2.1 is similar to the differential equation of the classical beam theory:

$$
\frac{d^{2} y}{d x^{2}}=-\frac{M(x)}{E I}
$$

This analogy shows that the funicular shape has the same form of the bending law of a reference simply supported beam with same span and applied loads [105]. With reference to the definition of an axial-only shape, bending moments in each point of the curve have to be zero. Bending moments, $M(x)$, for a generic curve can be expressed as:

$$
M(x)=M_{o}(x)-H y(x)
$$

where $M o(x)$ is the bending produced by the same distribution of load for a simply supported beam, $y(x)$ is the vertical coordinate of points and $H$ is the horizontal reaction. According to the definition of funicular geometry, $M(x)$ has to be equal to zero, thus the vertical coordinate of points $y(x)$ can be calculated as:

$$
y(x)=\frac{M_{o}(x)}{H}
$$

That result is of great importance because illustrates how the funicular configuration corresponds perfectly to the moment diagram of a beam with the same span and distribution of loads. In a more general case, if the distribution of load $q(x)$ is variable along $x$, the vertical position of nodes $y(x)$ corresponding to 
the funicular geometry is expressed by:

$y(x)=\frac{1}{H}\left[\int_{0}^{l} q(x) d x \cdot\left(1-\frac{\int_{0}^{l} q(x) x d x}{\int_{0}^{l} q(x) d x}\right)-\int_{0}^{x} q(x) d x \cdot\left(x-\frac{\int_{0}^{x} q(x) x d x}{\int_{0}^{x} q(x) d x}\right)\right]$

\section{Methods based on numerical strategies}

Numerical strategies have been recently developed in order to find the solution to a problem characterized by a strong geometric non-linearity, where the final bending-free shape is unknown. These methods are based on numerical algorithms where an iterative process stops when a static equilibrium is reached [66]. Their first applications were related to the design of cable-net roofs and tensile membranes. An in-depth state-of-art review was presented by Ramm [91], while a comparison of the methodologies is illustrated in Veenendaal [117].

In summary, the numerical methodologies can be divided in three different groups depending on the adopted computational approach:

- Dynamic relaxation method based on obtaining an equilibrated solution after a damped structural motion. The method of dynamic relaxation starts with a given geometry which mass is concentrated is some points. This system of concentrated masses has a damped dynamic movement that it is stopped when equilibrium is reached $[13,31]$. There is no physical representation of the method with the reality; furthermore, convergence and stability of operation are strongly related to surface discretization [66].

- Stiffness matrix method based on the use of stiffness matrices. By using this method, inner forces are calculated in the continue structure, no discrete network of elements is employed, and material properties have to be implemented leading to time-consuming procedures, without guaranteeing a stable convergence [66]. This approach has been adopted by the author for finding the antifunicular shape of arches supporting a curved deck [107].

- Force density method where each singular equilibrated configuration corresponds to an assumed force density (ratio of force to length) distribution. The method was initially developed in response to the 
need for computational modelling the Munich Olympic complex [66]. Pre-stressed cable nets need non-linear system of equations but the employment of force to length ratios, instead of forces, allows to solve the problem of equilibrium by a system of linear equations $[69,99]$. Results are strongly related to the mesh density and difficult to predict.

Computational approaches to form-finding are commonly implemented in software for structural analysis purposes. However their complex algorithms do not allow an easy control of the shape definition. In addition, if numeric approaches are essential for the design of three-dimensional structures, their use can be replaced by other methodologies for the design of two-dimensional structures, to which this study is mainly addressed.

\subsubsection{FinAl COMMENTS}

The previous sections have provided a brief overview of the different approaches aimed at finding two and three dimensional geometries in which only axial forces act. These methodologies are somehow conceptually equivalent, in fact by using materials with different properties in physical hanging models, by moving the pole in graphic statics, by changing the horizontal reaction in the method based on bending distribution, by varying the material properties in stiffness matrix method, by changing the starting prestress in the force density method and by varying the stiffness between nodes in dynamic relaxation methods, it is possible to explore all the different possible configurations of bending-free geometries for one distribution of loads.

As an attempt to summarize the previous analysis, a personal review of the main features of the methodologies for finding bending-free shapes is graphically presented in Figure 2.15. These graphs provide a visual recap of the main benefits and disadvantages of each form-finding methodology.

Figure 2.15 indicates that a perfect approach does not exist. According to the author, a combined use of different methodologies is a more promising strategy to produce structurally efficient solutions. 


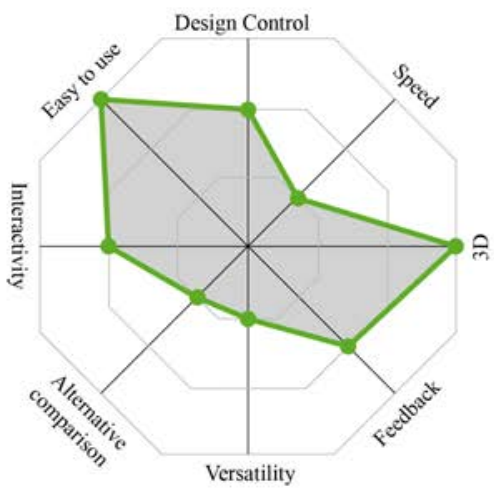

Hanging Models

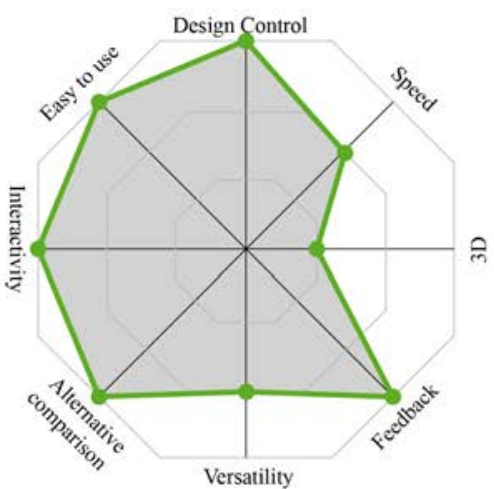

Graphical Methods

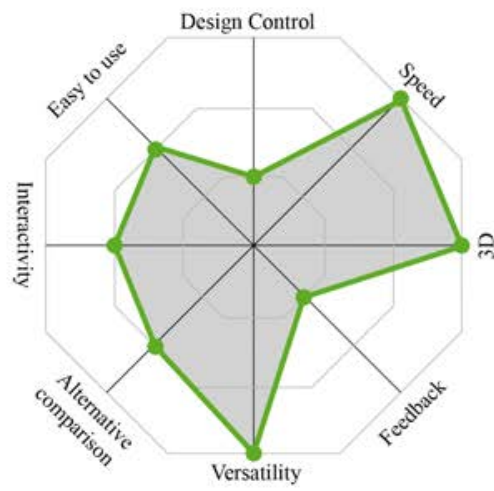

Computational Methods

Figure 2.15: Comparison of design methods 
This section, together with the previous one, has provided a critically review of the concept of funicularity, its historical development and the main methodologies to find funicular shapes. In order to visually summarize these information, and other data not reported in this thesis, a timeline has been sketched in Appendix 1.

The timeline, based on author's readings and understanding, provides graphically an historical overview of the funicularity concept and its most prominent employers. It is interesting to point out that:

- The concept of funicularity has been developed in approximately 250 years (from 1450 to 1700 ). After the contribute of Gregory no relevant advances have been produced.

- Hanging models have been used before for assessing structures and then, to design them. This methodology has been forgotten for centuries before its revival by Gaudí and Isler.

- Graphical methods lived their "golden age" during $19^{\text {th }}$ century, but then with the exception of few contemporary designers, they have been abandoned.

- Recently, more numerical approaches appeared in parallel with the development of computers. Advanced computational form-finding methods have practically replaced hanging models and graphical techniques, saving time but, in the other hands, decreasing understanding of structural behaviour and design attitude.

Finally, it is important to point out that the selection of a methodology is strictly related to the tools in which that approach is implemented. The next section provides an overview of the available computational tools, evidencing how, today, new software can provide a fertile soil for the revival of abandoned methodologies [79]. 


\subsection{Computational tools}

\subsubsection{INTRODUCTION}

This section is addressed to present a brief review of the computational tools that can be employed to find axial-only shapes. Depending on their distinguishing features, these software can be divided in three main groups: geometry-based, analysis-based and design-oriented tools.

\subsubsection{GeOMETRY-BASED tOOLS}

Geometry-based tools usually are computer-aided design (CAD) software, which allow the user to vary easily the geometry. That freedom in geometry alteration is counterbalanced by the lack of physical simulation. During last years new geometry-based computational tools, which implement graphic statics, have been developed. The result is a software in which it is possible to observe how internal forces change through the force polygon, giving the user the possibility of exploring different equilibrated solution. Most interesting examples of this kind of tools are represented by Active Statics [24], Equilibrium [3] and RhinoVAULT [3].

In order to evaluate the benefits of employing geometry-driven tools, the author has implemented graphic statics within Geogebra [39], a well-known dynamic mathematics software, and the analysis of a real structure has been performed in order to explore the thrust lines related to the permanent loads. The structure object of the analysis is the Tiemblo Bridge above the Burguillo River, a 165 meter concrete arch bridge supporting a roadway. The total length of the bridge is 268 meters and it has been designed by Fhecor Consulting Engineers. The geometry of the arch evidences some singularities (Figure 2.16): variable cross section with depth between 3.10 meters $(1 / 53)$ at the springing lines and 1.75 meters $(l / 94)$ at the crown and a constant width of 4.00 meters. The rise of the bridge, $f$, is 22 meters and the span-to-rise ratio, $\lambda=l / f$, is 7.5 .

The use of graphic statics, shown in Figure 2.17, allows to evaluate the discrepancy between thrust line (obtained for permanent loads related to arch, 

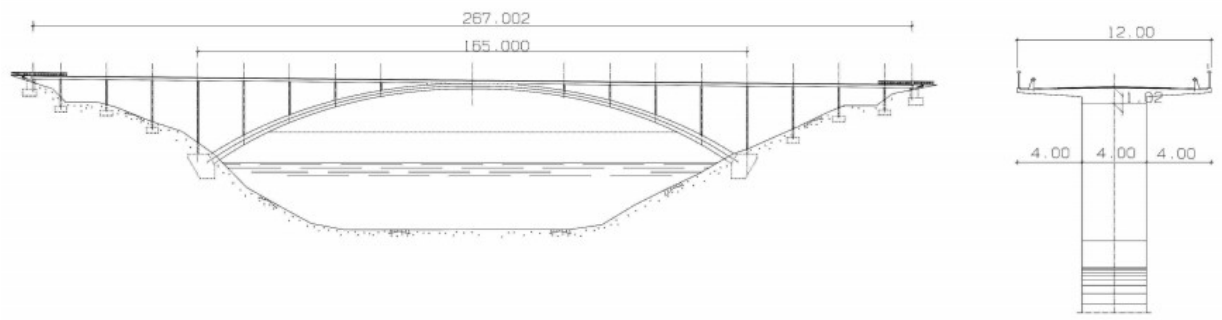

Figure 2.16: Front view and cross section of the Tiemblo bridge.

girder and columns) and arch shape. Figure 2.17 illustrates a perfectly match between the two curves, pointing out that, for permanent loads, only uniformly distributed compressive stresses act. The interactivity of the tool allows to realtime explore all the possible antifunicular shapes of the permanent loads just by moving the pole.

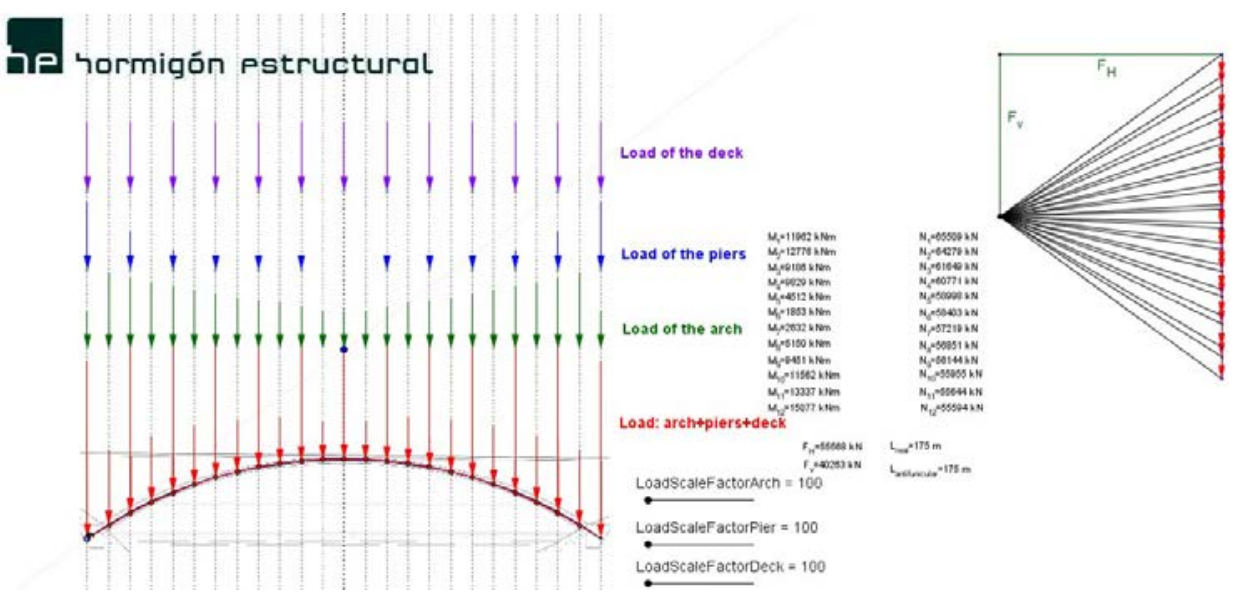

Figure 2.17: Graphic statics applied to the Tiemblo bridge

The previous example demonstrates that, with the aid of interactive geometrybased tools, graphic statics can be still used nowadays strongly reducing the time needed to build the model. Other example of geometry-based tool is represented by Catenary [56], that, based on the use of particle-spring systems, enables to find funicular geometries for a starting grid shell in which elastic bars are connected by particles. To each bar, corresponds an axial stiffness, thus bars represent the springs of the system. Being the initial geometry not in equilibrium, it is deformed through an oscillating movement (dampening factors have to be 
assigned to the bars). Once oscillation stops, an equilibrated shape has been reached. This method represents, somehow, the computational implementation of physical models. As an important difference with physical hanging models can be reported that using particle-spring approaches the computed springs near supports elongate more than those at mid-span, while the cable lengths in physical models remain constant [15]. Additionally another form-finding tool, based on the use of dynamic relaxation, has been developed by the Form finding $\mathrm{LAB}$ at Princeton University and it can be used in Google Chrome.

In summary, the use of geometry-driven tools has facilitated the back in vogue of historical methodologies as graphic statics, and the implementation of more computational ones as dynamic relaxation and particle-spring system. However, these geometry-driven tools lack of physical simulation and ultimate or serviceability limit state checks cannot be performed. Data have to be exported to other software with the aim of performing more refined structural analysis. Finally, the great geometric freedom and, sometimes, the simultaneous lack of immediate structural response can led to the development of intricate and nonsense forms.

\subsubsection{ANALYSIS-BASED TOOLS}

Analysis-oriented tools are software more focused on performance prediction than geometric alteration. In fact, these tools make easy the determination of stresses, deflections, deformations, etc... acting in the structures, and, usually, they are based on Finite Element Modelling. Several commercial Finite Element packages implement form-finding analysis, but the lack of geometry alteration limits the possibility of using these software during the first stage design. The possible range of optimization is very low because the starting geometry can be varied in a limited way. Furthermore, these tools miss of interactivity control of design and immediate feedback.

\subsubsection{Design-ORIENTED TOOLS}

Previous sections have illustrated the main features of existing computational tools classified as geometry-driven or analysis-driven. This sharp separation 
is not beneficial for conceptual design $[78,80]$. Thus, more unified and integrated design-oriented tools for finding efficient shapes are strongly needed. Summarizing the advantages of both, geometry- and analysis-driven tools, the main requirements of a design-oriented tool are:

1. Geometrical flexibility intended as the possibility to quickly generate, explore and evaluate different alternatives.

2. Immediate structural feedback to variation of shape, loads and boundary conditions.

3. Integrated numerical analysis where there is no need to transfer information from the geometric modeller to the structural analysis software $[40,41]$.

4. Graphical output and interactive user experience.

5. Parametric environment to better manage data approximations typical in the first stage of a project.

6. Optimization solvers for adjusting variables involved in the conceptual design process.

7. Customization for providing to the user the possibility to create its own script.

A software that incorporate all these features does not exist, but it is possible to assemble different tools/plug-in existing on the market to provide a unique framework in which all required features are satisfied. The core of this framework is represented by Grasshopper [74], a graphical algorithm editor, integrated with Rhinoceros's 3-D modeling tool [75] employed to build generative procedures.

Rhinoceros, a commercial NURBS-based 3-D modelling software, provides the required graphical output and the interactive user experience. Grasshopper works into a parametric and interactive environment, which allows the user to change parameters involved into the design and to quick evaluate different structural solutions. Furthermore, Grasshopper permits to concatenate 
parametric design with structural analysis in a dynamic and interactive way by using its embedded plug-in FE solver Karamba [89] or other similar extensions.

The structural analysis and the form-finding processes represent a joint procedure because are both implemented in the same environment. Karamba is suitable for early stage design, but if more advanced structural analyses are needed, a custom plug-in, karambaToSofistik, allowing the direct exchange of data between Karamba and Sofistik, has been developed within the Structural Concrete Research Group of the Technical University of Madrid. The tool can be freely downloaded from the research group's website [4].

Basic use of Grasshopper requires no knowledge of programming or scripting, but it still allows designers to build their own components, being totally customizable and extending incredibly the potentiality of the tool. Finally, optimization solvers for modifying variables involved in the design can be employed.

An application of a design-oriented tool was implemented by the author to find an antifunicular arch configuration for a deck with any geometry in the 3dimensional space. Methodology, tool and results have been presented in his thesis submitted for the master degree in Engineering of Structures, Materials and Foundations [107].

It is not unusual that the footbridge deck has to adapt to a complex geometry in plan as well as in elevation, due to regulations regarding handicapped access which entail the use of long ramps. Usually designers incorporate external ramps located on the obstacle's margins to decrease the slope in order to fulfil these regulations. An alternative to this solution is represented by the increase of the deck length, by making it curved in plan. Thus, spatial arch footbridges represent an innovative answer to demands on functionality, structural optimization and aesthetics for curved decks, quite popular in urban contexts.

The design of material-efficient spatial arch bridges requires the same concepts used for planar arch bridges, but the fact that hangers are not contained in the same vertical plane makes the problem more complicated.

The analysis of the existing literature on the topic illustrated that the structural behaviour of spatial arch bridges was studied in depth by several researchers 
$[52,58,61,98]$ and the form finding of an antifunicular arch for a curved deck was obtained by adopting different approaches $[53,58,60]$. The common result is an efficient geometry that resist loads, for the predominant load case, only with axial compressive forces. However, there was room for a more generalized design-oriented approach that had to be parametric and versatile for finding the corresponding antifunicular shape for any geometry of the deck and had to be integrated with a finite element solver to take into account other effects, such as the material stiffness and different loading conditions.

The author implemented a tool named SOFIA (Shaping Optimal Forms with an Interactive Approach), based on incremental analysis, that starting from a generic arch geometry allows to obtain its three-dimensional antifunicular shape for a curved deck [107].

SOFIA is interactive because the modification of the deck input geometry results in the automatic and real-time generation of the related antifunicular arch shape with display of forces and displacements. This provides instant feedback, in fact user interaction, visualization of the model and structural response occur simultaneously, without the need for the user to explicitly run the analysis [24, 25]. This leads to an intuitive understanding of the spatial arch bridges' structural behaviour. In summary, geometry input, form-finding and consequent structural analysis are integrated in the same tool, thus greatly simplifying the work-flow.

The above described tool allows to explore antifunicular arches for any geometry of the deck. Examples of antifunicular geometries for bridges with C- and S-shaped decks are shown in Figure 2.18. The antifunicular arches, for a generally curved deck, are not only curved in elevation, but also double-curved in plan.

\subsubsection{Final COMMENTS}

The previously presented review of computational tools has shown that software implementing form-finding methods are mainly analysis-driven tools addressed to generate static design options, rather than the exploration of solution spaces, or geometry-driven tools, mainly addressed to geometric variation, than structural prediction. Despite that, some progresses have been made with tools can 


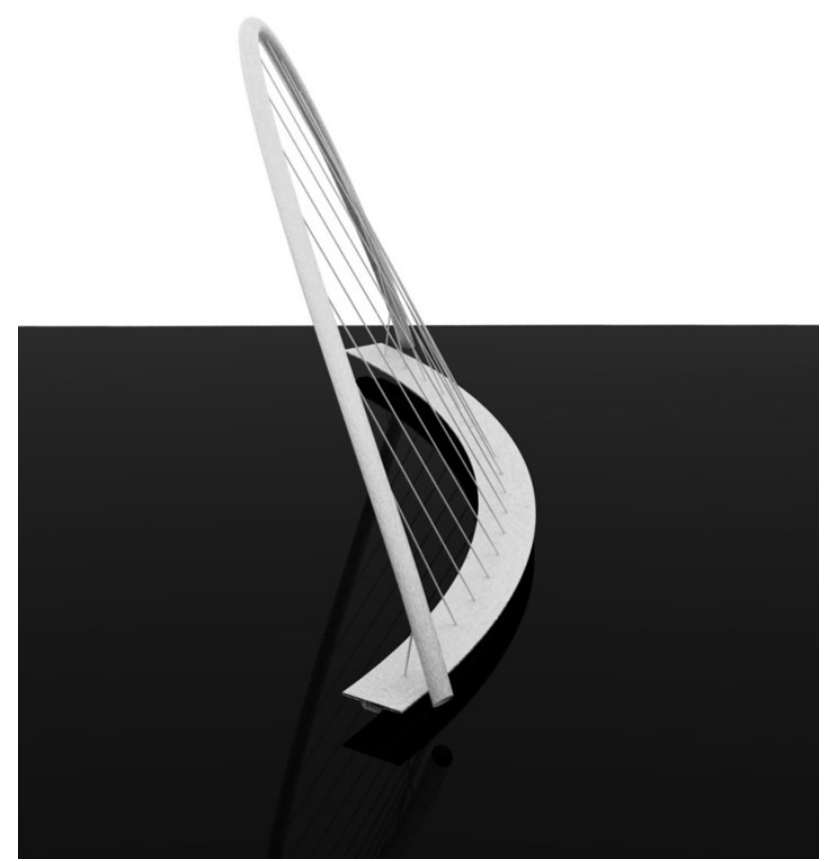

(a) C-shaped deck

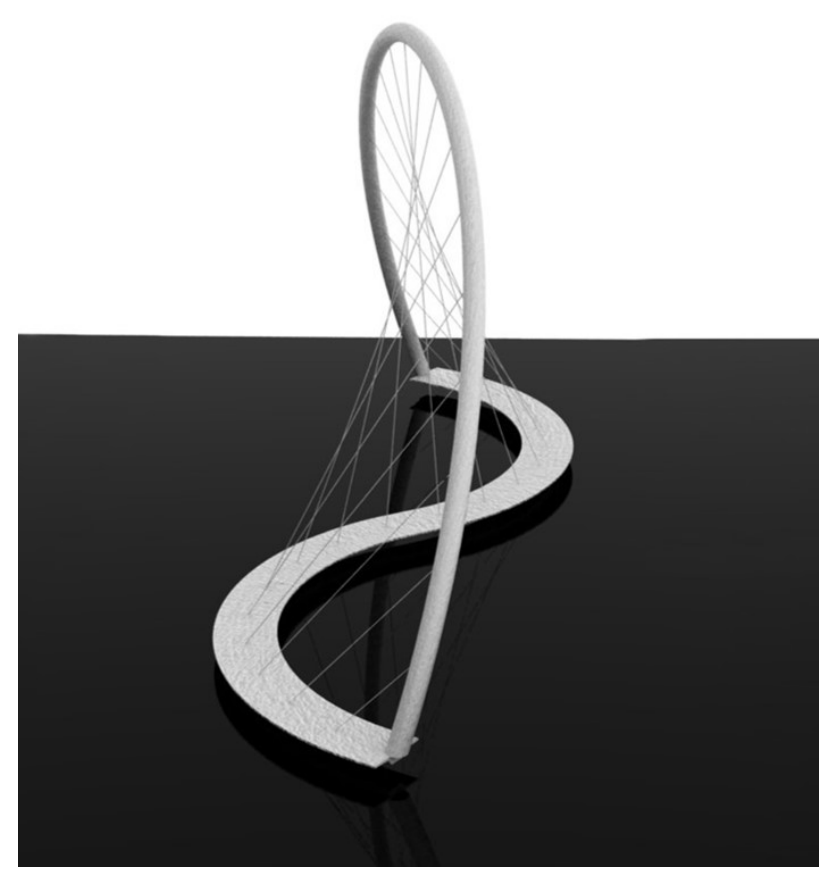

(b) S-shaped deck

Figure 2.1 8: Resulting antifunicular arches for curved decks 
be used for conceptual design of efficient shapes [80]. In fact during last decades several interesting software have been developed in order to perform form-finding analysis, saving computational cost, within friendly and innovative environments.

The combination of some tools, based on the core Grasshopper, can allow to assemble a design-oriented software more focused on the exploration of space design, and able to bridge the gap between geometrical definition and structural considerations. These modern tools can be a great resource to support the designer for thinking about the structural behaviour while exploring the design space.

\subsection{SUMMARY}

The literature review presented in this Chapter has been addressed to briefly analyse the concept of funicularity, methodologies to find bending-free geometries and software in which these approaches can be implemented.

Despite the funicularity principle and its implications represent an indispensable part of the structural designer expertise, traditional formfinding approaches, based on hanging models and graphical constructions, have been replaced by numerical procedures. In this computational approach the geometrical definition and its structural analysis correspond to different stages of a project. Furthermore, a more frequently use of analysis-driven tools has decreased the control of design. Thus, the current design process is characterized for being unidirectional and with strong lack of interoperability.

However, today there are new interactive and integrated environment where geometric modeling and structural evaluation are blended to take advantage of their combined potential. In fact, Part II presents a new approach, where the combined use of well-know design-methods and novel design-driven tools, allows to overcome the limited interoperability between structural analysis and geometric freedom for the design of more versatile and material-efficient structures. 



\section{Part II}

\section{Post-Tensioned Antifunicular Structures}



Engineering is the art of directing the great sources of

power in nature for the use and convenience of man.

Thomas Tredgold

\section{3 \\ Background}

\subsection{INTRODUCTION}

As illustrated in Chapter 2, curved structures are characterized by the critical relationship between geometry and structural behaviour, and selecting an appropriate shape in the conceptual design of such structures is important for achieving material-efficiency.

However, non-structural conditions, such as aesthetics, functionality, and geotechnical issues, often prohibit the selection of a structurally ideal funicular shape: in contrast to a free hanging chain, forces cannot act in pure axial compression or tension under self-weight and gravity loads, decreasing the structural efficiency of the design through the introduction of bending moments.

In contrast with form-finding problems, where a bending-free shape is found starting from a given set of loads, Part II of this thesis studies the opposite problem: how to introduce additional loads that convert a non-antifunicular shape into an antifunicular one without changing its base geometry. 


\subsection{BACKGROUND}

The intuition of changing the distribution of loads to get a better structural behavior is very old [21]. As it has been illustrated in Section 2.2.1, Roman constructions, commonly built with a circular geometry, are far from the antifunicular geometry due to the self-weight of a constant-thickness arch, which is a catenary. However, Roman builders applied different techniques to indirectly achieved better structural stability by changing the distribution of the permanent loads.

A more recent existing example of this concept is represented by the façade of the Pavilion of the Future (Figure 3.1), built in Seville for the Universal Exposition in 1992, and designed by Peter Rice of Ove Arup and Partners.

The main design concept takes advantage of the gravity loads generated by roof beams in order to apply a set of radial equal forces onto the circular arch of the façade, forcing the thrust line to pass closer to centroid line of the arch [64].

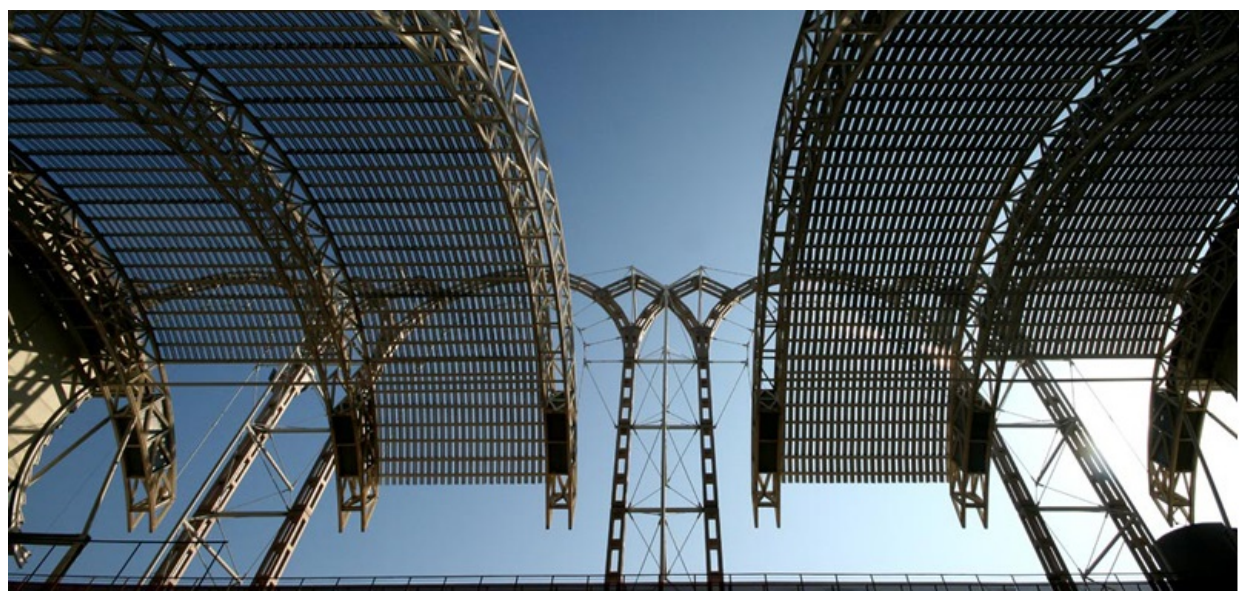

Figure 3.1: Photo of the Façade of the Pavilion of the Future [64].

The façade structure, shown in Figure 3.2 (adapted from [64]), is one of the key elements of the building, employing an innovative structural system that combines stone and steel. The load-bearing structure of the façade has to work only in compression because it is made of discrete masonry elements.

If only the distribution of self-weight is considered (Figure 3.2a), the geometry 
chosen for the arch, the semicircle, would collapse because the thrust line is not contained within the structural thickness (Figure 3.2b). Therefore, a thicker arch size would normally be required to resist internal bending moments (i.e., eccentricity of the thrust line).

Aware of this problem, the designer modified the external loading on the arch with a series of radial struts (Figure $3.2 \mathrm{c}$ ), tensioned by the weight of the adjacent roof [64]. This changed the dominant loading on the arch so that the semicircular shape was closer to be antifunicular and the structure achieved stability (Figure 3.2d). 


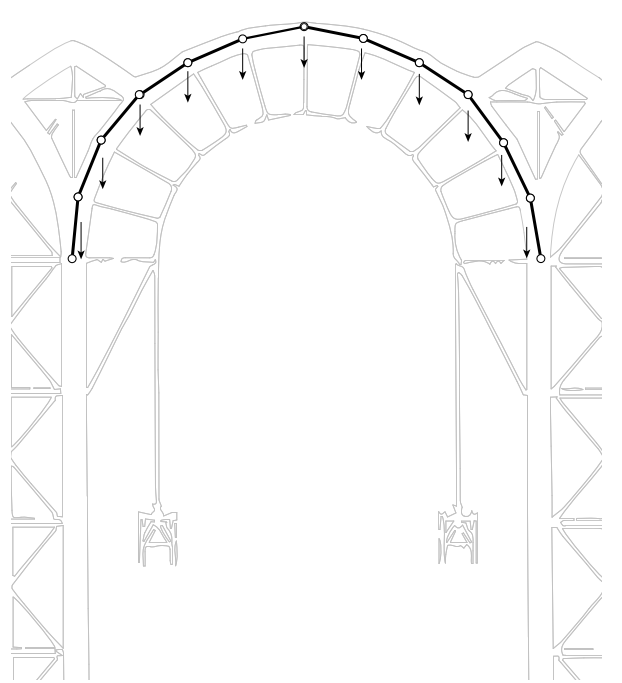

(a)

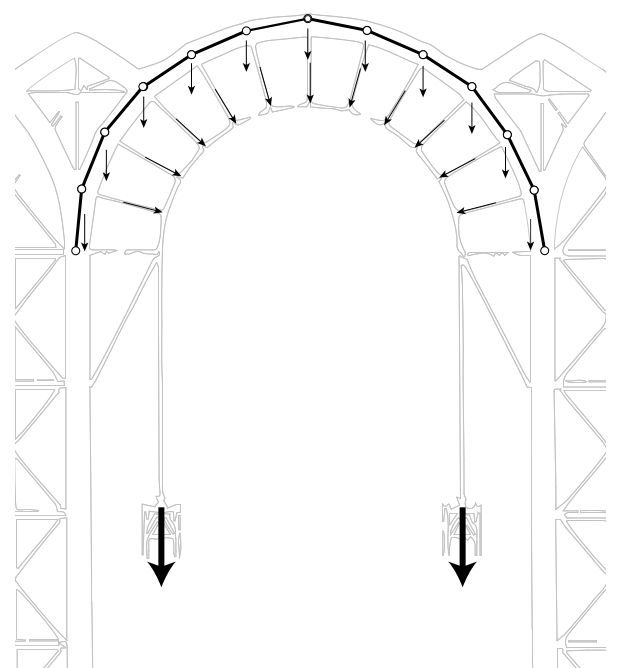

(c)

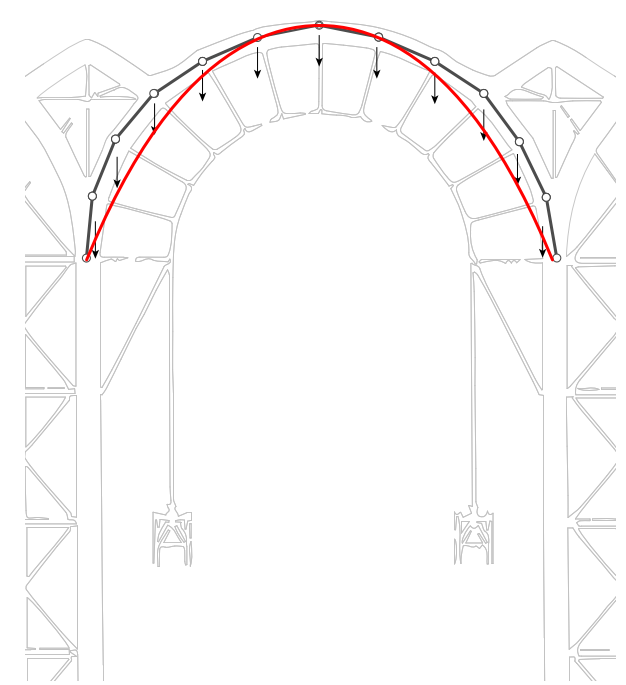

(b)

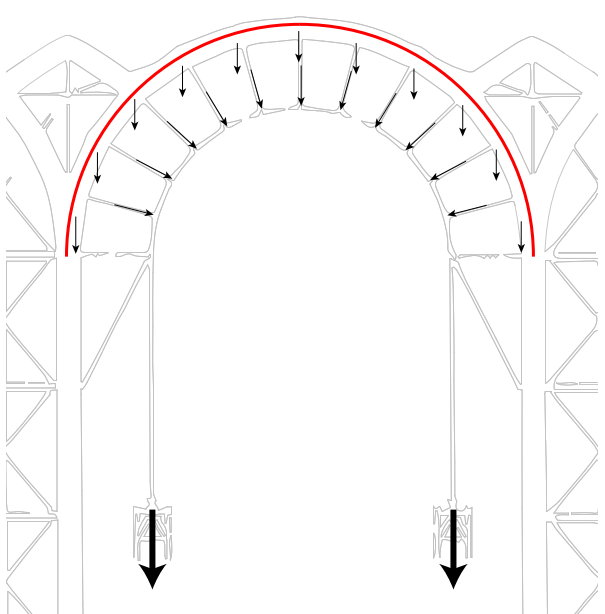

(d)

Figure 3.2: Façade of the Pavilion of the Future (1992). 
However, the application of external loads as hanged weights, often, it is not a possible solution. An alternative option consists in intelligently employing external post-tensioning for generating the required external loads. Prestressing allows to redirect the force of gravity for achieving the required internal force distribution $[5,34,65,88,118]$.

The concept of prestressing become reality through the development of a new material (high-strength steel) and novel construction techniques during the first decades of the $20^{\text {th }}$ century $[67,70]$.

The historical development of external post-tensioning is even more recent, and most applications are related to bridges which are straight in elevation $[77,96]$. Prestressed tendons, depending on their position with respect to the deck, can generate different types of bridges $[77,81,95]$.

Figure 3.3 illustrates the use of external post-tensioning applied to the Zabalgana footbridge designed by Fhecor Consulting Engineers. The footbridge has a span of 60 meters and employes an U-shaped cross-section.

The two pinned elements (Figure 3.3a), which connect the deck and the prestressed cable, add vertical point loads to the structure equilibrating totally the dead load of the bridge. Figure $3.3 \mathrm{~b}$ illustrates the connection detail between prestressing and connecting element.

The application of external forces decreases the effective span of the bridge by introducing two "invisible columns" (as Eduardo Torroja did in the Tempul Aqueduct [23]). 


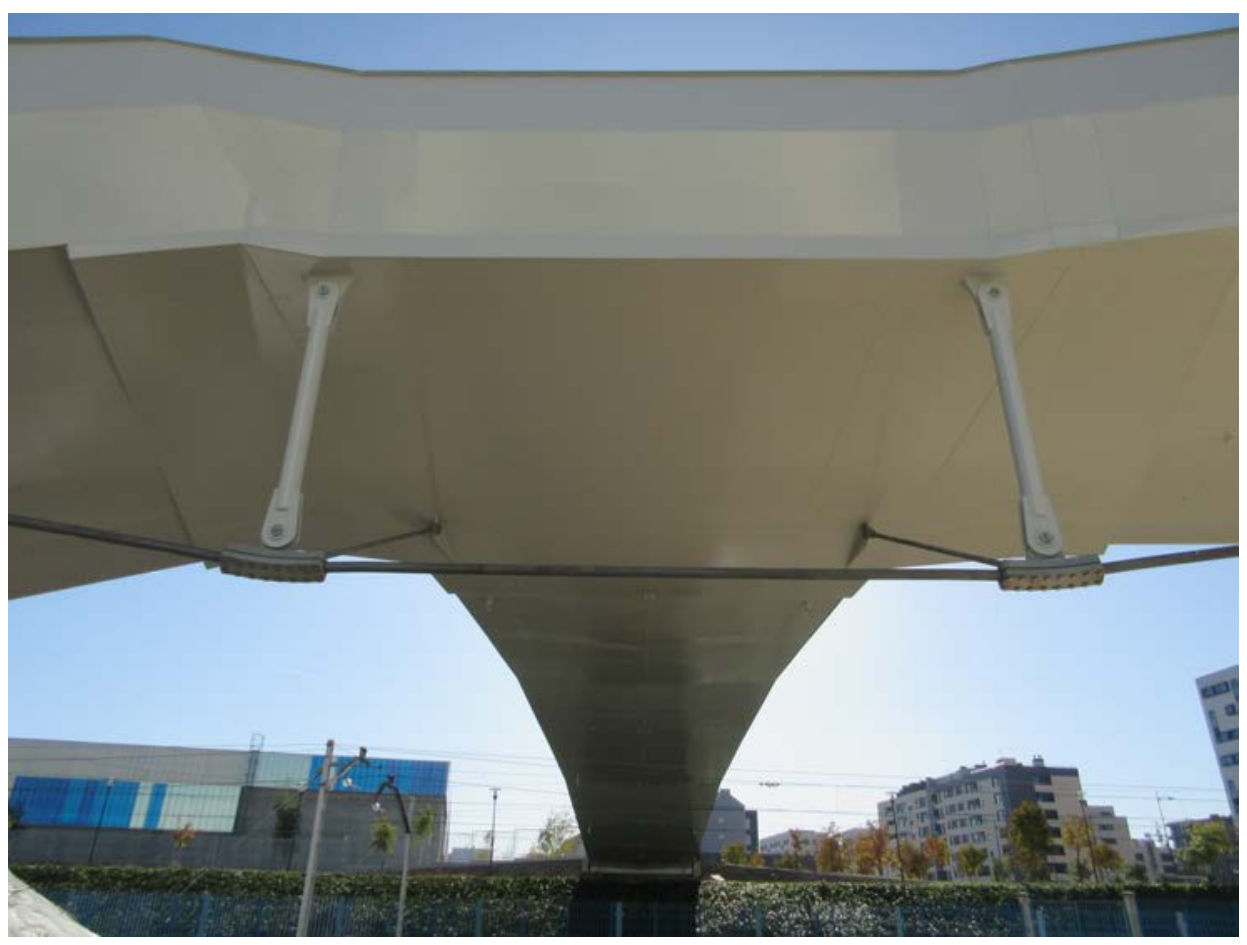

(a)

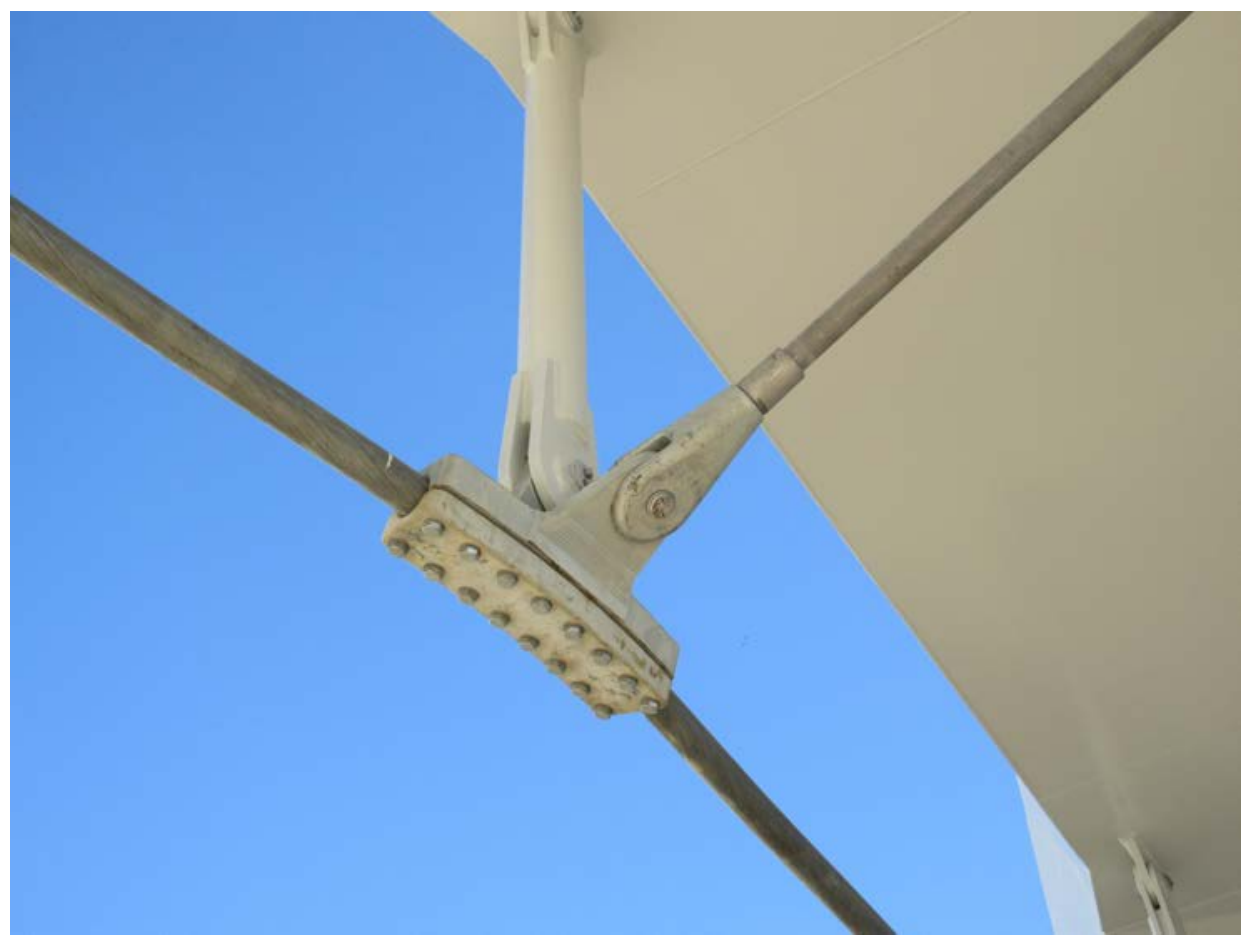

(b)

Figure 3.3: Externally post-tensioned bridge. Courtesy of Fhecor. 
However, the post-tensioning technology is not restricted to only bridges and it can be applied to many other structural typologies, enabling designers to control the structural behaviour of curved structures, e.g., shells, arches, roofs, etc... $[102,103]$. An example of application of post-tensioning to a planar curved structures is represented by the glass roof of the Berlin Main Train Station. Tensioned cables follow the bending moment law and transform the basket arch into the thrust line [2]. The engineer is familiar with the technical aspects of prestressing, but he seldom has the architectural background to exploit the structure's possibilities in layout and form [68]. In fact, any material with reasonable compression characteristics can be efficiently combined with prestressed tendons to achieve an efficient structural solution: prestressing can make bending structures behave like axial-only geometries.

Inspired by the Pavilion of the Future and by the recent examples of externally post-tensioned structures, this study explores the use of a generalized design approach that converts any planar curve into an antifunicular shape without changing its base geometry; instead, a bending-free behaviour is achieved through the introduction of new forces using external post-tensioning.

\subsection{Organization of the Part II}

Part II of this dissertation presents an original general theory and implementation for eliminating bending moments in two-dimensional curved geometries through external post-tensioning systems.

Part II is structured as follows: first, a graphical methodology for the geometric definition of the post-tensioning system and its implementation in a designoriented tool (EXOEQUILIBRIUM) are described in detail (Chapter 4). This chapter, presenting a generalized theoretical methodology, shows how this concept can be applied to designs in a broad sense.

Next, the developed software is employed for achieving funicularity for a great number of geometries (Chapter 5 ). In the same chapter, possible design criteria, and their effect on internal force distribution, are evaluated.

Finally, real applications related to reduced physical models and to a built temporary pavilion are illustrated and critically analyzed in Chapter 6. 


\subsection{SUMmary}

The choice of an appropriate bending-free shape in curved geometries is an important decision for designing materially efficient structures. However, optimal shapes from a structural point of view are often at odds with other requirements, and non-antifunicular geometries must be used.

The idea behind this research is to add external forces to a general curved shape and to convert it into an antifunicular geometry. This can be accomplished by using a post-tensioning system that, following a determinate shape, generates a change in forces within the base structure and makes it bending-free.

This would allow to take full advantage of the structural efficiency while also allowing for architectural and geometric flexibility. 
The overall quality of many structures today leaves

much to be desired. The rapid technological progress

does not reflect adequately in their variety, beauty and

sensitivity. Too often structural engineers neglect the

creative conceptual design phase by repeating standard

designs and not sufficiently contributing with own ideas to

the fruitful collaboration with architects. Engineers thus

often waste the chance to create building culture.

Jörg Schlaich

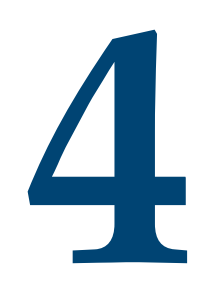

\section{Methodology and Implementation}

\subsection{Methodology}

\subsubsection{INTRODUCTION}

The problem described in Chapter 3 has been solved with a graphical approach. This introductive Section 4.1.1 provides a simple implementation of graphic statics needed for better understanding the more complex procedure described in the following Section 4.1.2. Bow's notation [11] has been used in the following examples.

Figure 4.1 shows form and force polygons of a bending-free shape and its related loads ( $a b$ and $b c$ ). The antifunicular shape is the same in both Figures $4.1 \mathrm{a}$ and $4.1 \mathrm{~b}$ because the slopes of $d a, d b$ and $d c$ do not vary.

However, by changing the position of the point $a$ (there are an infinite number of possible point locations along the direction $d a$ ), geometry and size of the force 
diagrams, and thereby the reactions, change as well. The forces $a b$ and $b c$ have unchanged slopes, but different values.

These two graphical constructions show that as to one distribution of loads correspond infinite antifunicular shapes (Section 2.2.2), to one shape correspond infinite loads to make it antifunicular. This indeterminacy is referred as indeterminacy 1 (or first indeterminacy) in this research.

In this investigation the slopes of the forces $a b$ and $b c$ are related to the directions of struts, which carry external loads. Those elements connect base geometry and prestressed cable. This concept is more in-depth explained in the following Section 4.1.2.

Next, once the forces $a b$ and $b c$ have been fixed (i.e., the point $a$ has been defined), Figure 4.2 illustrates the simple graphical construction for finding an external system of forces able to generate those two point loads.

Figures $4.2 \mathrm{a}$ and $4.2 \mathrm{~b}$ show two alternative solutions. The problem is again indeterminate: there are infinite positions of the pole $e$ for generating the required loads ( $a b$ and $b c$ ). The line of poles, $d e$, remains the same, but the reactions change adapting to the pole position. This indeterminacy is referred as indeterminacy 2 (or second indeterminacy) in this research.

In this study the slope of the forces $a e, e b$ and $e c$ is related to the direction of a tensioned cable, which generates the required loads $(a b$ and $b c)$ in the deviation points.

In summary: given a shape, there are infinite distributions of loads to make this geometry funicular ( 1 st indeterminacy); after defining a set of loads, there are infinite positions of a cable for generating these loads (2nd indeterminacy). 


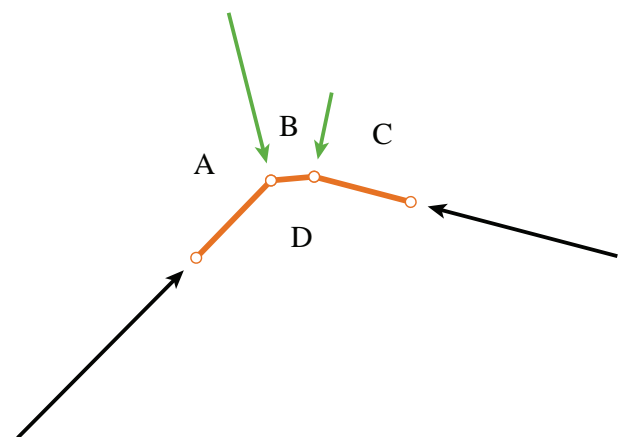

Form Polygon

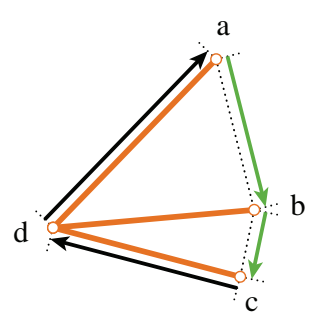

Force Polygon

(a)
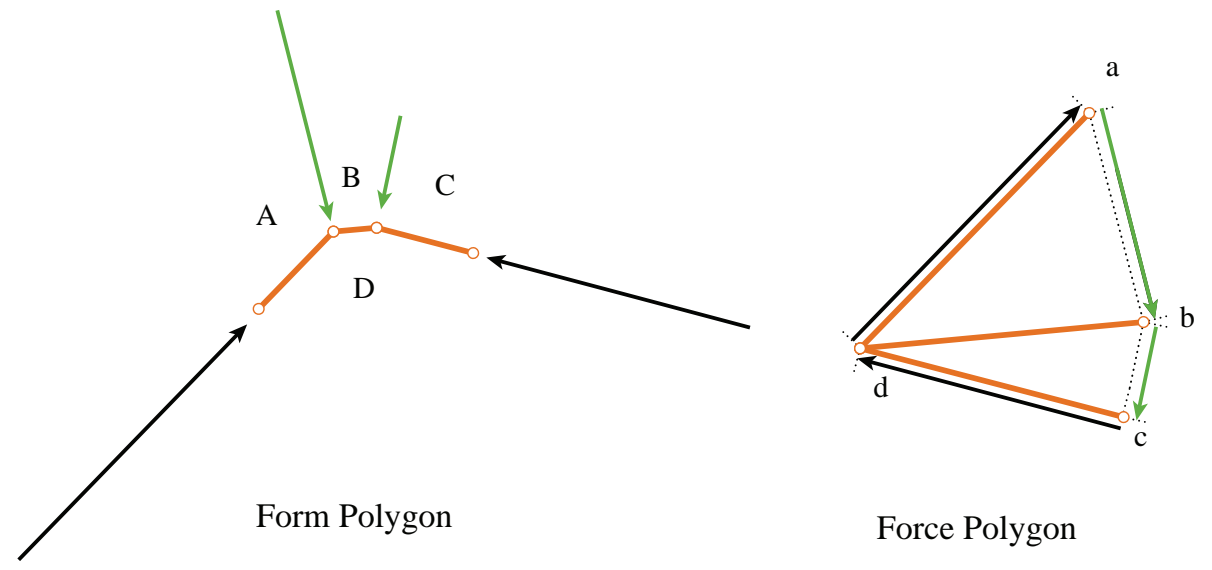

(b)

Figure 4.1: Graphical construction for finding the point loads. 

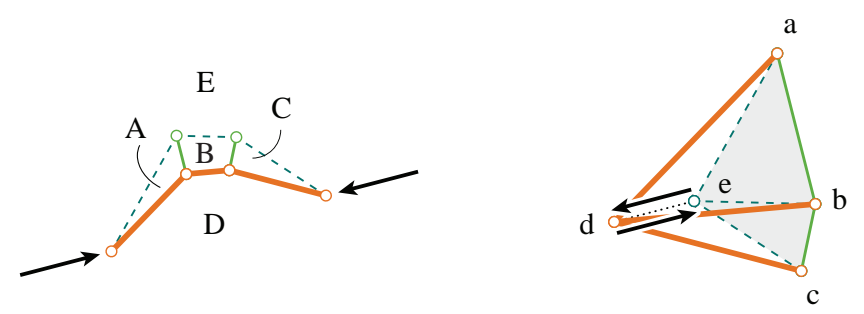

Form Polygon

Force Polygon

(a)

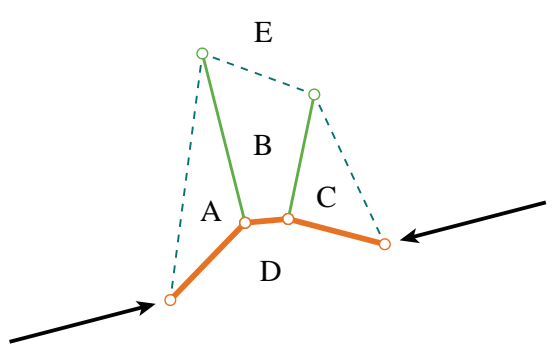

Form Polygon

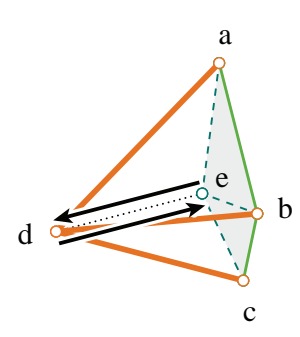

ForcePolygon

(b)

Figure 4.2: Graphical construction for generating the point loads. 


\subsubsection{Graphical CONSTRUCTION}

This section presents the complete graphical procedure for finding the position of a tensioned cable that, applying defined loads to each deviation point, allows the base geometry to be antifunicular.

The developed graphical construction is divided in two main steps:

1. Step 1. To find a set of external loads, that added to the existing ones, makes the curve antifunicular.

2. Step 2. To find the layout of post-tensioned tendons that can generate these loads in each deviation point.

Referring to Figures 4.3 and 4.4 (that have to be read as only one figure), the two steps are described in the following.

Step 1:

- The graphical construction starts with a given planar geometry (Figure 4.3a). In the illustrated example, it is a circular one, but the methodology can be applied to any plane curve. The starting geometry is loaded with a known distribution of loads (usually corresponding to permanent loads).

- The base curve has to be subdivided into a polyline, and every subdivision can be represented by a vertical load vector, whose size depends on the corresponding load (Figure 4.4b). Thus, a first hypothesis of the method lies in the fact that distributed loads are represented as a discrete number of loads. The higher the number of subdivisions, the lower the discrepancy with the real behavior of the structure. The right side of Figure $4.4 \mathrm{~b}$ points out that the shape is not antifunicular for its dead load, in fact the force diagram is not closed, and equilibrium with only uniform compressive stresses is not possible.

- On each vertex, the direction of the strut carrying external loads to the base structure has to be chosen. In Figure $4.3 \mathrm{c}$ every strut is assumed to be normal to the curve, although the procedure is not limited to perpendicular loads. The graphical construction for closing the force 
diagram is shown in Figure 4.3c where new forces, combined with the existing ones, are needed at each vertex in order to close the force polygon. These forces are parallel to the directions of the struts. As stated before, infinite sets of loads exist to make a single geometry antifunicular. In other words, the direction of the internal forces is fixed but their magnitude is variable. This assumption represents the first indeterminacy of the problem. The solution is unique if one parameter is fixed (e.g., the maximum compressive force in the curve).

- Figure $4.4 \mathrm{~d}$ shows another equilibrated solution obtained with a different magnitude of loads by moving the point $i$. In this case the forces to be introduced in each vertex have the same direction but have higher magnitude.

Step 2:

- Once one distribution of external forces inducing a state of uniformly distributed compressive stresses has been identified, the graphical construction for finding the external post-tensioning shape generating the forces identified in Figure 4.4e must be performed. The start and end points of the tension curve should be defined. In the described examples, these points coincide with the supports in order to evaluate their contribution to the horizontal reactions. The force polygon can be graphically constructed, guaranteeing the equilibrium at each joint of the structure. First an arbitrary pole $q$ is selected, and then lines connecting this point to the force vector can be drawn, as shown in Figure 4.3 e. The position of the pole $q$ is arbitrary because to one set of loads corresponds infinite cable layout in order to generate that load distribution (second indeterminacy of the problem). Fixing one parameter (e.g., the maximum value of post-tensioning force or the starting inclination of the tendon) yields a unique solution; there is a unique relationship between post-tensioning force and geometry of the external system.

- Figure 4.4f shows another equilibrated solution for generating the required loads and to make the starting curve antifunicular. In this case the pole $q$ 
has been moved, and this corresponds to different axial forces in the cable.

- Figure 4.3g shows the complete graphical construction obtained superimposing Figure 4.4 d and Figure 4.3e.

- Figure $4.4 \mathrm{~h}$ shows the complete graphical construction obtained superimposing Figure 4.4 d and Figure 4.4f. 


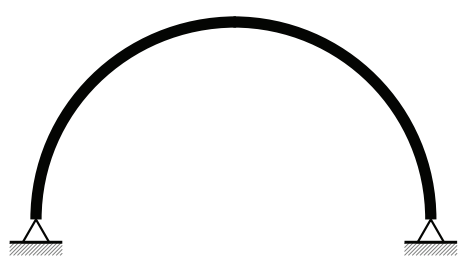

a)
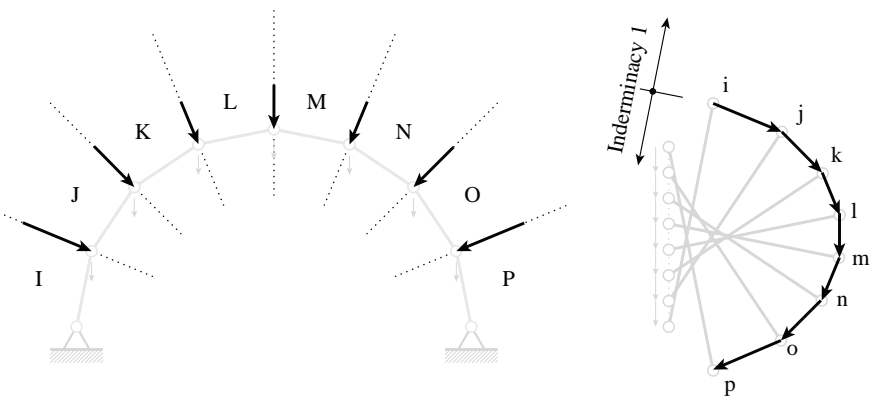

c)

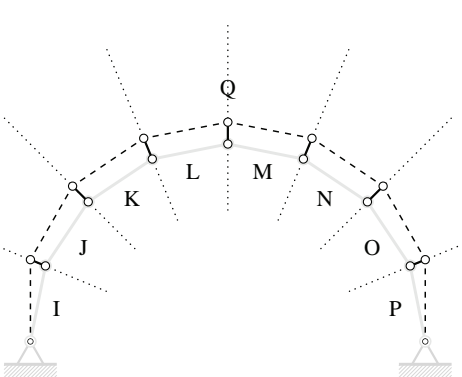

e)
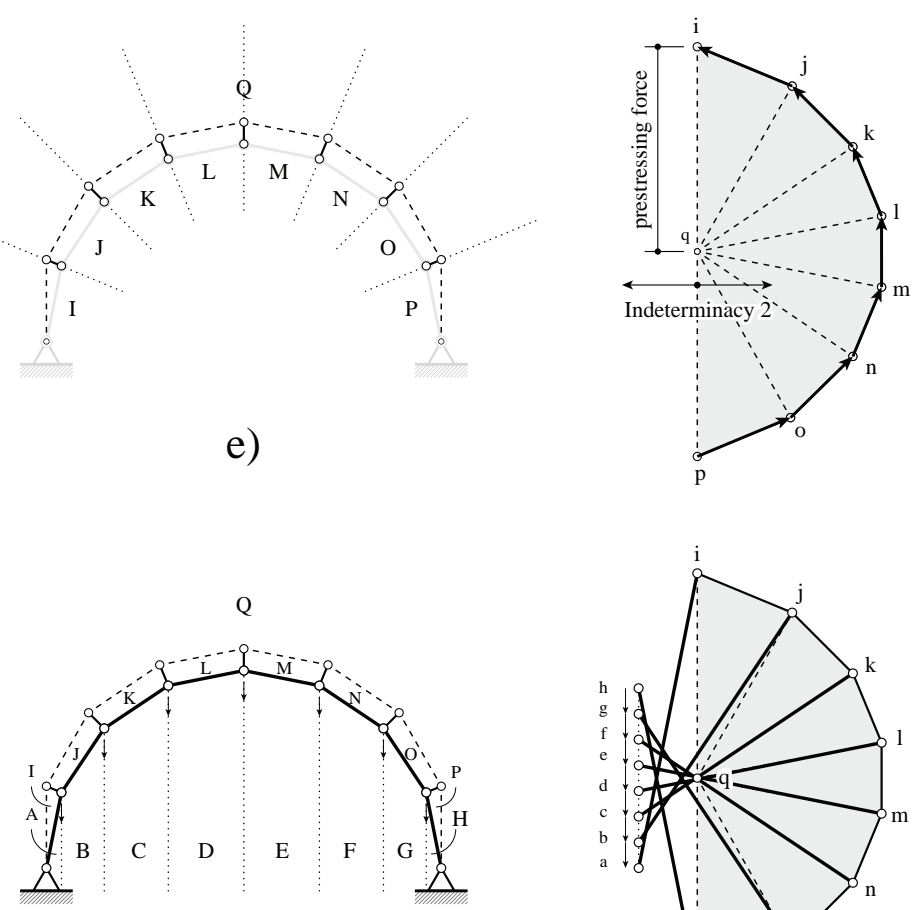

g)

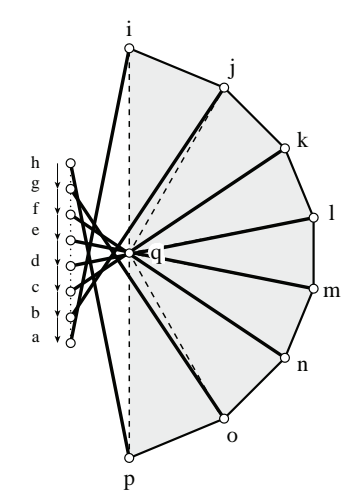

Figure 4.3: Graphical construction (left side of the figure) 


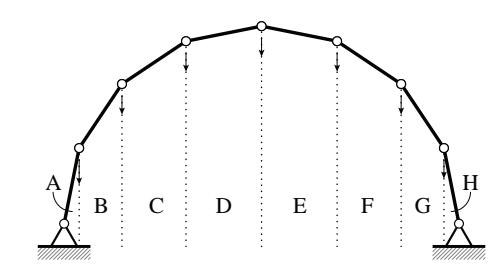

b)

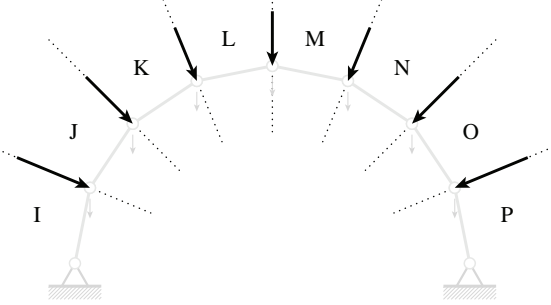

d)

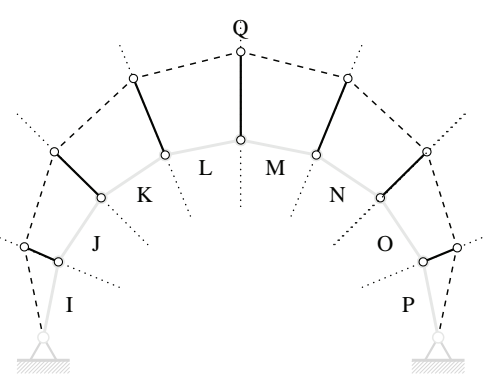

f)

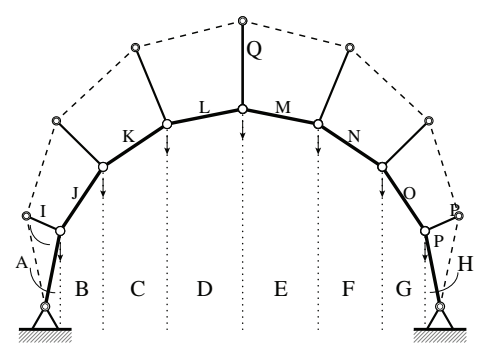

h)
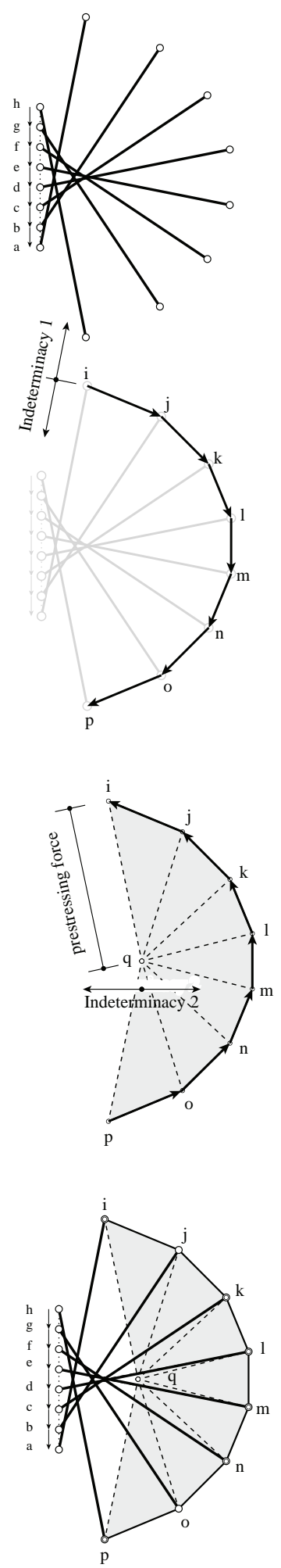

Figure 4.4: Graphical construction (right side of the figure) 
It is relevant to point out that the structure is statically indeterminate (or hyperstatic) thus the post-tensioning has influence on the reactions. In fact, the net horizontal reaction is the sum of the horizontal thrust due to the self-weight, $H_{1}$, and the horizontal thrust associated to the introduction of the stressed cable $\mathrm{H}_{2}$. Figure 4.5 shows the reactions obtained from the graphical construction of Figure 4.4h. The tensioned cable increases the starting horizontal reaction $\left(H_{2} \neq 0\right)$. If the cable had an inward inclination, the horizontal reaction would be lower. The effect of post-tensioning position on horizontal reactions is more in-depth explained in the next Chapter 5 .

Figure 4.6 illustrates the horizontal and vertical components of the reactions obtained from the graphical construction of Figure 4.3g. In this case, the posttensioning cable starts with a vertical inclination and it has no contribution to the horizontal reaction $\left(H_{2}=0\right)$.

This methodology results in an equilibrated geometry where bending moments are eliminated in each vertex and only axial forces with uniformly distributed compressive stresses in the cross-sections are obtained. 


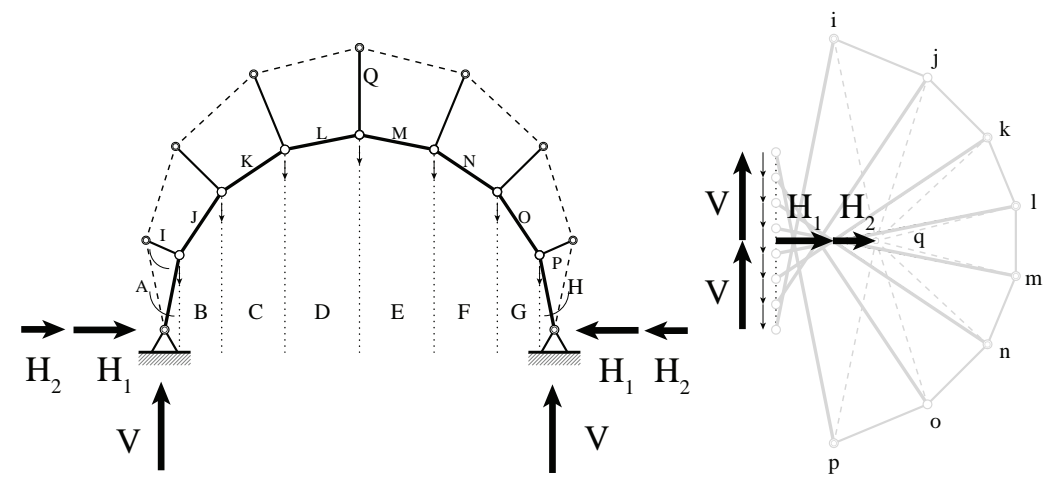

Figure 4.5: Reactions with $H_{2} \neq 0$.

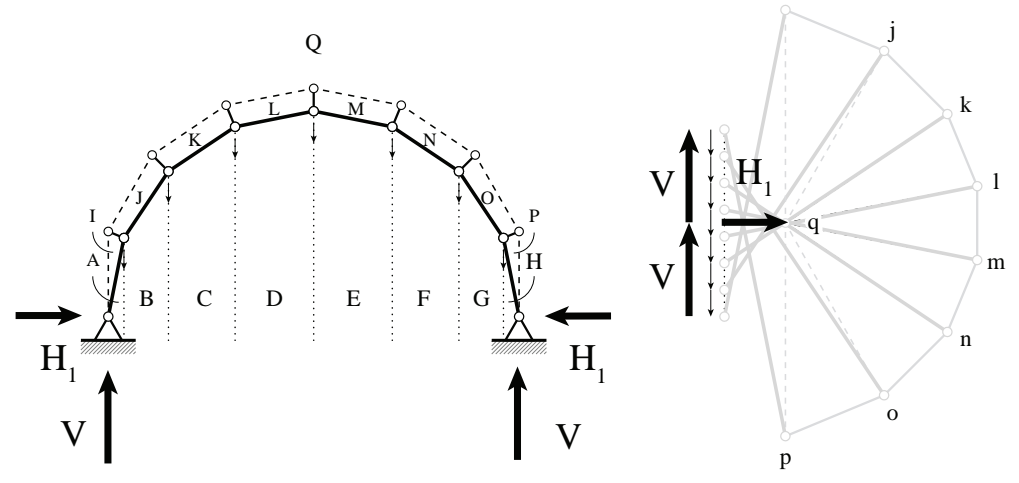

Figure 4.6: Reactions with $\mathrm{H}_{2}=0$. 


\subsubsection{MANAgING INDETERMinacies}

The aim of this section is to study the effect of the two indeterminacies on the final geometrical configuration and internal force distribution.

Summarizing, the first indeterminacy is related to the magnitude of the forces to be added to the main geometry to make it bending-free. The second indeterminacy is related to the position of the tensioned cable or, equally, to the magnitude of forces within the cable.

Two different non-antifunicular shapes commonly used in existing structures have been chosen as case studies: the circular arch and the ellipsoidal arch. The main feature of the circular arch is the constant curvature that allows an easier construction. The second geometry responds to functional problems as evidenced by Muttoni [83]. These geometries are not efficient from a material perspective because the self-weight generates internal bending moments.

The previously described methodology makes possible to explore different design alternatives to convert these base geometries in antifunicular ones. Figure 4.7 and Figure 4.8 show different options for these two geometries, obtained by fixing the first indeterminacy and by changing the second one (i.e., the inclination of the cable). The variation of the cable position and, thus, the distance between post-tensioning tendon and base geometry results a change in support reactions. As already explained previously, the net horizontal reaction is the sum of the horizontal thrust due to the self-weight, $H_{1}$, and the horizontal thrust associated to the introduction of the stressed cable $\mathrm{H}_{2}$. It is important to point out that:

1. There is one position of the pole related to the second indeterminacy which corresponds no net horizontal reactions at the supports under dead loads (Figures $4.7 \mathrm{c}$ and $4.8 \mathrm{c}$ ). In this case, the horizontal thrust due to the self-weight is equilibrated completely by the horizontal thrust due to the introduction of the post-tensioning system.

2. The minimum post-tensioning force to be applied at the end of the cable corresponds to one half of the resultant of the point loads generated at each deviation point. The prestressed cable starts with a vertical direction. 


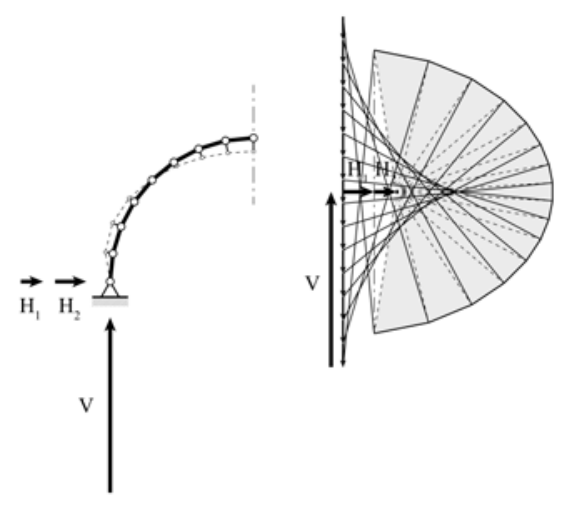

(a)

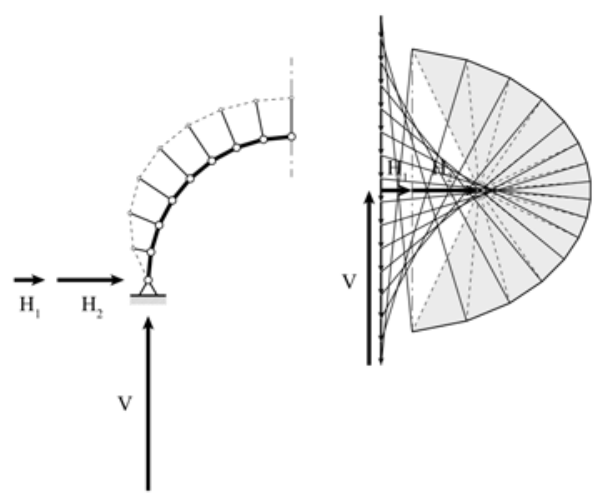

(b)

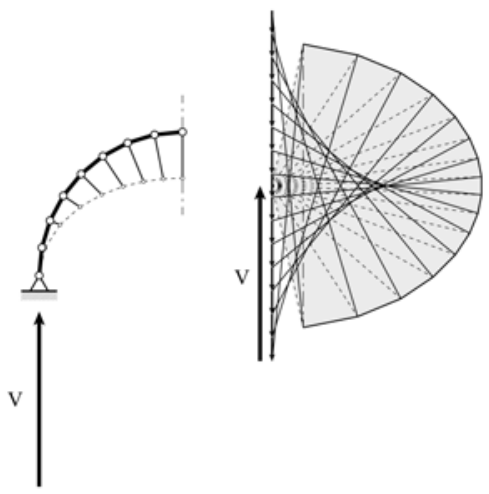

(c)

Figure 4.7: Examples of different tendon layouts for a circular arch. 

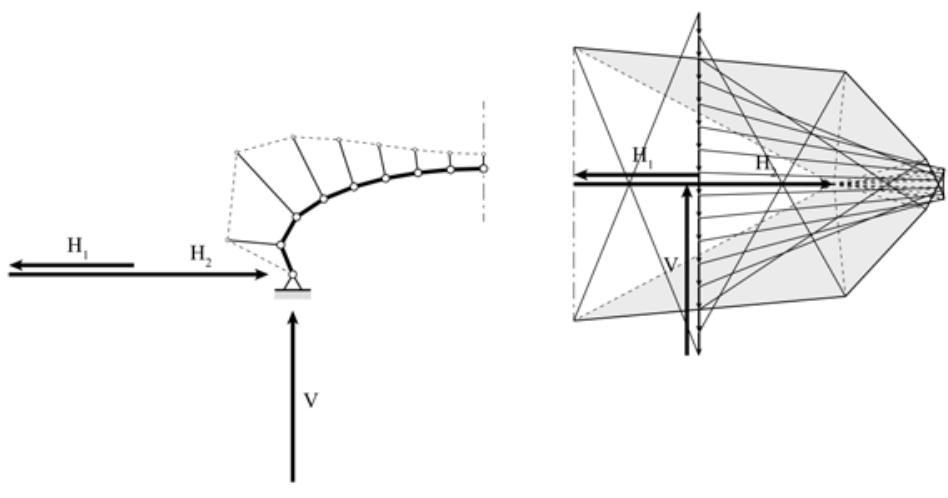

(a)
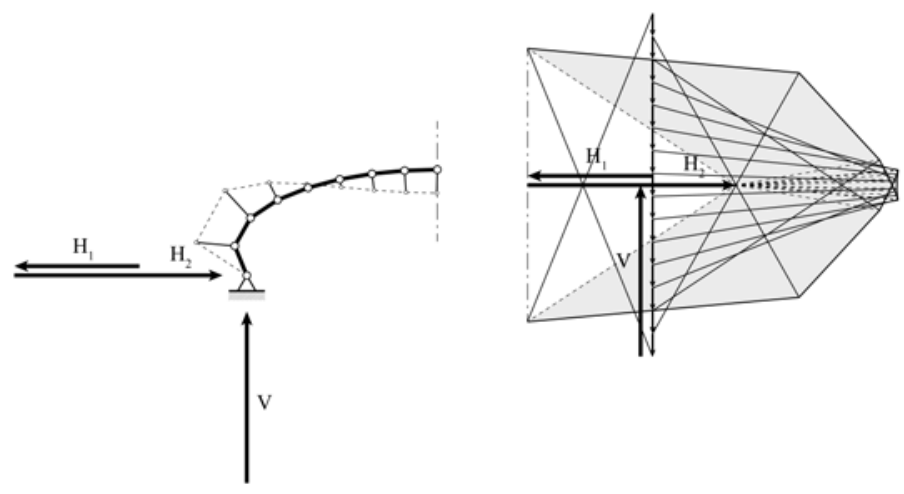

(b)
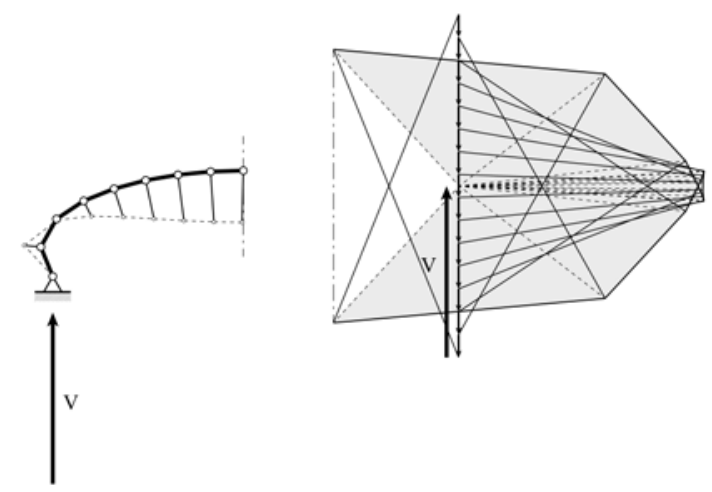

(c)

Figure 4.8: Examples of different tendon layouts for an elliptical shape. 
3. By fixing the first indeterminacy and the magnitude of the post-tensioning force to be applied at the end of the cable, there are two possible layouts of the prestressed cable. Figure 4.9 demonstrates this statement: the vector $i q$ has a variable magnitude, depending on the position of the pole $q$ that can freely move horizontally. If the prestress value at one end is fixed, there are two possible layouts of the post-tensioning, corresponding to different position of the pole $q$ (Figure 4.9a and Figure 4.9b). These pole locations are symmetrical with respect to the direction $i p$.

As pointed out in the previous paragraph, the main difference between the two options lies in the horizontal reactions, that in the case of Figure 4.9a decrease, while in the case of Figure $4.9 \mathrm{~b}$ increase. Furthermore, the forces within the post-tensioning system shown in Figure 4.9a are considerably higher compared to the forces in the post-tensioning system illustrated in Figure $4.9 \mathrm{~b}$ 


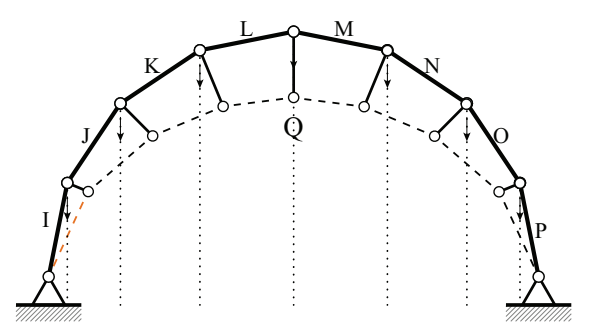

(a)
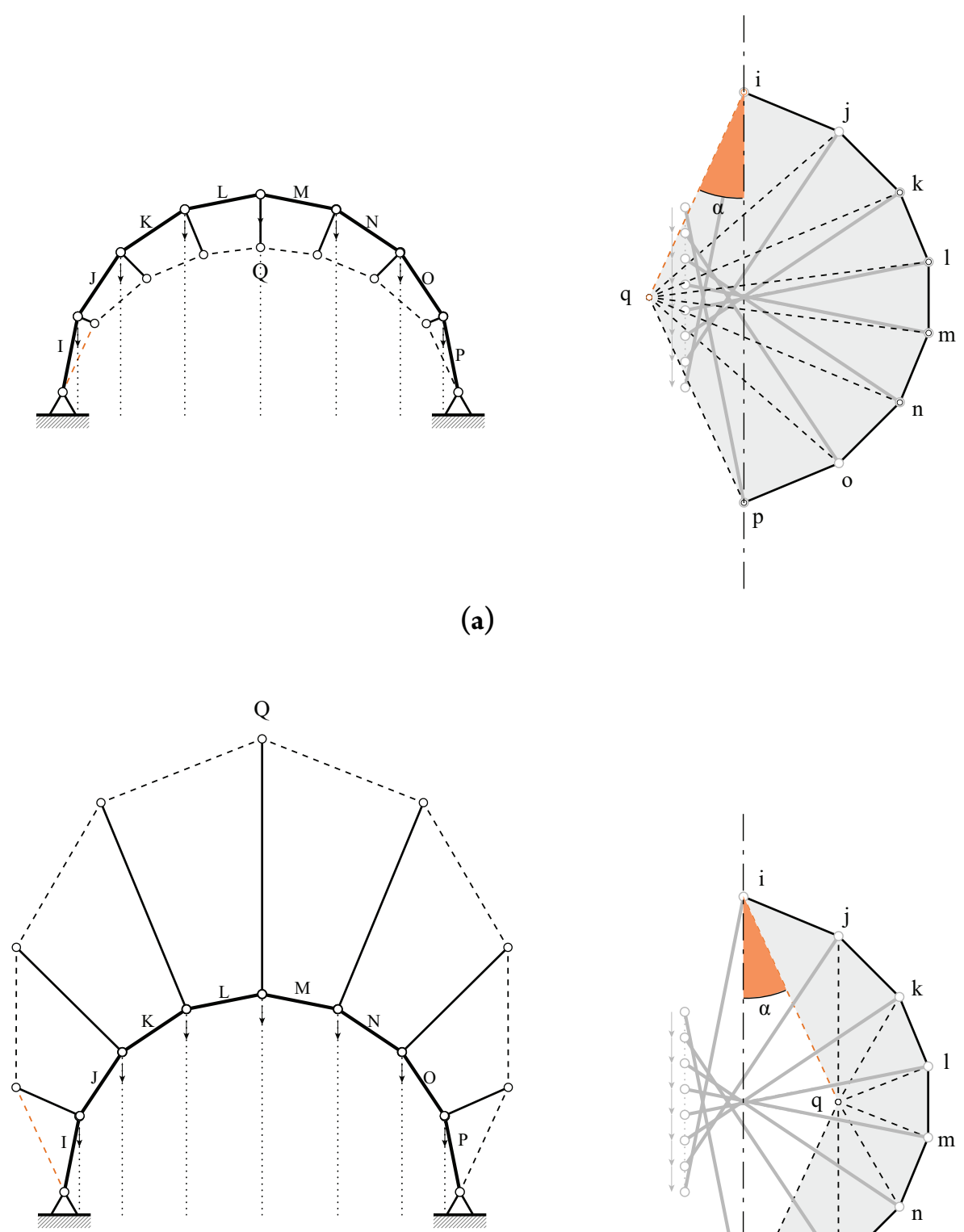

(b)

Figure 4.9: Solutions with same prestress force at one end. 


\subsection{IMPLEMENTATION}

As explained in Chapter 2, the use of graphic statics for design purposes has been limited until recently, in part because a variation of the geometry or the loads changes the model and the graphical construction, which must be updated, is time-consuming to complete manually. Today new computational tools have been developed to implement graphic statics in a very intuitive and user-friendly way $[36,98]$. In addition, an interactive tool for finding the geometry of trusses using graphic statics has already been developed [59].

The author of this dissertation has developed a new design-oriented software, EXOEQUILIBRIUM, which implements the methodology described in Section 4.1. This tool is also interactive, in that a change of the starting shape results automatically in a new post-tensioning system configuration. Equilibrium is always ensured due to the dual reciprocity between force diagram and form polygon. The tool has been implemented using the parametric plug-in Grasshopper [74] for the software Rhinoceros [75] creating custom components in Python. The tool is available for free download [4]. Figure 4.10 shows the basic algorithm implemented in the tool. The model definition has four inputs:

1. Starting geometry of a two-dimensional structure

2. Number of segment in which the curve has to be divided

3. Direction of the struts connecting the compressive curve with the posttensioning. Currently, vertical and radial directions for struts have been implemented, although others are possible as well.

4. Magnitude and distribution of existing loads

As described in the previous section, the problem has a two indeterminacies, so the user can explore the infinite range of equilibrated solutions using two parameter sliders. The first slider changes the starting point of the graphical construction for closing the force polygon (point $i$ referring to Figure 4.3 and 4.4), fixing the internal forces in the original geometry. The second slider changes 


\section{INPUTS \\ ANALYSIS \\ OUTPUTS}

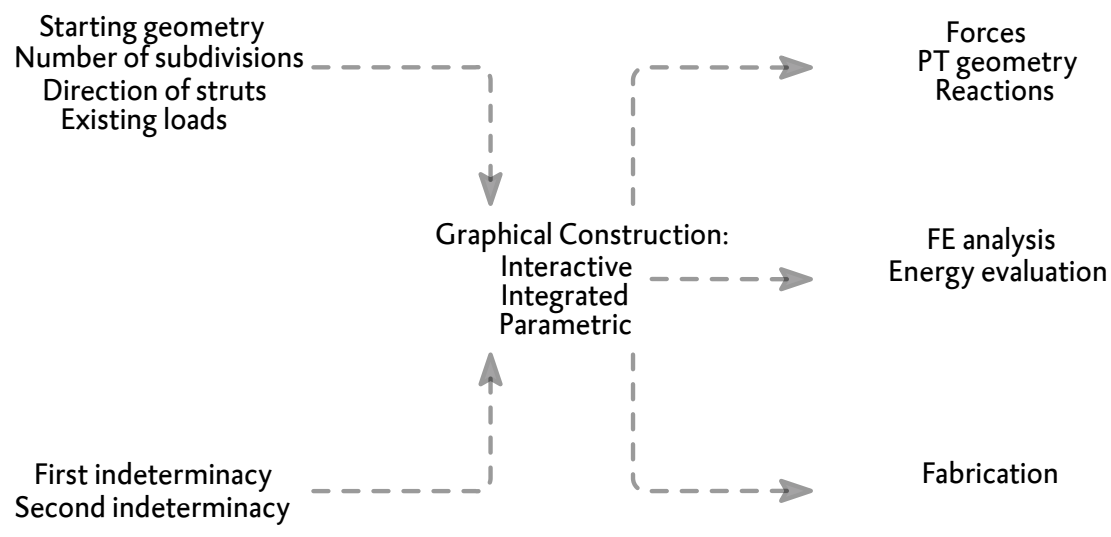

Figure 4.1 o: Algorithm of the tool implemented in Grasshopper.

the pole (point $q$ referring to Figures 4.3 and 4.4) for finding the appropriate tendon layout, adjusting the global geometry of the post-tensioning system.

Axial forces in the arch and the post-tensioning force applied to the tendon depend on the chosen solution: the smaller the distance between the compressive curve and the post-tensioning system, the higher the forces are in both components.

Grasshopper, as an interactive design environment, allows the user to quickly change parameters involved in the geometry and distribution of loads in order to investigate different structural solutions.

Outputs are represented by reactions, internal forces within the base structure, post-tensioning and connecting elements, and by the layout of the tensioned cable.

Furthermore, results have been validated with a finite element software which shows that once the post-tensioning force is applied, if infinite axial stiffness is considered, the structure works as an axial-only shape without bending moments. 


\section{$4 \cdot 3$ Summary}

This Chapter has presented a graphical approach for finding the distribution and the magnitude of external forces (applied through a post-tensioning system) that convert any two-dimensional geometry in an antifunicular one. The dualism between force and form polygons ensures the equilibrium in each node.

Furthermore, the methodology has been implemented in an interactive design-oriented tool that allows users to explore all the design alternatives for a given two-dimensional geometry.

Next Chapter demonstrates how the combination of the graphical-based design technique embedded in an interactive environment gives great freedom in designing new shapes for buildings and spatial structures. 

Good buildings come from good people, and all problems

are solved by good design.

Stephen Gardiner

\section{Applications and Design Criteria}

\subsection{ApplicAtions}

\subsubsection{RANDOM GEOMETRIES}

The parametric tool developed in this thesis, EXOEQUILIBIRUM, enables the interactive exploration of antifunicular alternatives for any two-dimensional geometry. As previously described, the methodology and the implemented tool are not limited to radial struts connecting the main geometry and the posttensioning tendon. In fact, Figure 5.1 shows the graphical construction of one possible tendon layout for generating vertical loads that makes a three-pointed geometry works in pure compression.

Next, Figure 5.2, Figure 5.3 and Figure 5.4 illustrate the application of the methodology to arbitrary shapes. 


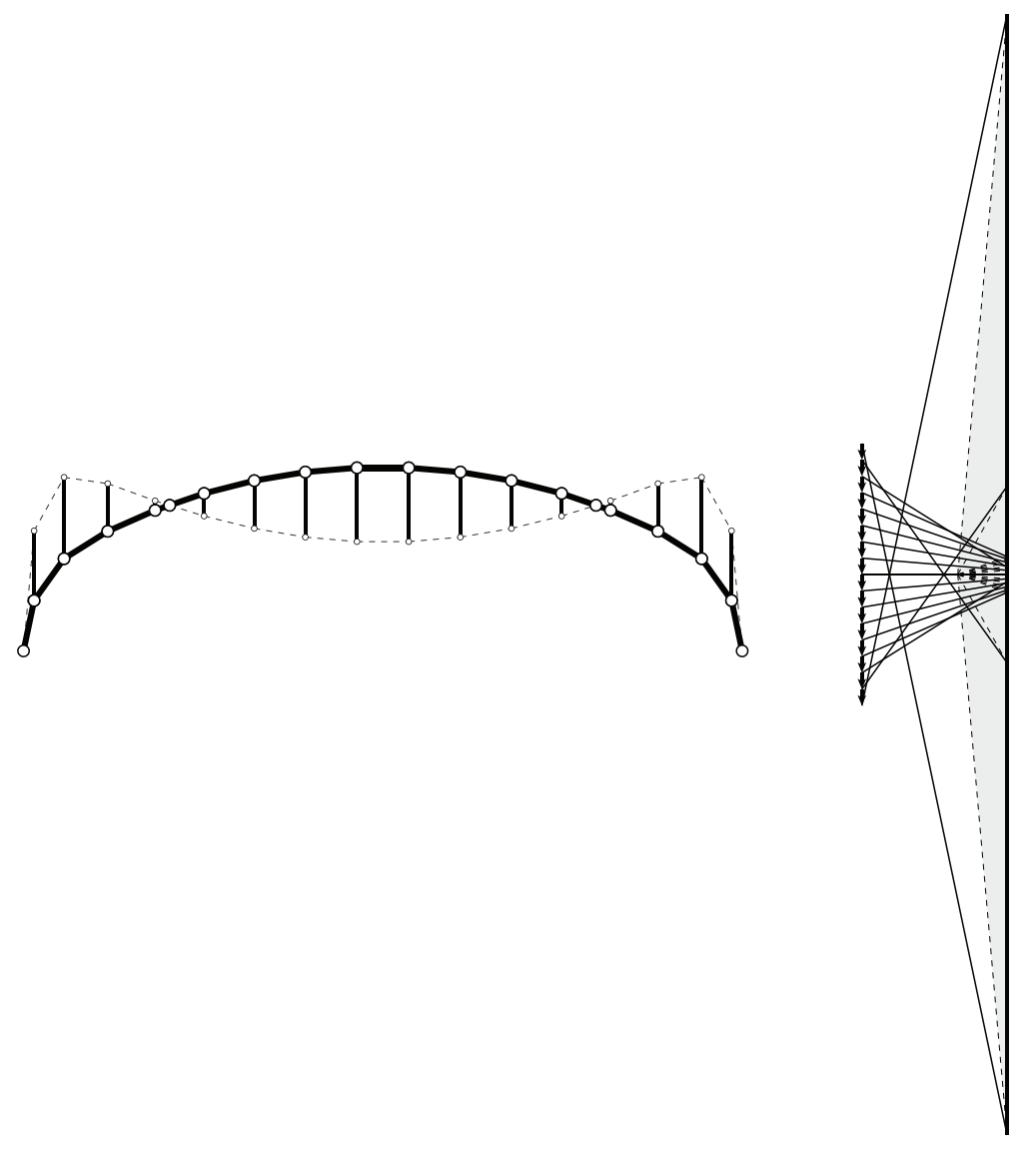

Figure 5.1: Antifunicular three-pointed arch with vertical struts. 

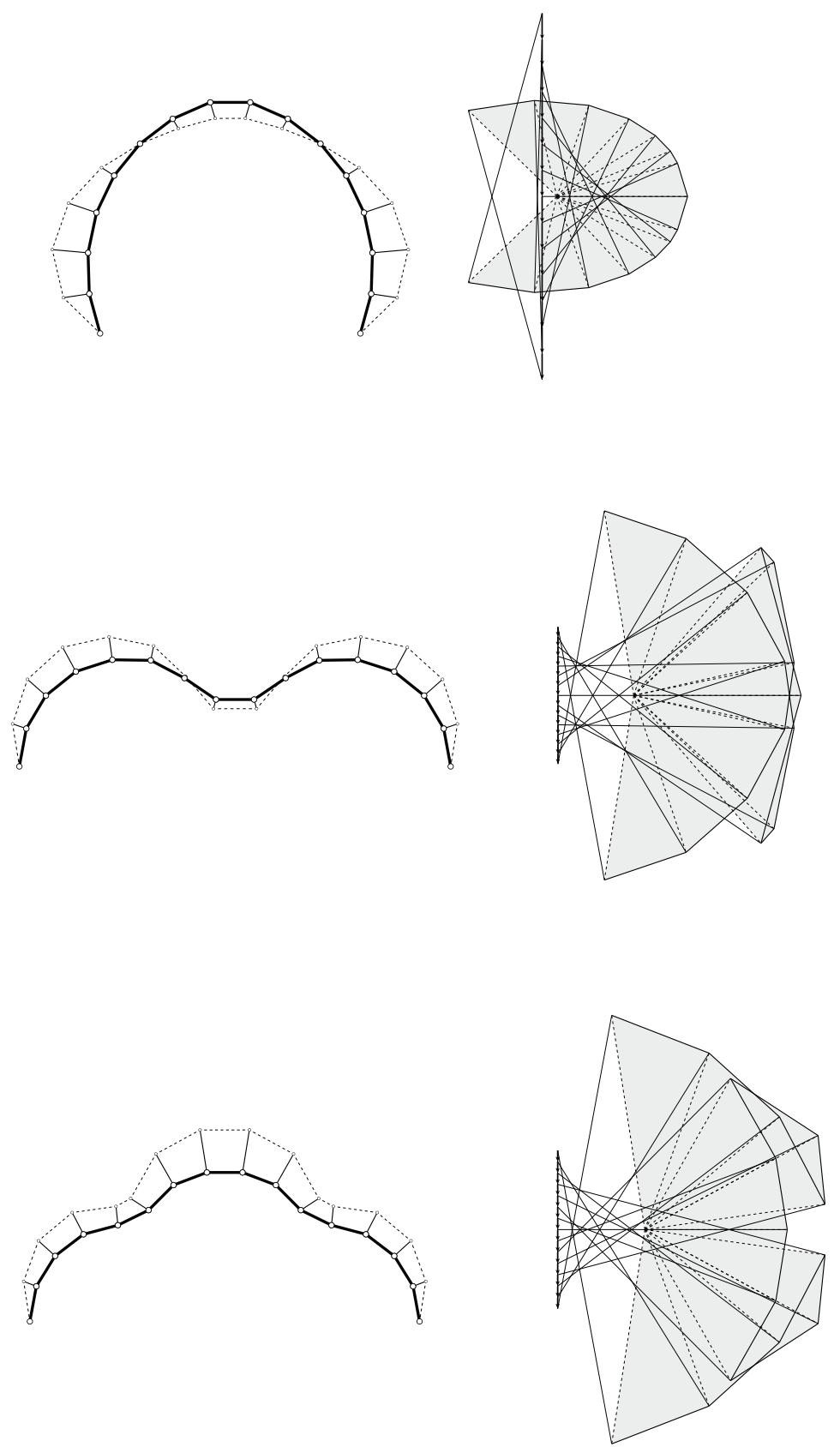

Figure 5.2: Resulting post-tensioned forms for arbitrary geometries ( $1 \mathrm{of}_{3}$ ). 

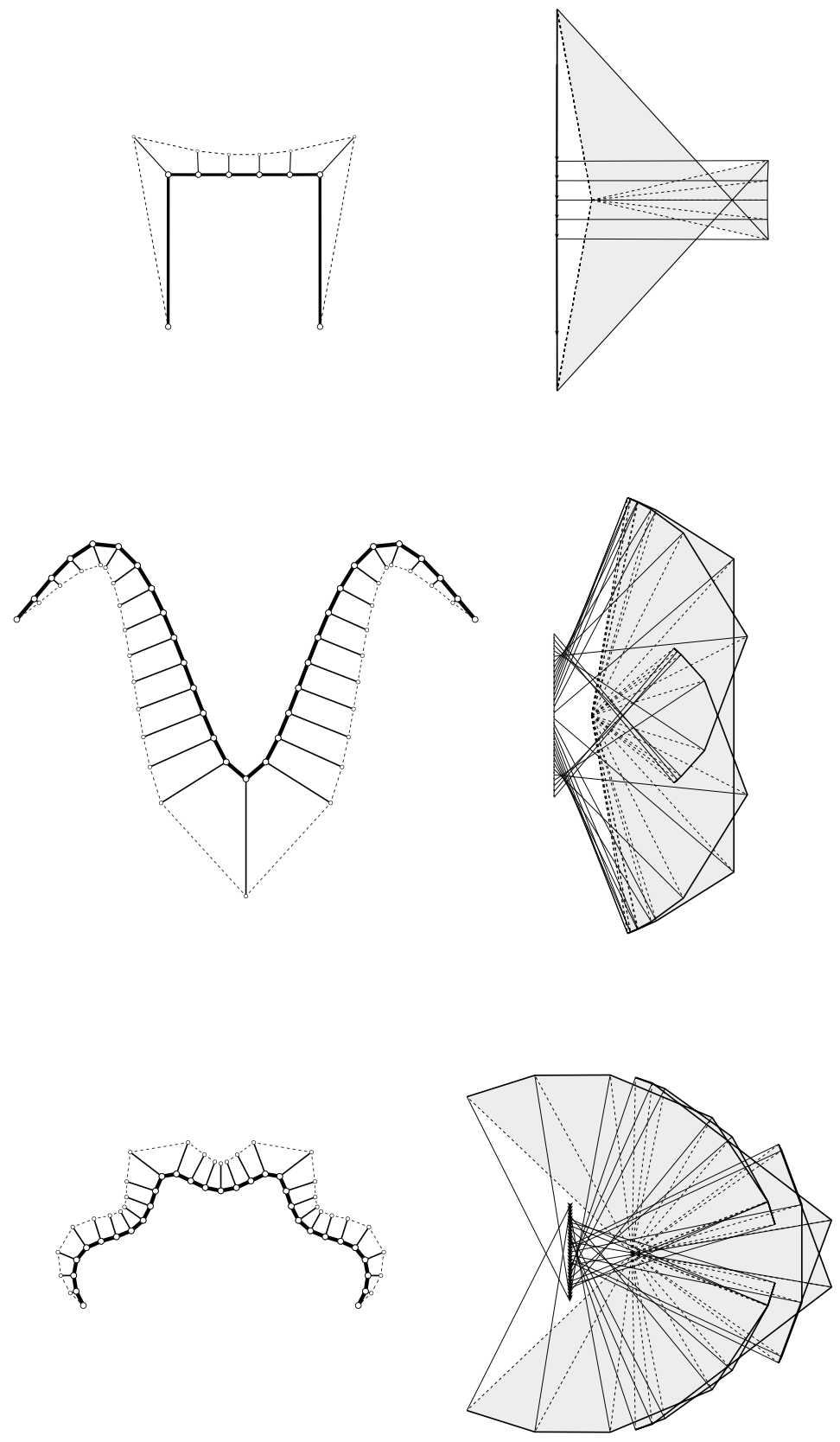

Figure 5.3: Resulting post-tensioned forms for arbitrary geometries ( $\left.2 \mathrm{of}_{3}\right)$ 

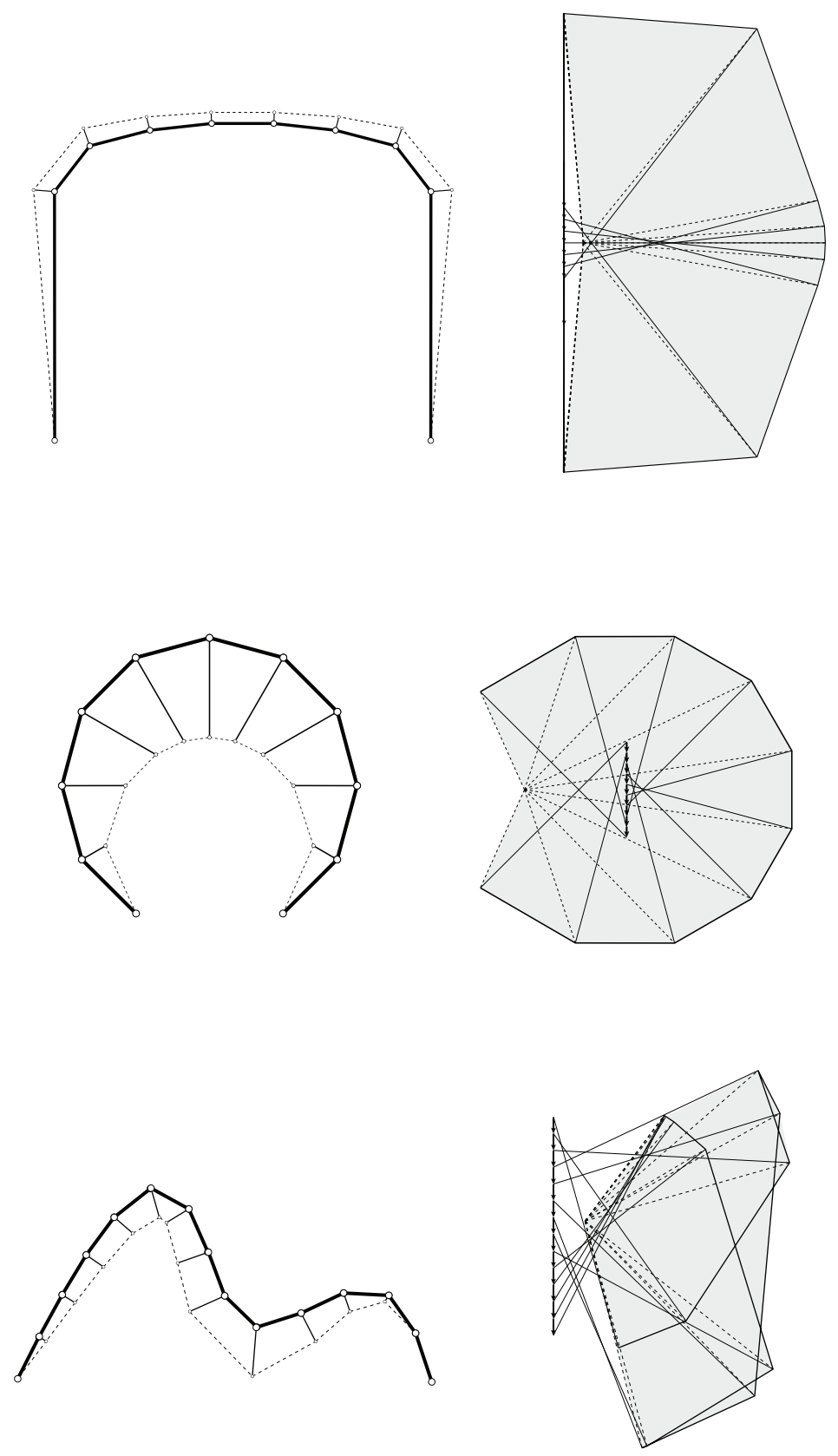

Figure 5.4: Resulting post-tensioned forms for arbitrary geometries ( $3 \mathrm{of}_{3}$ ).

The collection of examples, with varying degrees of curvature and both symmetrical and asymmetrical forms, demonstrates the versatility of the 
methodology and of the implemented tool for any two-dimensional geometry. Forces in all structural members can be read in the force diagram, giving to the designer the possibility of evaluating the performance of the whole system consisting of the compressive geometry, the post-tensioning system and the connecting struts.

\subsubsection{EXTENSION TO NON-UNIFORM DISTRIBUTION OF LOADS}

The developed methodology has been, until now, applied to structures loaded with uniformly distributed weight along the curve. However, the method is more general and it is not limited to a uniform distributed load. In addition, a nonuniform set of loads is frequent in common structures (e.g., arches supporting roofs or decks).

Figures 5.5a and 5.5b show the application of the graphical procedure for a starting non-antifunicular shape where non-uniform loads act. The construction is exactly the same of the previous cases, and, again, it provides the geometry of a post-tensioning cable to transform the starting geometry into a bending-free one. In both figures, the forces to be applied to the structure in order to achieve antifunicularity are the same; the difference lies on the post-tensioning position, in fact, the pole $q$ changes its position, moving horizontally. As main result, the methodology can be generalized to any starting load distribution.

\subsubsection{EXTENSION TO TWISTED 2D GEOMETRIES}

In the previous examples the graphical procedure has been employed to design geometries contained in a plane. However, it can be easily extended to twodimensional structures that are contained in different planes.

This is the case of a footbridge with a Y-shape in plan illustrated in Figure 5.6. The footbridge has a circular base geometry (in elevation) and it bifurcates in the middle with an angle of $30^{\circ}$. Depending on functionality issues, the deck, after the bifurcation, can assume a variable width. In this example, the load of the deck after the bifurcation is assumed to be the $50 \%$ of the deck load before the bifurcation. 

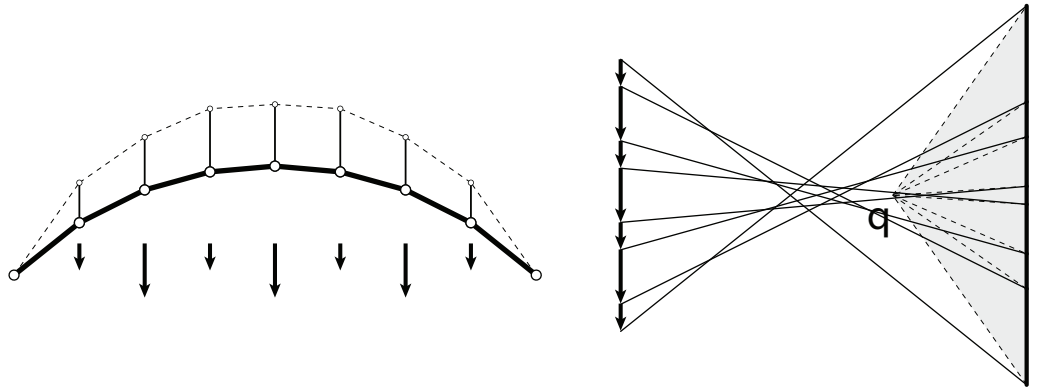

(a)
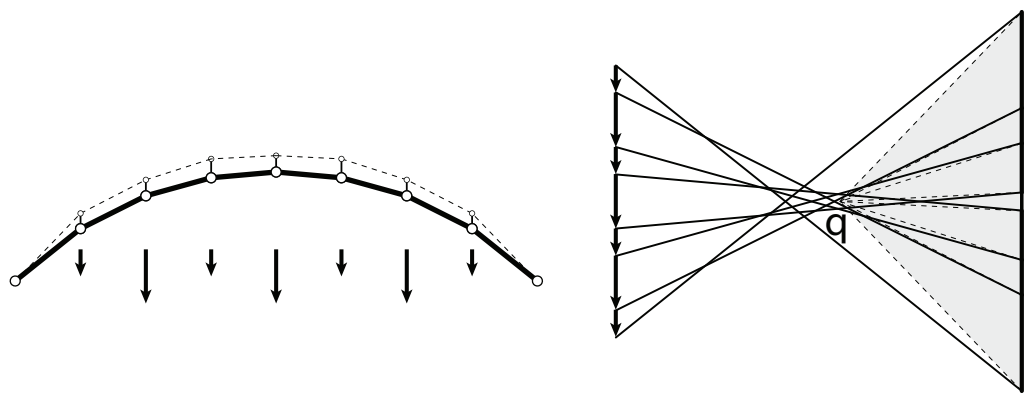

(b)

Figure 5.5: Design for non-uniform load distribution. 
The only difference, compared to the previous described graphical construction, lies in the fact that the force polygon is more complex to construct because the force in the compressive member, just after the bifurcation, has to be obtained by the decomposition of the compression force in two deviated forces.
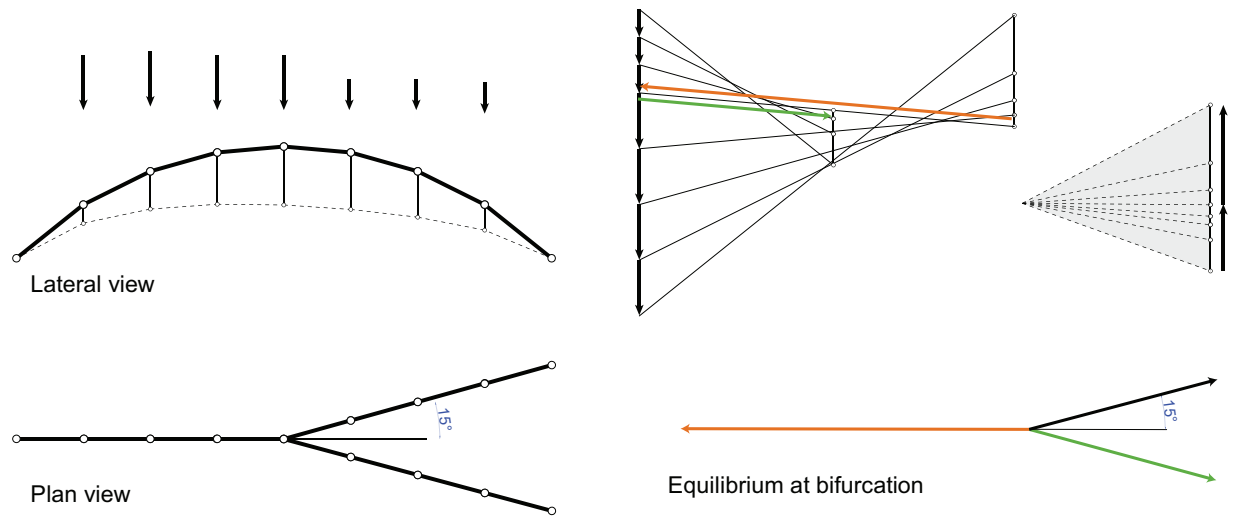

Figure 5.6: Design of a footbridge with Y-shape in plan.

\subsubsection{BEHAVIOUR FOR ADDITIONAL UNIFORM LOAD}

It has been described before that the graphical procedure adopted in this research is based on a base geometry and a starting distribution of loads. However, often structures during their life face different distributions of loads. This section aims to briefly introduce the study of the consequence due to a linearly increasing of the permanent load (by 1.5 times) after construction and prestressing of the cables.

Figure 5.7a describes the starting condition, where three point forces $G_{i}$ act on a non-antifunicular shape and the post-tensioning layout is found using the graphical construction previously described.

Figure $5.7 \mathrm{~b}$ shows that if a different set of loads $G_{i}^{*}$ is applied in addition to the forces employed for designing the post-tensioning system, bending moments are inevitably produced in the structure. The bending moment can be calculated as the horizontal reaction of the post-tensioning system multiplied by the eccentricity between the position of the prestressed cable and the new position in which it should be located. This bending moment has its maximum value at the 
middle, where the eccentricity is $f$. An option for eliminating bending moments related to additional (permanent or variable) loads would require a responsive structure (Section 7.2).

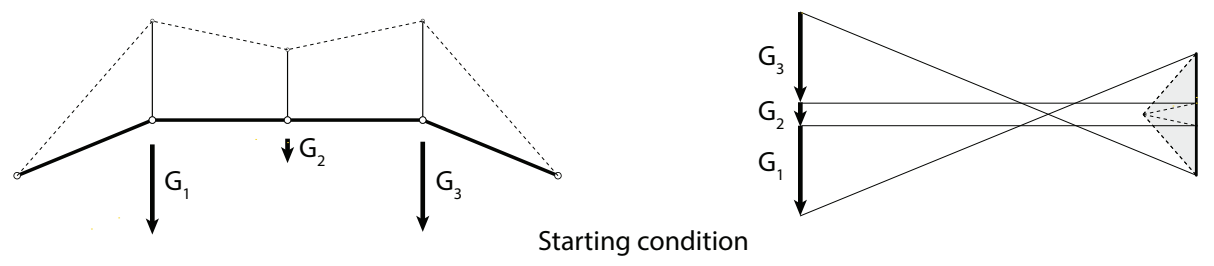

(a)
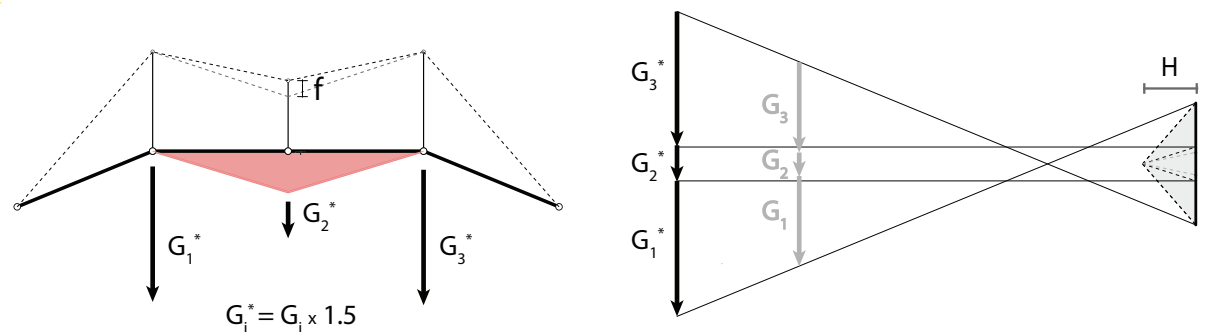

Passive solution

(b)

Figure 5.7: Behaviour for additional distributed loads.

\subsubsection{MATERIAL-EFFICIENCY OF THE SYSTEM}

\section{CAse STUdies}

While the interpretation of the force polygon reveals the magnitude of forces in the system, more detailed evaluations must be performed in order to assess the efficiency of the described approach. The goal of this section is to evaluate the effects on the global structural behavior of obtaining a bending-free geometry using an external post-tensioning system. This is achieved with a simplified comparison between bending and antifunicular solutions for three non-funicular base geometries.

The starting data are the geometry of the initial curve (all of them have a span of $30 \mathrm{~m}$ ), the direction of the struts (radial) and the uniform 
distributed dead load magnitude $(12 \mathrm{kN} / \mathrm{m})$. Concrete circular hollow profiles (thickness/diameter $=0.05, f_{c}=30 \mathrm{~N} / \mathrm{mm}^{2}$ ) have been adopted for the compressive curve. The cross section design, computed within the elastic range, depends on the forces in the structural elements, and the minimum section satisfying both global buckling of the structure and yield stresses is taken.

The result, consequent to the application of the previous described posttensioning method, for a known geometry is not determinate (i.e., there are infinite solutions for each starting geometry). The user can explore the infinite range of equilibrated solutions by varying related parameters, as the horizontal reactions, the magnitude of axial forces in the compressive curve and the posttensioning force applied to the tendon.

The external forces to be added to the starting geometry, to make it antifunicular, are related to the maximum allowable offset between the compressive curve and the post-tensioned tendon. This distance between the two curves is described by a percentage of the span and it is a relevant parameter for evaluating the efficiency of the system. As a general rule, the smaller the distance between the compressive curve and the post-tensioning system, the higher the forces in both components.

\section{ANALYSIS OF RESULTS}

The design of the bending solution, which considers combined axial forces and bending moments, is governed by the allowable stress and uses an hollow cross section which total mass for the non-funicular structure is $M^{*}$.

The design of the antifunicular solution, which considers only axial forces (higher compared to the bending solution), is governed by the allowable stress and requires a hollow cross section; the total mass of the compressive curve is $M$.

Figure 5.8 shows the comparison in term of required mass of the starting geometry $\left(M / M^{*}\right)$ for, respectively, three-pointed arch, circular arch and freeform asymmetrical curve. Each computed comparison is related to the maximum offset between post-tensioning system and compressive curve. Defined a target maximum offset, the minimum set of forces to be added to the existing loads have been selected for the comparison. 
M: mass of the non-antifunicular structure

Offset: maximum distance between compressive geometry and post-tensioning (as percentage of the span)
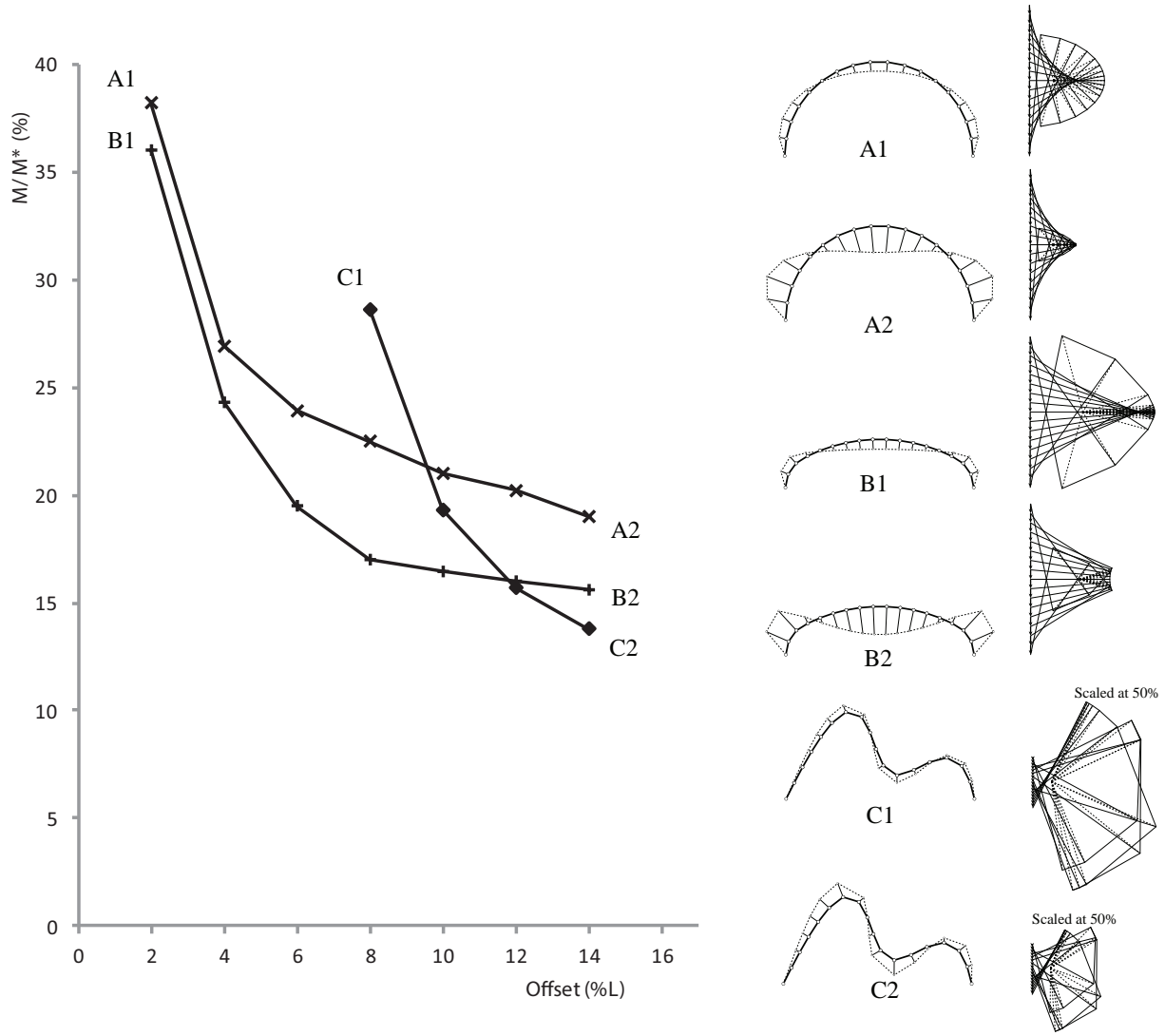

Figure 5.8: Comparison between bending and post-tensioned solutions. 
Results obtained for different offsets illustrate how the position of the posttensioned tendon strongly influences the structural performance for all the analyzed shapes. If the cable has a minimum offset (i.e., it is closer to the compressive curve) high values of external forces are needed, compressive forces in the curved geometry are higher, inevitably decreasing the efficiency of the proposed system. Furthermore, the reading of the force polygons reveals the difference between dead loads and forces to be added for making the geometry funicular and shows how far a shape is from being funicular for its loads. In this example, the asymmetrical shape results the one with highest forces to be introduced.

However, independently of the offset, the overall structural behavior of the post-tensioned solution results in savings of $60 \%$ to $85 \%$ of the whole mass compared with the bending solution. Results illustrate that despite the introduction of higher axial forces, the act of removing bending moments allows to design more cost-effective structures.

While this simplified analysis is not sufficient for a complete design, the approach is consistent with the aim of the assessment: a first simplified comparison between different solutions for a preliminary evaluation of their structural performances. Further analytical and experimental research has to be carried in the future (see Section 7.2).

\subsection{DESIGN CRITERIA}

\subsubsection{INTRODUCTION}

It has been illustrated before that, given a starting geometry and its related design loads, the problem to solve is indeterminate: an infinite number of force distributions make the geometry antifunicular (Section 4.1.3).

This section presents an original procedure that enables the mastery of this infinite domain of solutions by means of specific design criteria (DC). Several design criteria can be adopted for the design of curved externally post-tensioned structures. The DC described in the following are related to geotechnical, mechanical and aesthetic issues. The selected criteria are not exhaustive and more 
criteria can be used, depending on the boundary conditions and specific needs.

All the possible solutions can be explored by varying the two indeterminacies related to the magnitude of the forces to be added to the compressive geometry and of the forces within the prestressed cable, respectively.

This section, first, presents the analysis of six different design criteria and, then, their implementation in EXOEQUILIBRIUM to parametric explore their effects on the internal force distribution.

\subsubsection{Notations}

With reference to Figure 5.9, the following notations have been employed:

- $L_{i}^{N}$ : length of the elements of the compressive structure

- $L_{j}^{S}$ : length of radial struts between compressive structure and cable

- $L_{i}^{P}$ : length of the prestressed segments

- $N_{i}$ : axial forces in the compressive geometry (measured as a length in the force diagram)

- $F_{j}$ : axial forces in radial struts (measured as a length in the force diagram)

- $P_{i}:$ prestress forces in the cable (measured as a length in the force diagram)

Where $i$ is the number of element in which the compressive shape is divided, and $j$, number of connecting elements, is equal to $i-1$.

\subsubsection{DESIGN CRITERIA}

1. DC 1 : no horizontal reactions

One of the most important drawback of the "arch behaviour" is the horizontal thrust generated by the structure that has to be equilibrated by the soil. The post-tensioning system, depending on its position with respect to the vertical direction, can increase or decrease the total horizontal thrust. Generally speaking, if the cable has an inward direction it contributes to decrease the horizontal thrust. 

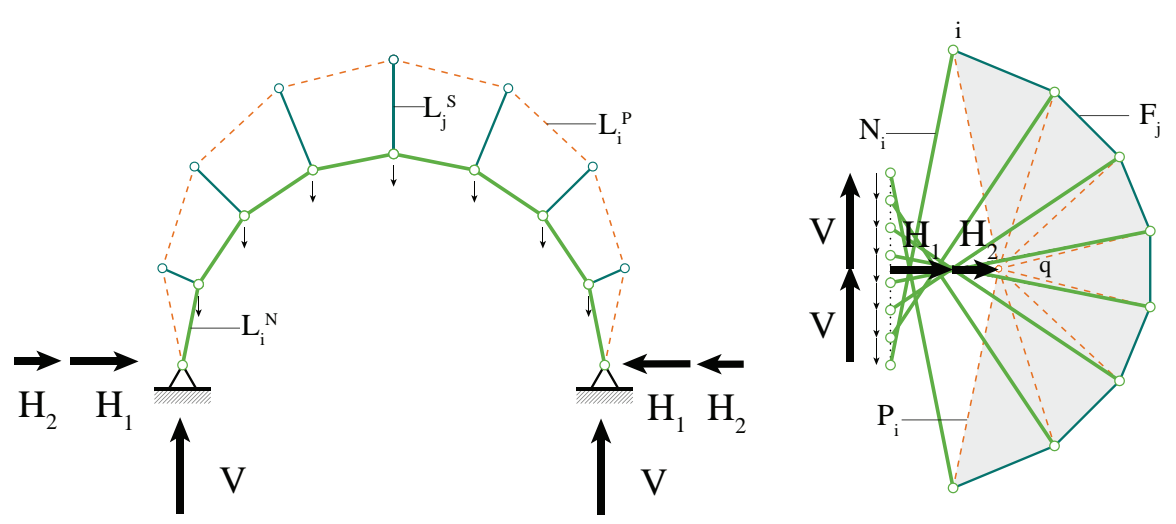

Figure 5.9: Notations.

The total horizontal force is the sum of the horizontal thrust due to the permanent loads acting on the compressive structure, $H_{1}$, and the horizontal thrust associated to the introduction of the prestress, $H_{2}$. The first design criterion responds to the possible need, due to geotechnical issues, of having no net horizontal thrust at the supports.

$$
\Delta H=\vec{H}_{1}+\vec{H}_{2}=\mathrm{o}
$$

2. DC2: minimum forces in the compressive geometry

The $\mathrm{DC}_{2}$ is a criterion aimed at saving material for the design of the compressive geometry. It consists in minimizing the forces to be transferred from the cable to the compressive geometry. The different equilibrated configurations can be explored by moving the point $i$ (Figure 5.9) related to the first indeterminacy. The criterion is based on minimizing forces needed to close the polygon of forces:

$$
\min F=\min \sum F_{j}
$$

3. DC 3: minimum forces in the prestressed cable

The $\mathrm{DC}_{3}$ is an optimization criterion which aims to find the posttensioning configuration corresponding to the minimum amount of forces 
within the prestressed cable. In graphic statics this goal is achieved by minimizing the lengths of the segment in the force diagram.

$$
\min P=\min \sum P_{i}
$$

4. DC4: minimum strain energy in the prestressed cable

The $\mathrm{DC}_{4}$ is another optimization criterion that aims at minimizing the strain energy related to the cable because it should correspond to its most efficient position. If the linear elastic behaviour applies the strain energy of the cable, $D^{P}$, can be expressed as [100]:

$$
D^{P}=\sum \frac{1}{2} \frac{P_{i}^{2} L_{i}^{P}}{E_{i}^{P} A_{i}^{P}}
$$

Where $E_{i}^{P}$ and $A_{i}^{P}$ are young modulus and area, respectively, of each $i$ segment of the cable. Assuming a constant young modulus and area, this criterion of minimum strain can be expressed as:

$$
\min D^{P}=\min \sum P_{i}^{2} L_{i}^{P}
$$

5. DC5: minimum strain energy in the whole system

The $\mathrm{DC}_{5}$ is an optimization criterion that aims at minimizing the strain energy of the whole structure. This solution should be globally the most material-efficient option because it takes into account all the structural members. If the linear elastic constitutive laws are assumed, the total strain energy $D$ can be expressed as:

$$
D=\sum \frac{1}{2} \frac{N_{i}^{2} L_{i}^{N}}{E_{i}^{N} A_{i}^{N}}+\sum \frac{1}{2} \frac{P_{i}^{2} L_{i}^{P}}{E_{i}^{P} A_{i}^{P}}+\sum \frac{1}{2} \frac{F_{j}^{2} L_{j}^{F}}{E_{j}^{F} A_{j}^{P}}
$$

Assuming a constant modulus of elasticity $E$ (e.g., steel is employed in all 
structural members), the strain energy can be expressed as:

$$
D=\frac{1}{2 E} \sum \frac{N_{i}^{2} L_{i}^{N}}{A_{i}^{N}}+\sum \frac{P_{i}^{2} L_{i}^{P}}{A_{i}^{P}}+\sum \frac{F_{j}^{2} L_{j}^{F}}{A_{j}^{P}}
$$

Assuming that all structural members are designed for the maximum allowable stress value (no constant cross-section areas), the total strain energy can be expressed as:

$$
D=\frac{1}{2 E}\left(\sum N_{i} L_{i}^{N} \sigma_{i}^{N}+\sum P_{i} L_{i}^{P} \sigma_{i}^{P}+\sum F_{j} L_{j}^{F} \sigma_{j}^{F}\right)
$$

If the allowable stresses of cable $\left(\sigma_{i}^{P}\right)$ and compressive members $\left(\sigma_{i}^{N}\right.$ and $\left.\sigma_{i}^{F}\right)$ are, respectively, $1500 \mathrm{MPa}$ and $300 \mathrm{MPa}$, it follows that:

$$
D=\frac{\sigma_{i}^{N}}{2 E}\left(\sum N_{i} L_{i}^{N}+5 \sum P_{i} L_{i}^{P}+\sum F_{j} L_{j}^{F}\right)
$$

Assuming constant modulus of elasticity (E) and allowable stress $\left(\sigma_{i}^{N}\right)$, it follows that this criterion can be expressed as:

$$
\min D=\min \left(\sum N_{i} L_{i}^{N}+5 \sum P_{i} L_{i}^{P}+\sum F_{j} L_{j}^{F}\right)
$$

6. DC6: prestressed cable above the compressive geometry

This criterion provides the most material-efficient solution with the prestressed cable always above the structure. This criterion responds to a double need:

- to have always compressive struts (this would imply a simpler connection detail, see Section 6.1.3)

- to leave free the inner space.

\subsubsection{PARAMETRIC ANALYSis AND IMPLEMENTATION}

This section illustrates a parametric analysis based on the design criteria before described in order to understand their effects on the structural efficiency of the 
structure. Three different starting geometries have been used: a circular arch, a basket arch and an asymmetrical free-form shape. The number of subdivisions is constant for all cases, as the total weight of the compressive geometry.

As it has been pointed out in from Section 5.1.5, internal force distribution is strongly related to the relative position between compressive structure and prestressed cable. For this reason a key parameter is the offset (as a percentage of the span) which represent the maximum length of the struts connecting compressive shape and tensioned cable. The offsets adopted for the circular and basket arches are 5\%, 10\% and $15 \%$ of the span. The offsets employed for the asymmetrical shape are $4 \%, 6 \%$ and $8 \%$ of the span.

A design-oriented tool, EXOEQUILIBRIUM, has been already developed for the parametric exploration of various design solutions. It has been further extended for including the design criteria described before. The use of interactive and parametric tools allows to exploit the benefits of using graphical constructions.

The procedure is based on the manipulation of the two indeterminacies until a target criterion is achieved. Forces are measured in the force diagram, while segment lengths are measured in the form diagram.

\subsubsection{Results}

Before starting with the in-depth analysis of the results obtained with the parametric analysis, it is important to point out that the design criteria from 2 to 5 are accomplished by the same form diagram. The theoretical reason behind this result is related to the fact that the second indeterminacy (forces within the prestressed cable) is affected from the first one (forces within the struts). This means that high forces to be introduced in the structure, inevitably generate low structural performance of the whole structure, independently on the position of the prestressed cable. As consequence of this fact, in the following analysis, criteria from 2 to 5 are represented by one graphical construction.

Figures 5.10 to 5.18 show the graphical results after the application of the design criteria to a circular arch, a basket arch and a free-form asymmetrical shape. The graphical constructions in the same row are characterized by the same 
design criterion.

The first insight obtained by an overall reading of the force diagrams is the further confirmation that the offset (maximum length of struts) plays a key role for determining the forces in the structure. To higher offsets (Figures 5.12, 5.15 and 5.18) correspond lower forces in the structural members. By using an offset of $5 \%$ of the span, instead of $15 \%$, the forces are 4 times higher, which affect greatly the size of the structural members.

The first rows of the figures 5.10 to 5.18 show that the total compensation of the horizontal thrust ( $\mathrm{DC}_{1}$ ) requires huge forces, especially if the allowable offset is low. In this case, a partial compensation can be favorable. The graphical constructions illustrate that inevitably the prestressed cable has to be inside the structure, and this constraint can be disadvantageous for functional issues.

The second rows of the figures 5.10 to 5.18 , which corresponds to the DC from 2 to 5 , illustrate that the optimal solutions would require a prestressed cable passing through the compressive structure. The graphical comparison between these force diagrams and the previous ones illustrates the great difference in term of required mass that can be saved by adopting a design criterion based on forces or, similarly, on strain energy instead of geotechnical issues.

The third rows of the figures 5.10 to 5.18 describe the graphical constructions based on the criterion of having a prestressed cable only above the structure (DC6). The cable is tangent to the compressive shape in the middle (if the compressive shape is symmetrical), and required forces are inversely proportional to the offset. In the first two cases (circular and basket arches) the required prestressed forces are higher than the case where no horizontal reactions are required. Differently, in the free-form shape the forces required for having a cable always above the compressive geometry are really high compared to the forces needed to compensate the horizontal reaction (note that the force

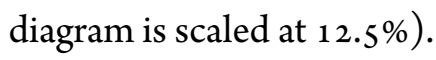



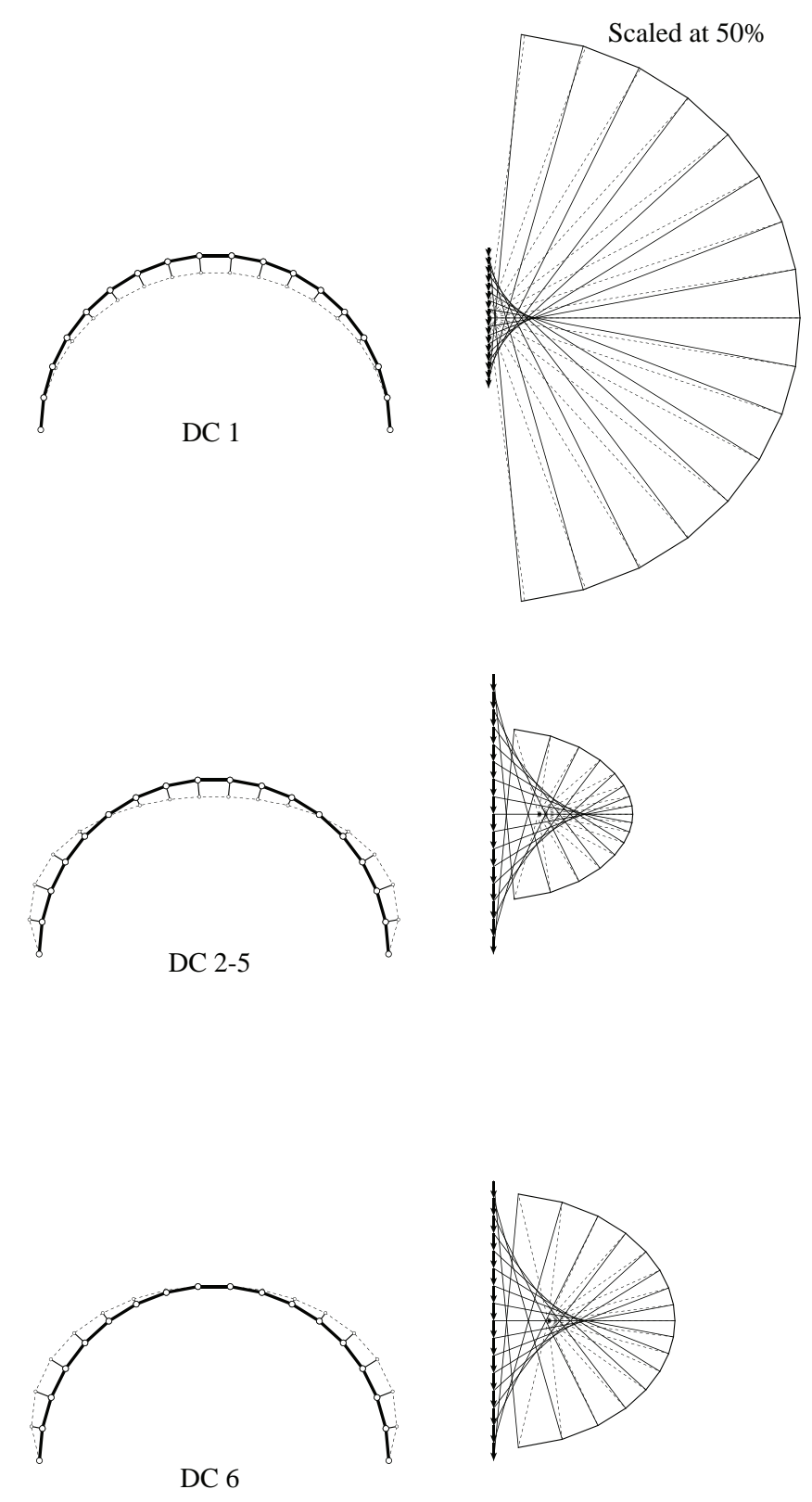

Figure 5.1 0: Application of DC to a circular arch (offset $=5 \%$ ). 

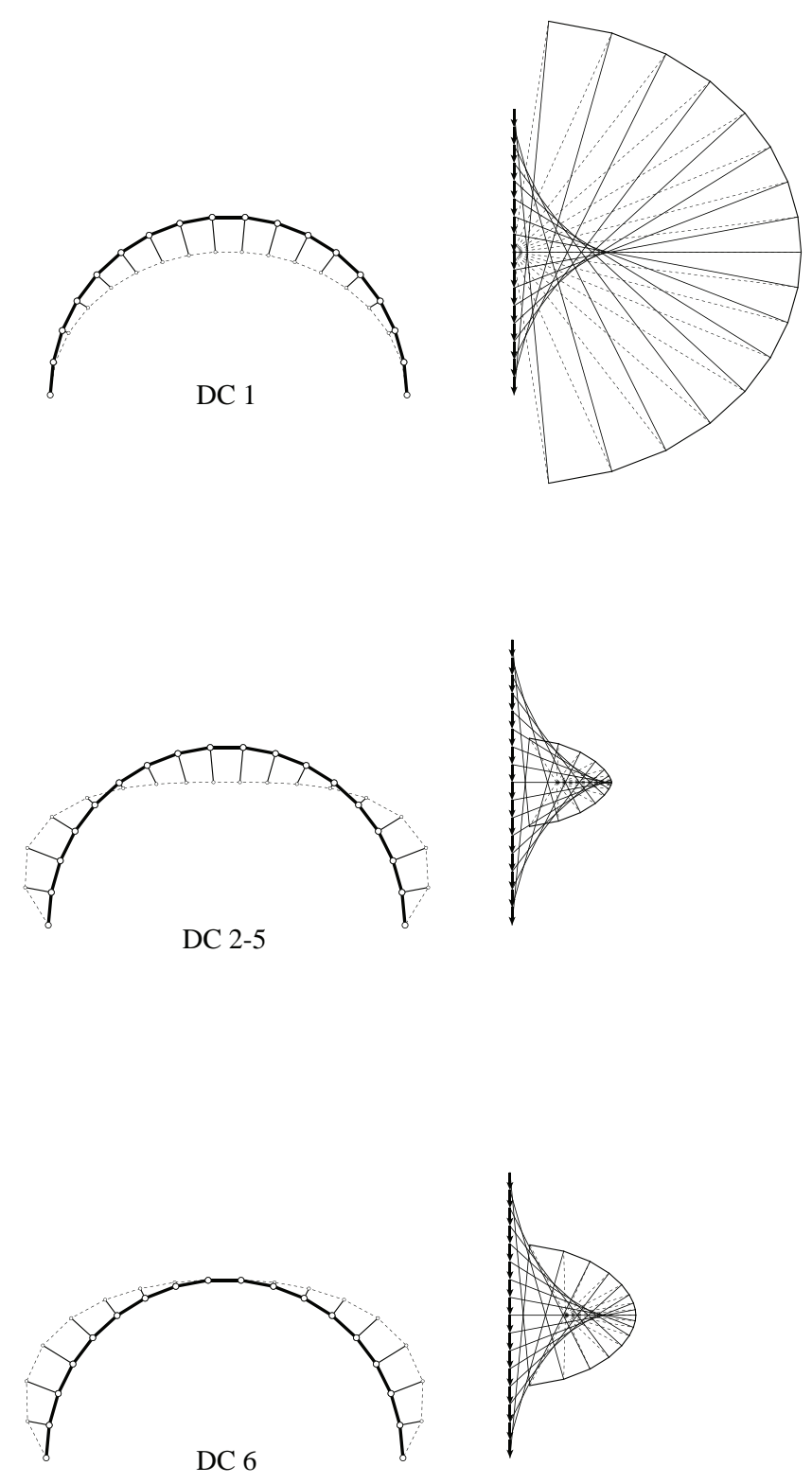

Figure 5.1 1: Application of DC to a circular arch (offset=10\%). 

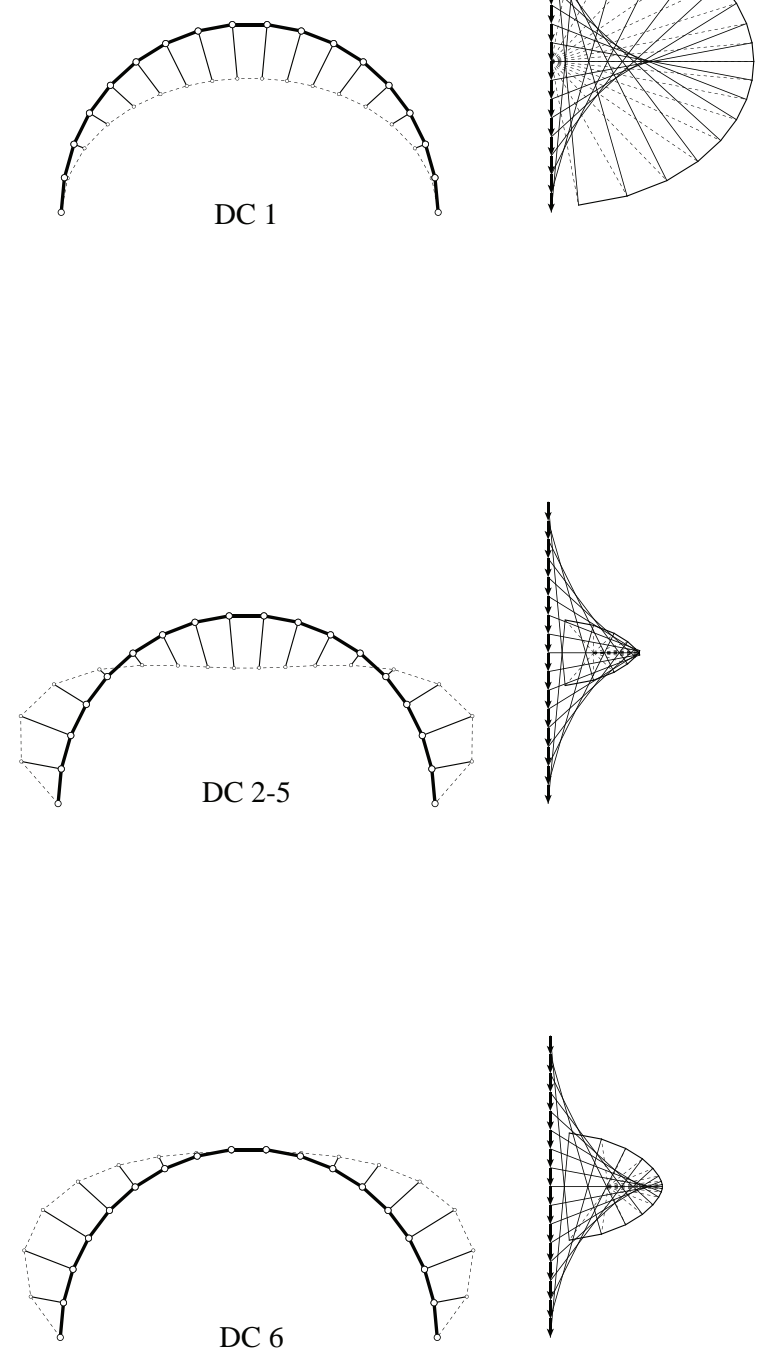

Figure 5.12: Application of DC to a circular arch (offset $=15 \%$ ). 

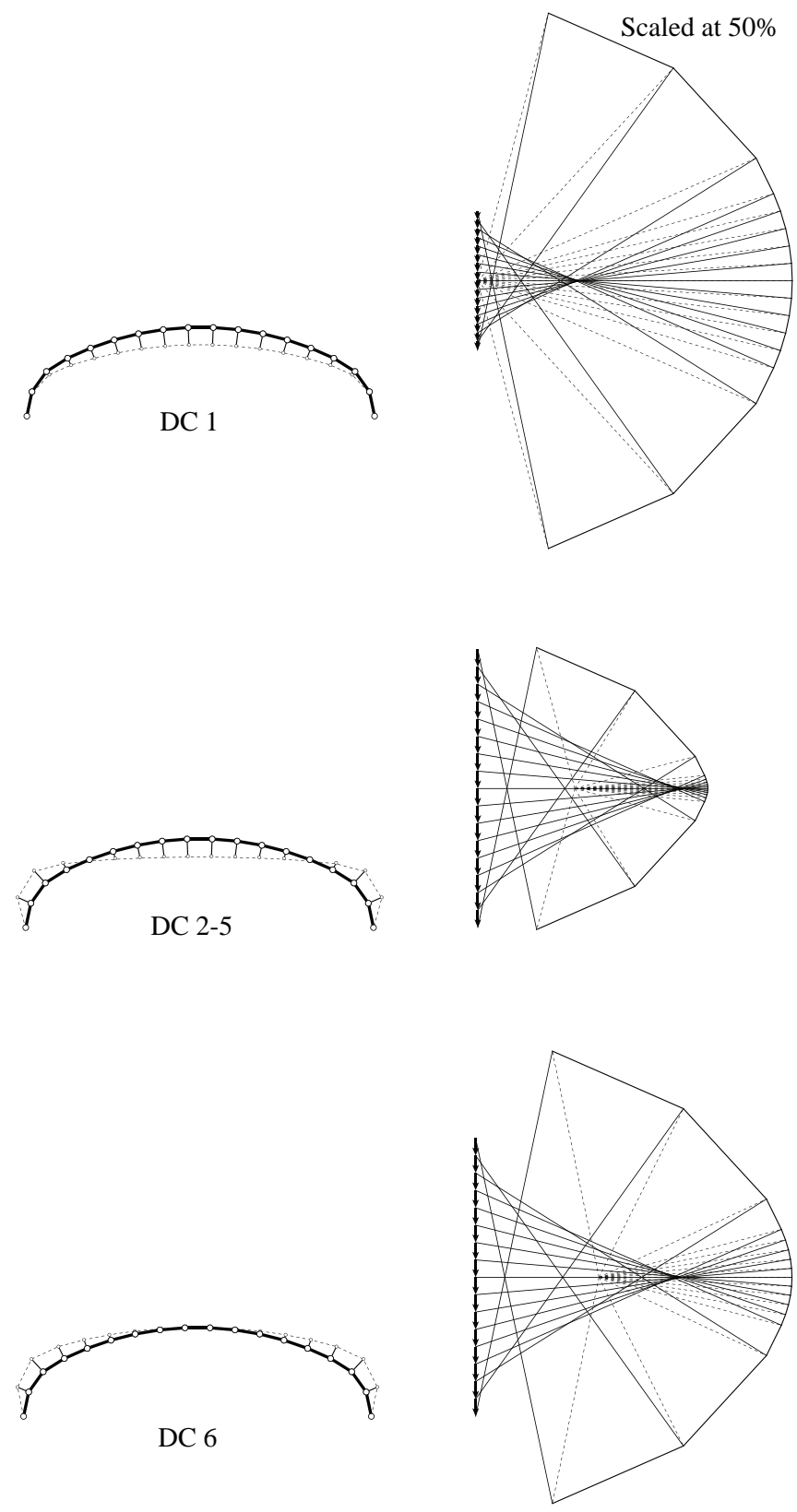

Figure 5.1 3: Application of DC to a basket arch (offset $=5 \%$ ). 

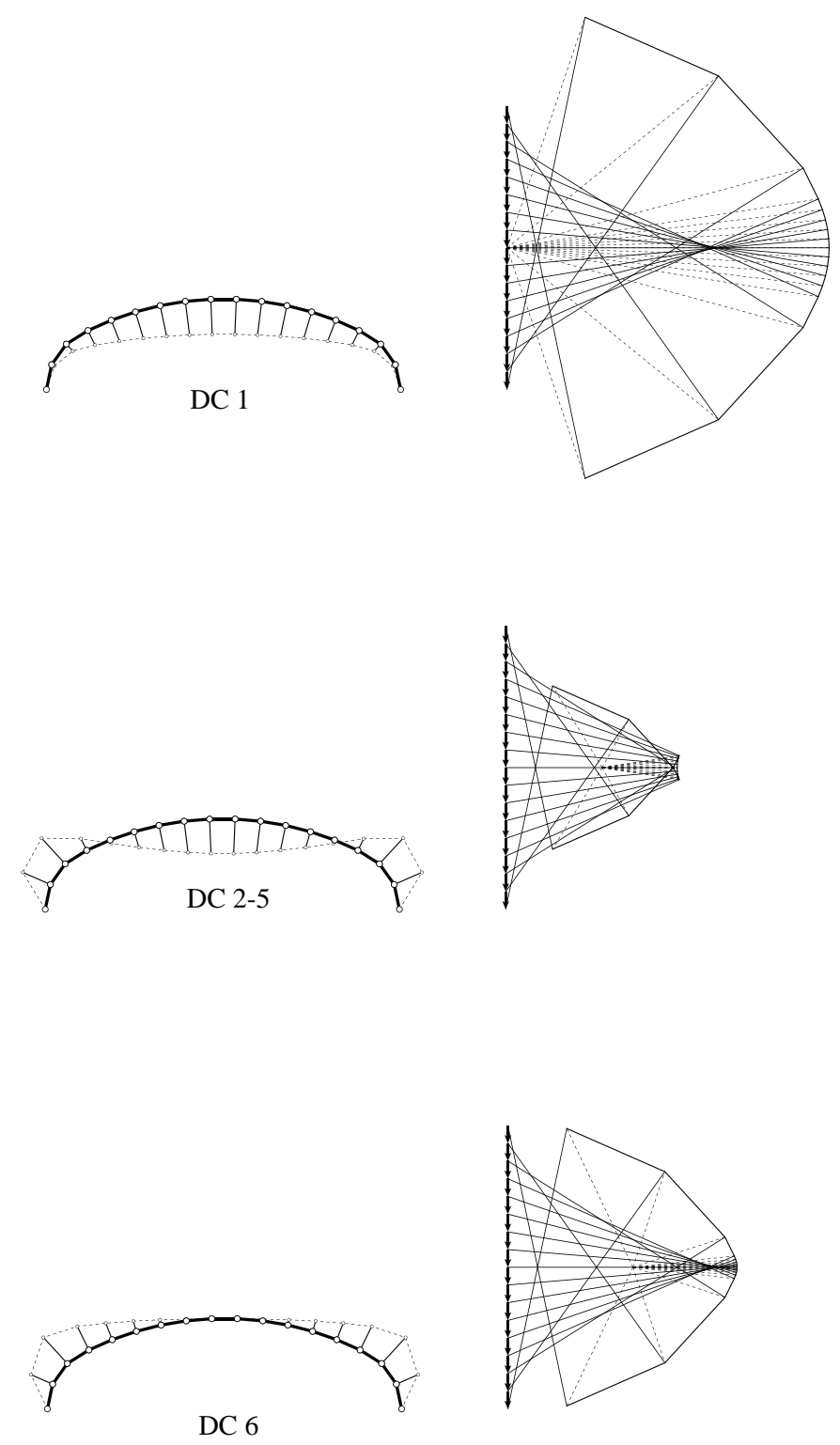

Figure 5.14: Application of DC to a basket arch (offset=10\%). 

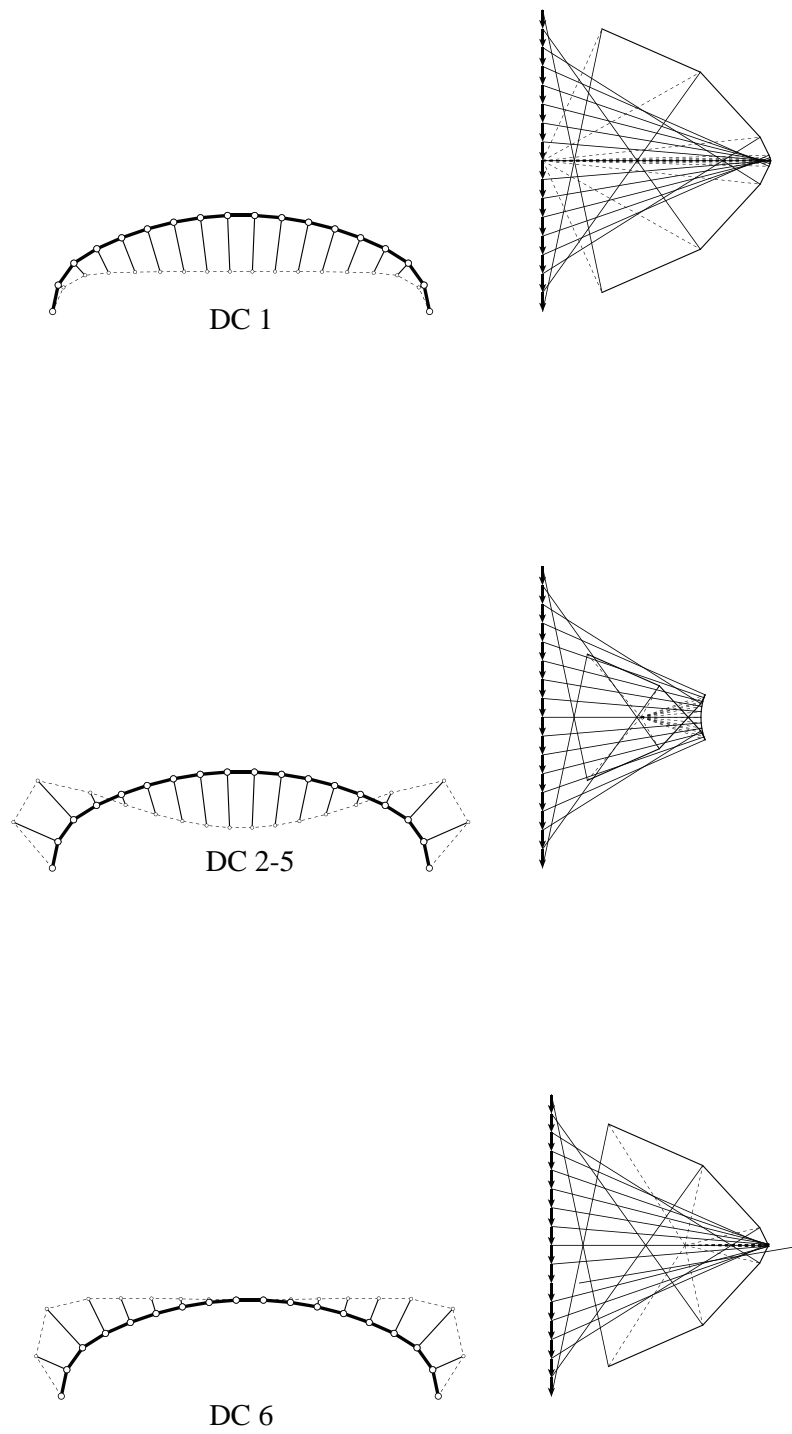

Figure 5.1 5: Application of DC to a basket arch (offset=15\%). 


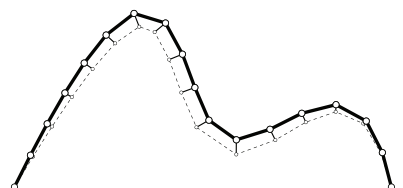

DC 1

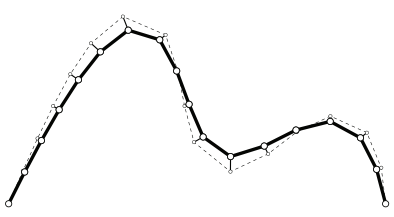

DC 2-5

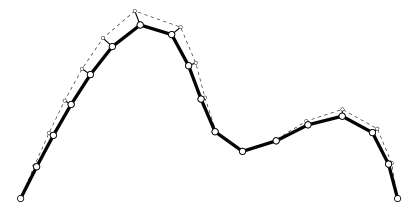

DC 6
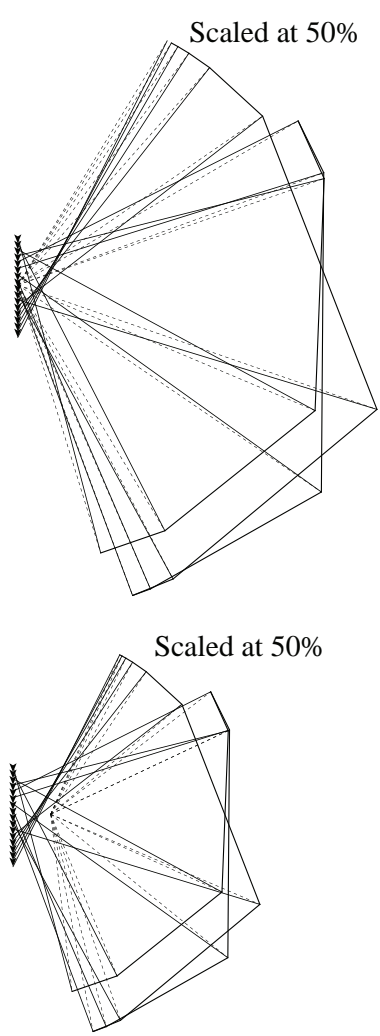

Scal ed at $12.5 \%$

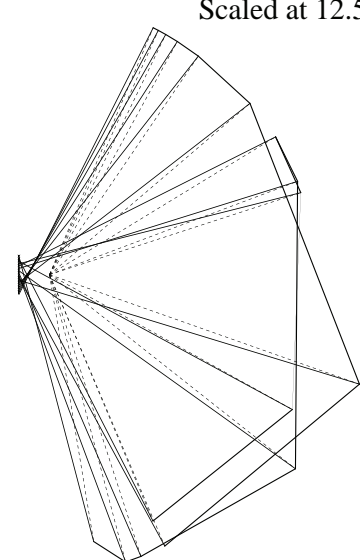

Figure 5.16: Application of DC to a free-form shape (offset=4\%). 
Scal ed at 50\%

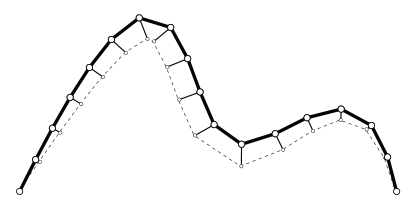

DC 1

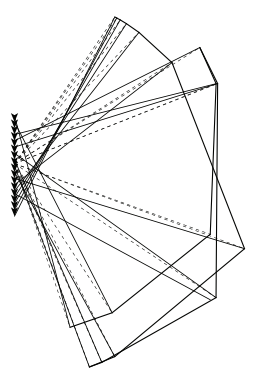

Scaled at $50 \%$

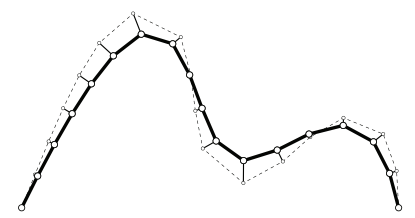

DC 2-5

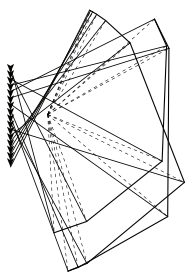

Scaled at $12.5 \%$
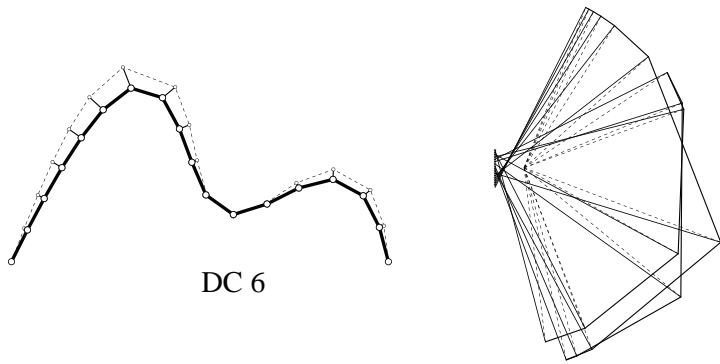

Figure 5.17: Application of DC to a free-form shape (offset=6\%). 
Scal ed at 50\%
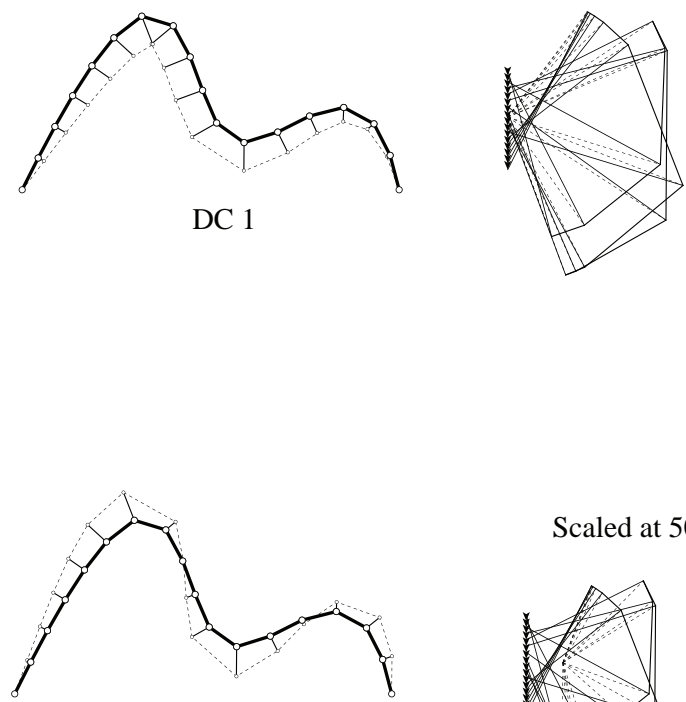

Scal ed at $50 \%$

DC 2-5

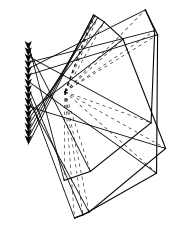

Scal ed at $12.5 \%$
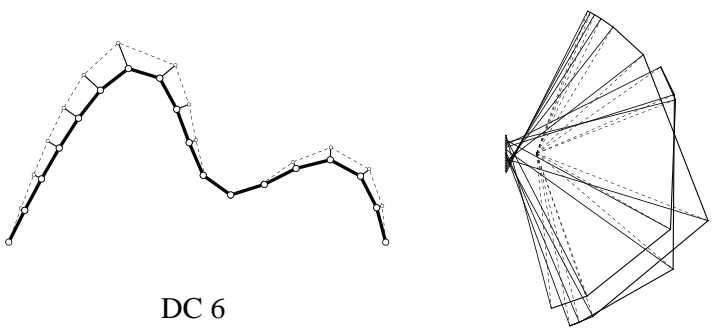

Figure 5.1 8: Application of DC to a free-form shape (offset=8\%). 
The previous analysis indicates that design criteria based on optimization purposes have to be chosen if there are no other constraints (e.g., geotechnics, aesthetics).

In order to better understand the relation of the criterion $\mathrm{DC}_{5}$ with the two indeterminacies, Figures 5.19 and 5.20 show a detailed analysis, by plotting the total strain energy versus the first and the second indeterminacies without limiting the offset. The plots clearly confirms the great preponderance of the first indeterminacy and, consequently, the low significance of the second indeterminacy with respect to the first, on the force distribution. 

CHAPTER 5. APPLICATIONS AND DESIGN CRITERIA

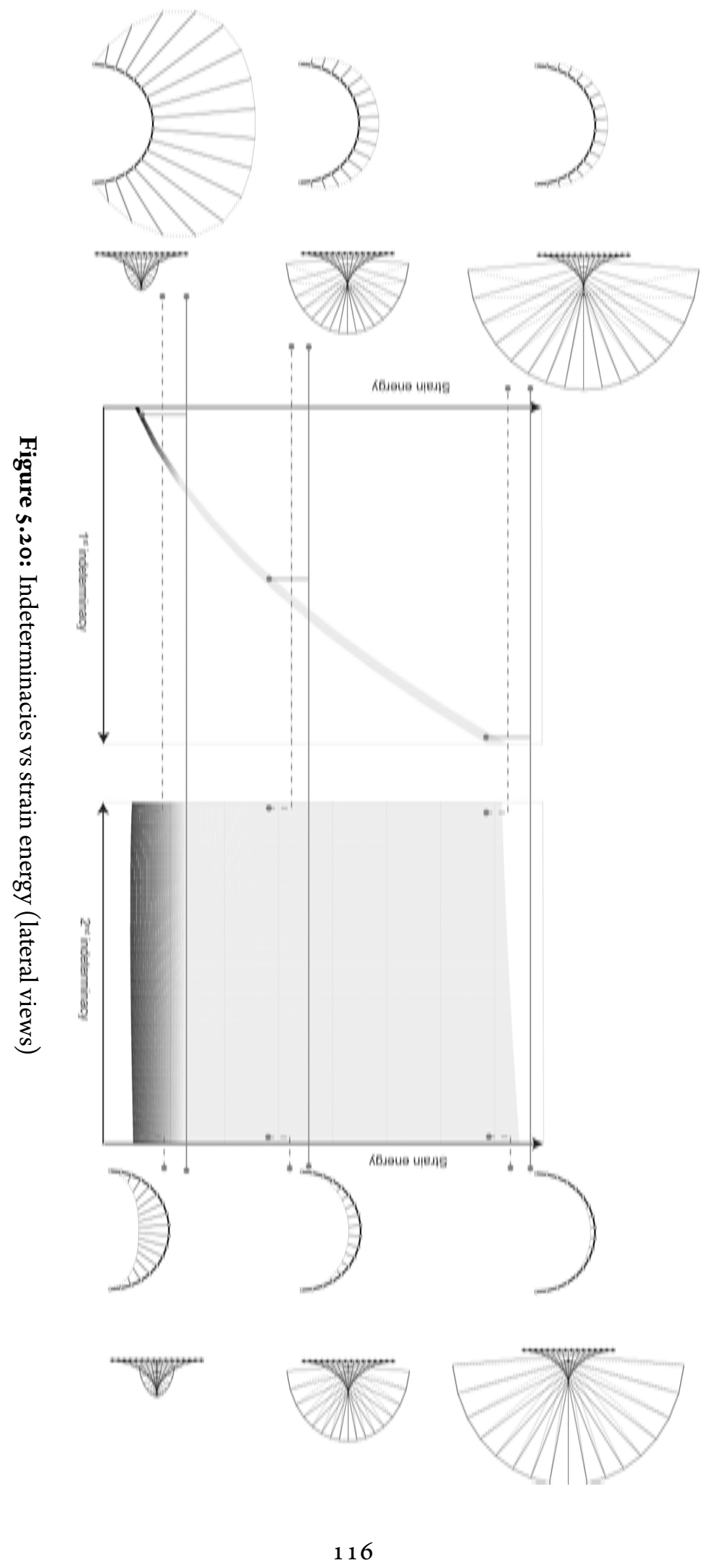




\section{$5 \cdot 3$ Summary}

This Chapter has illustrated many applications of the developed graphical procedure. Those examples include random geometries, twisted shapes and nonuniform distribution of loads. Furthermore, different design criteria (related to geotechnical, mechanical and aesthetic issues) have been implemented in EXOEQUILIBRIUM and their effect, in term of force distribution, has been studied. These design criteria are achieved by manipulating the force diagram, instead of the form diagram, thus equilibrium is always ensured $[16,17]$.

Results point out that:

- The graphical methodology is general and versatile. It can be used for any curved geometry, any distribution of starting loads, and it can be extended to twisted $2 \mathrm{D}$ structures.

- A simplified structural analysis has pointed out the great efficiency of this approach in terms of mass saving.

- The offset (maximum distance between the compressive geometry and the prestressed cable) plays a key role in optimizing the material-efficiency of the whole structure. Higher offsets correspond to lower material volumes, thus, higher cost-effective structures.

- The design criteria related to the need of having no horizontal thrust (DC 1 ) or a cable always above the compressive geometry (DC6) require high amount of forces.

- Different design criteria ( $\mathrm{DC}_{2}$ to $\left.\mathrm{DC}_{5}\right)$ based on the structural element optimization provide the same optimal cable layout. The key role is played by the first indeterminacy, which is responsible of internal force distribution.

- The implementation of graphical procedures in a parametric tool provides a well-suited environment for the interactive computational exploration of equilibrate solutions within the structural design space. 

One should not calculate a structure he cannot draw.

Formulae should not be used if their physical meaning is

not understood. A structure should not be designed by

computer if we do not know how to calculate it by hand.

Javier Rui-Wamba

\section{Reduced- and large-scale physical models}

\subsection{REDUCED-SCALE PHYSICAL MODELS}

\subsubsection{INTRODUCTION}

This section focuses on physical modeling, testing and validation of reduced-scale models where, as described in Section 4, a system of external forces transforms an initial non-antifunicular shape into an antifunicular one.

The reduced-scale structures are modelled with a combination of: i) base geometries fabricated through additive manufacturing ( $3 \mathrm{~d}$ printing), and ii) a post-tensioning system constructed with thin wire and precise laser-cut struts.

First, the section presents a brief historical review of physical models; next, it illustrates the employment of physical reduced models to test and validate the described method. Finally, conclusions and closing remarks are pointed out. 


\subsubsection{REVIEW OF PHYSICAL MODELS}

Since ancient times, master builders have employed physical models to understand more or less complex structural phenomena. Galileo Galilei was the first to point out the non-linearity of scaling for some structural phenomena such as material strength and buckling, as opposite to structural characteristics (e.g., equilibrium) that are independent of scale [9]. This can lead to a first categorization of physical models: dependent- or independent-of-scale.

Physical models, depending on their use, can be classified in three groups. In fact they can be aimed at:

1. finding bending-free shapes. These models, independent-of-scale, are based on the use of chains and its related principle of inversion (Section 2.3 );

2. analyzing the stability of existing structures as the models employed by Poleni for assessing the stability of St. Peter's dome in Rome (Section 2.3). These models can be defined as independent-of-scale;

3. understanding/predicting the behaviour of a structure. These models can be affected by the scale effect, depending on the phenomenon to be analyzed. Physical modelling of dependent-of-scale structures are mostly related to structures and materials with bending stiffness whose safety is related to strength or buckling and not to stability. On the other hand, physical reduced-models for testing masonry structures are independent of scale if, as generally happens, the collapse is due to a lack of equilibrium and not to material strength [43].

Due to the high computational cost and need of data of numerical methods, ${ }_{3} \mathrm{D}$ printed small-scale models have been employed recently for testing masonry structures in order to compare experimental results with analytical and numerical predictions [19, 32, 90, 115$]$. 


\subsubsection{Manufacturing PRocess}

Geometrical configurations, obtained with the graphical procedure described in Section 4, have been experimentally validated through reduced-scale models fabricated using a combination of additive manufacturing $(3 \mathrm{D}$ printing) and laser-cutting.

The employed physical models were composed by three elements:

1. Main structure working in compression. It is made of discrete elements printed individually by using a ZCORP ${ }_{3} \mathrm{D}$ printer. An alternative would consist in printing a monolithic structure but the collapse would be more related to material strength than stability. The bricks are made of plaster which strength is higher than internal stresses in order to avoid collapse for excessive compressive stresses.

Furthermore, blocks were impregnated with a liquid for improving strength and durability. Friction tests in literature indicate a coefficient of friction with an average value of 0.7 [90]: this value is high enough to prevent sliding of blocks.

2. Wire. External forces are applied manually by employing a turnbuckle that provides tension to the wire.

3. Connecting elements. Main structure and wire are connected by elements made of extruded acrylic ( $4.7 \mathrm{~mm}$ thick). Their lengths are obtained from the graphical construction.

The detailed design of the connecting elements is related to the forces applied in each one of them, in fact depending on the position of the cable, these elements can work in tension or in compression.

Figure 6.1 illustrates the designed connection detail for compressive and tensioned elements. If the connecting elements work in compression (Figure 6.1a), the contact between the main geometry and the connecting elements is enough to transfer loads and no mechanical connection is needed. However these elements can suffer buckling, thus a large cross section has been adopted. On the other hand, connecting tensioned elements need a more complex detail 
in order to transfer loads from the wire to the compressive shape (Figure 6.1b). In this case, the discrete ${ }_{3} \mathrm{D}$ printed elements provide a place to allocate the connecting elements that has the same shape of the mold. This results in a strong joint where sliding of the connecting tensioned elements is prevented by the cast and friction between plaster and acrylic.

The employment of these reduced-models includes some important approximations: i) without having the possibility of measuring forces in the wire, a trial/error method has been applied until the structure was stable; ii) the friction between wire and connecting elements has not been taken into account; iii) the connecting elements are clamped (no rotations are allowed) to the base geometry and this can generate local bending moments. In summary, these reduced-scale models involve relevant approximations that generate eccentricities between the line of centroid and the thrust line. In spite of that, the author believes that these models can still provide a visually evidence of the developed approach. This is illustrated in the following section. 


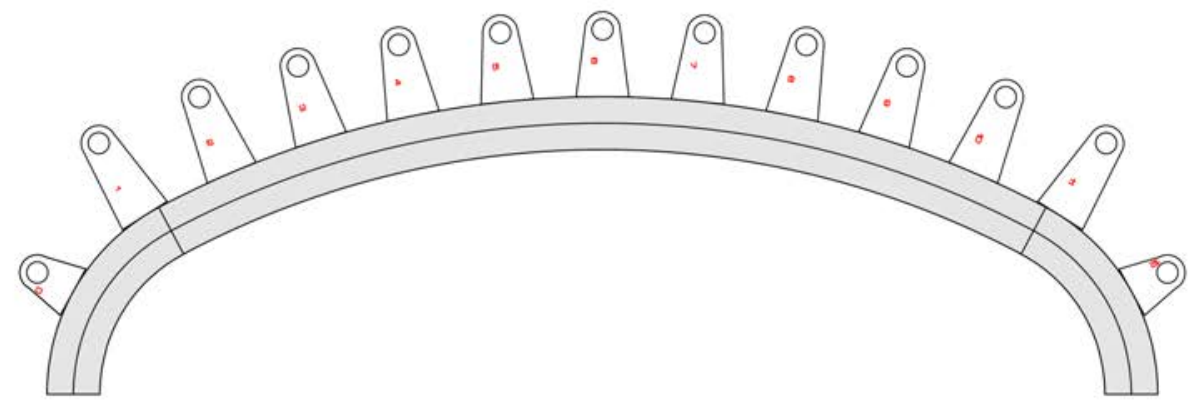

(a)

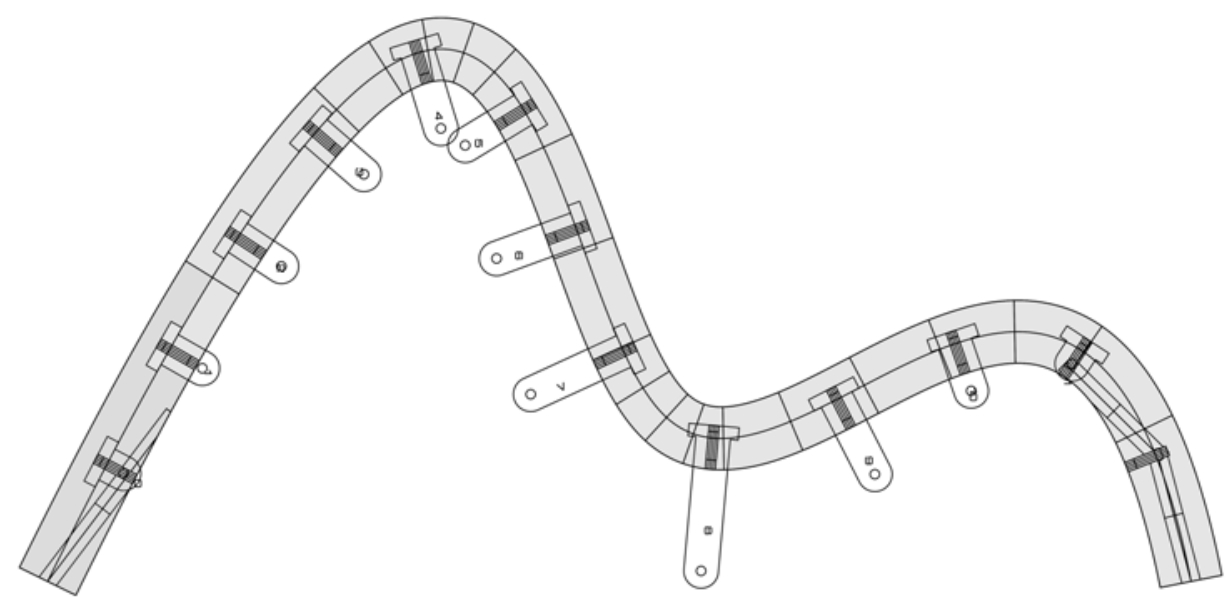

(b)

Figure 6.1 : Connection details for compressive and tensioned elements. 


\subsubsection{EXPERIMENTAL RESULTS}

Physical experiments have been carried out with three different shapes: a basket arch, a circular arch and an asymmetrical free-form geometry. Each test was filmed using a high-speed digital video camera proving carefully observation of collapse mechanism and slow-motion videos useful for didactic purposes. Figures 6.2, 6.3 and 6.4 show, at the top, the graphical construction that allows to find the layout of the external prestressed wire and the lengths of connecting elements. While, at the bottom, photos taken during the collapse mechanism of the models (after cutting the wire) are shown.

Physical models illustrate that once the post-tensioning force is applied, the non-antifunicular shapes, made of discrete elements, are stable. This can be considered as a further validation of the approach. Next, once the wire is cut (external forces are removed), the structures inevitably collapse because there is no way to achieve equilibrium.

Experimental testing shows that non-antifunicular structures can be in equilibrium only if external loads are added in a proper way: a wrong position of external forces, or their lack, inevitably causes the collapse of the structure. It is interesting to point out that the starting position of hinges is located in zones where the eccentricity (i.e., the distance between thrust line and centroid line) is maximum. 

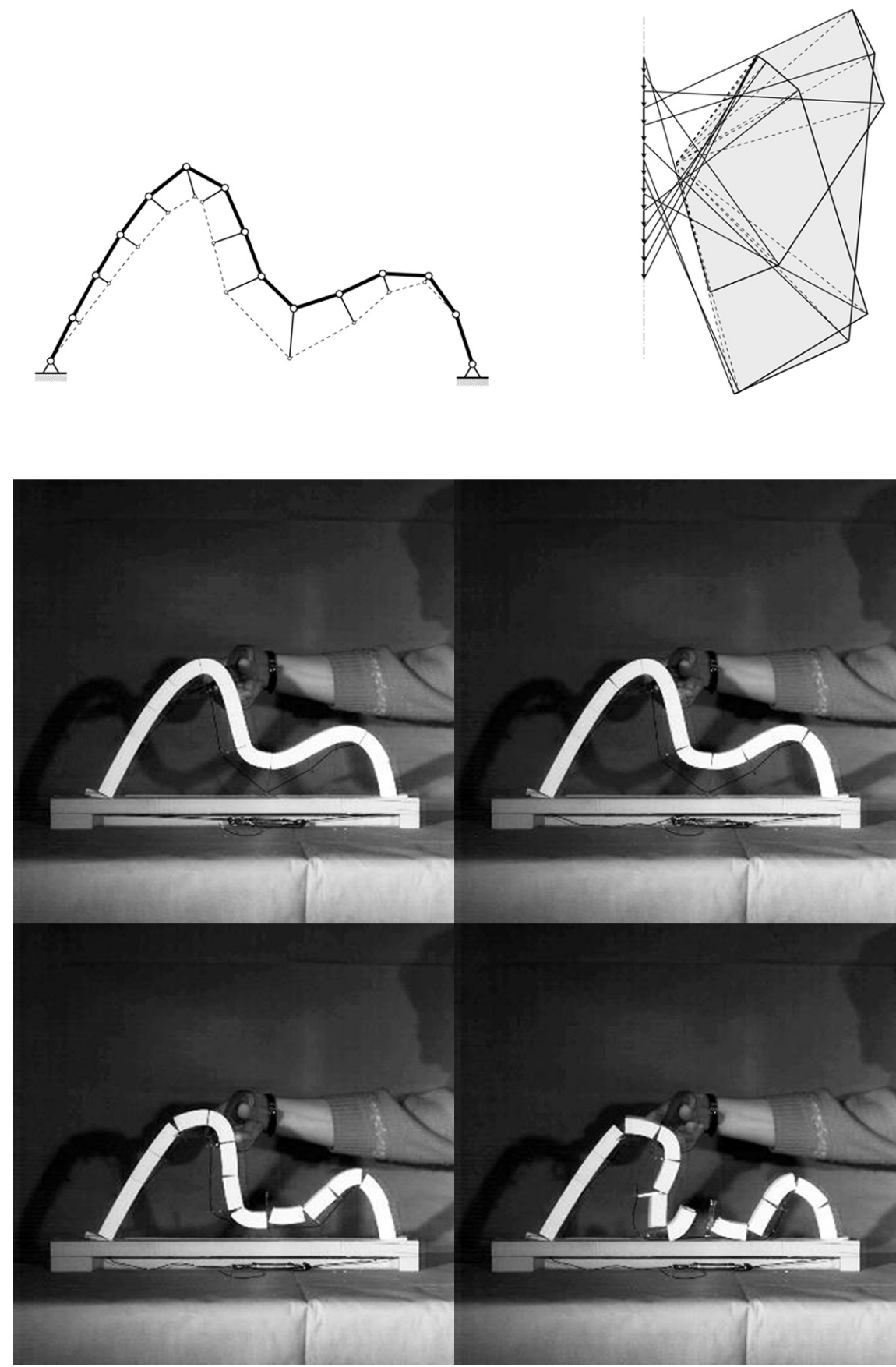

Figure 6.2: Graphical construction and collapse sequence of a free-form asymmetrical shape. 

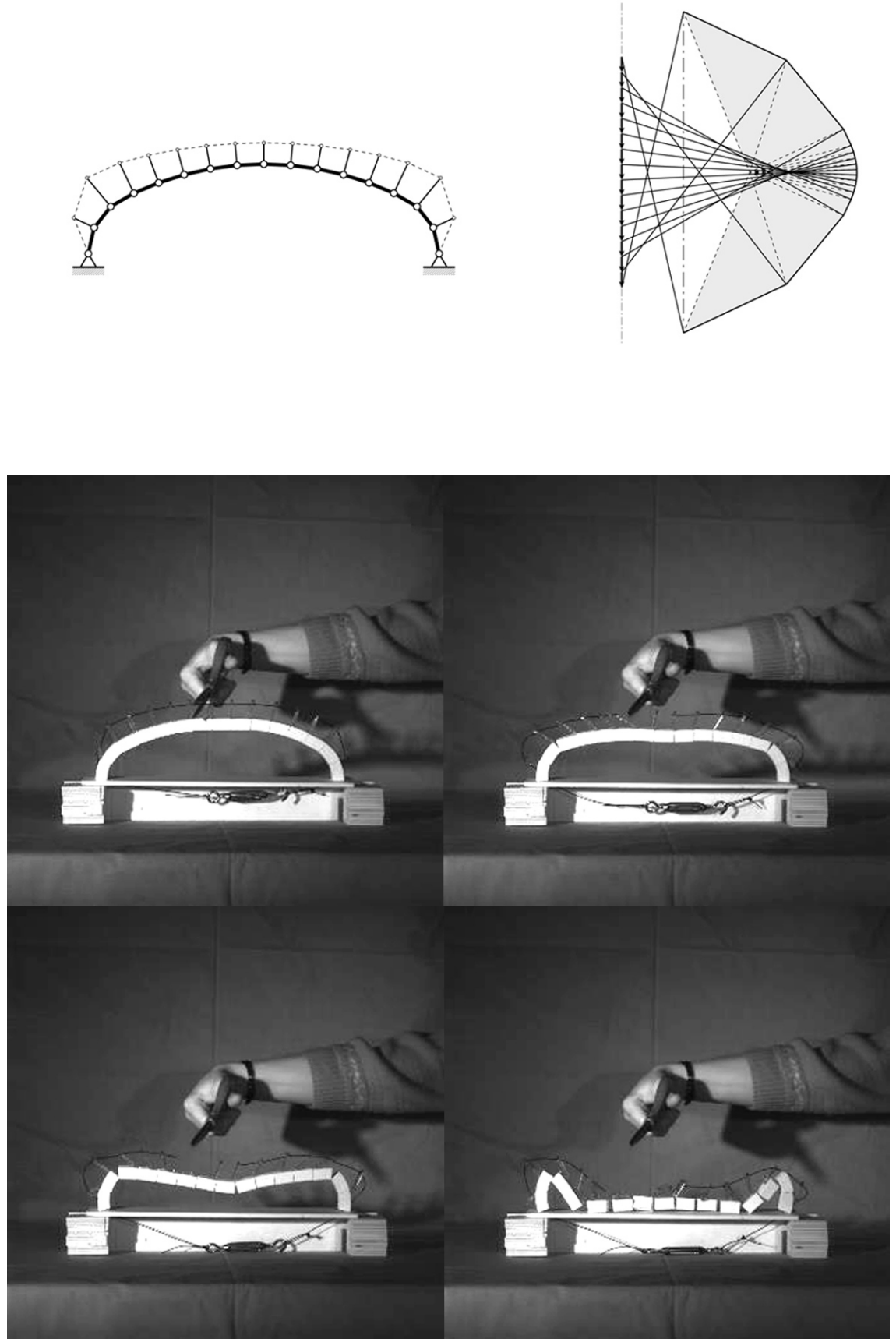

Figure 6.3: Graphical construction and collapse sequence of a basket arch. 

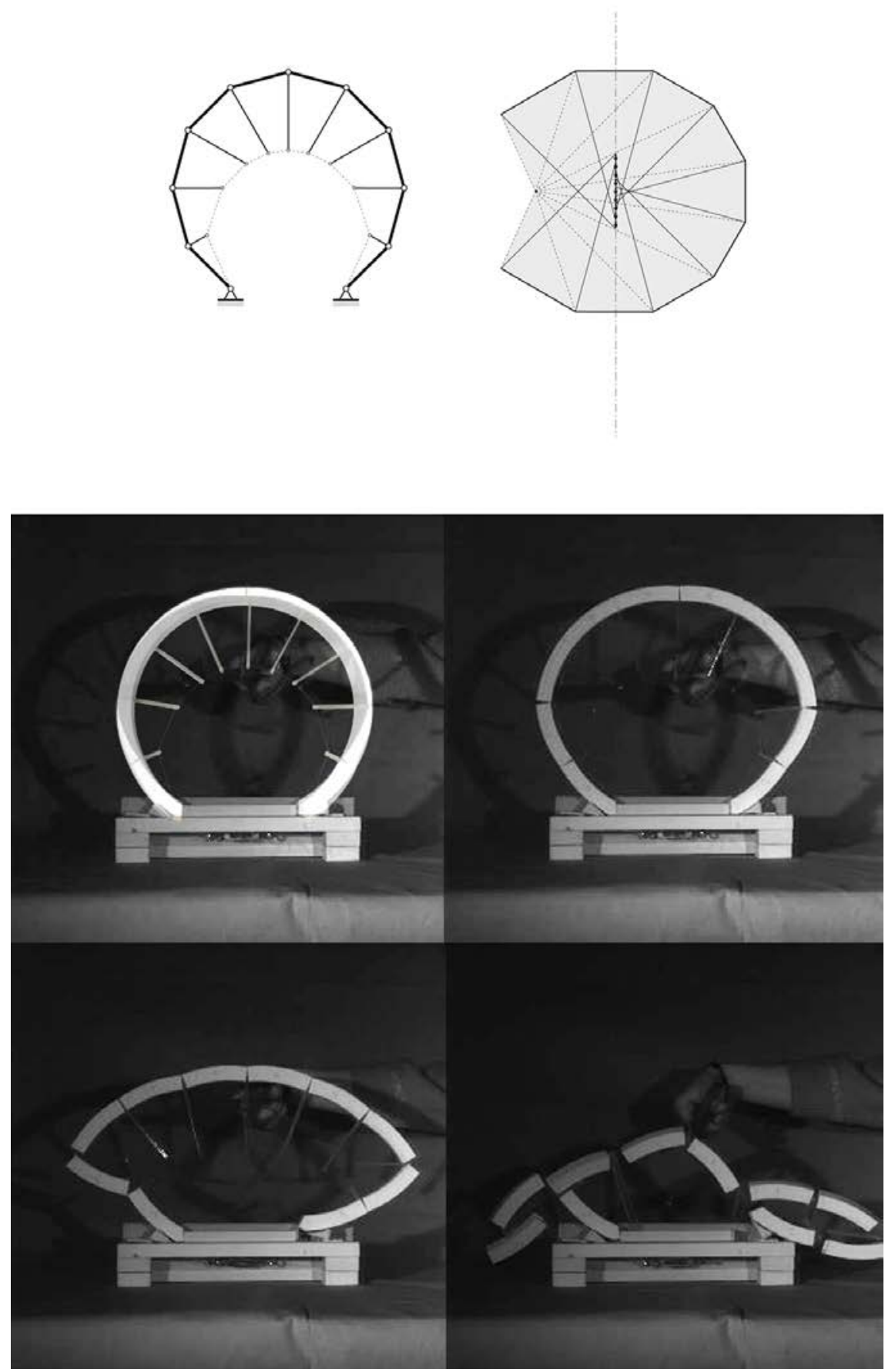

Figure 6.4: Graphical construction and collapse sequence of a circular arch. 


\subsubsection{Conclusions}

Despite the large and common use of computational methods, physical models remain an important support in the early stage design and for teaching purposes. The use of physical models, is informative but also didactic, illustrating the possibilities and trade-offs in funicular explorations for architectural design.

Small-scale models are less expensive and invasive compared to the real scale ones, but they are able to provide the same feedback if the structural behaviour is independent-of-scale. The use of reduced models for complex two-dimensional structures is now easier compared to the past with the support of the improved rapid prototyping technologies.

This section has shown the successful further validation of the author's theory, by producing stable scale models of discrete elements with non-antifunicular shapes. These models allow for a first experimental validation of the theory and provide new insights about the structural behaviour of such novel nonantifunicular forms.

Furthermore reduced physical models visually demonstrate the importance of adding external forces to non-antifunicular structures in order to make them stable, and provide slow-motion videos that can be used for didactic purposes.

\subsection{PAVILION AT THE 2015 IASS Symposium}

\subsubsection{INTRODUCTION}

The 2015 IASS Symposium organizers invited universities and/or companies to participate in a contest and an exhibition of structurally innovative pavilions. The pavilions had to give a future vision on structural design and innovation, and had to be the outcome of (excellent) structural research (http: //Www . iass2015 . org). The pavilions had to be exhibited in the summer of 2015 and during the 2015 IASS Symposium in the Muziekgebouw in Amsterdam.

The author, together with other colleagues (Section 6.2.6) of the Digital Structures Research Group at MIT (https://digitalstructures.mit. edu/), was involved in this contest. Their pavilion proposal was called Paperwave. 
Paperwave is a series of post-tensioned wave forms, constructed nearly entirely of cardboard. The graphic-statics-based method described in Section 4 has been used to design the geometry, ensuring that the cardboard boxes in each curved wave are balanced by the tensioned strap and cardboard tubes, which pull and push the waves into equilibrium. Using low-carbon, inexpensive and lightweight materials, this pavilion demonstrates the power of structural geometry to achieve creative and high-performing designs.

\subsubsection{Project SPecifications}

The two main constrains to the design were:

- Transport and weight: the material to be employed for the pavilion had to fit in 6 (imaginary) boxes that could be transported as "regular" luggage by an airplane (i.e., a maximum of $1 \times 0.75 \times 0.65 \mathrm{~m} / 32 \mathrm{~kg}$ per box). The maximum allowed weight was $192 \mathrm{~kg}$.

- Flammability: the pavilion needed to meet B - s2 d2 of the European Standard EN-1350-1. This means that the material had to provide a very limited contribution to fire.

\subsubsection{MATERIAL}

For buildings with a short lifetime, such as pavilions, embodied energy plays a prevalent role on the total environmental impact. It is well known that the embodied carbon calculation is based on the Embodied Carbon Coefficient (ECC) that multiplied for the material quantities allows to obtain the Global Warming Potential. The materials employed to build this pavilion address this need: to minimize the embodied carbon emissions by using materials with very low ECC.

The main components of the curved waves, which act in compression, have been made from custom-cut corrugated cardboard (Figure 6.5a), assembled onsite into multi-faceted boxes that achieve stiffness through their folding patterns. Corrugated cardboard has a density of $300 \mathrm{~kg} / \mathrm{m}^{3}$ if compacted, and a density that range between 30 and $90 \mathrm{~kg} / \mathrm{m}^{3}$ if uncompacted. Furthermore, its ECC is 
around 1.29 and it is estimated that $65 \%$ of corrugated cardboard has a recycled content.

Compressive or tension connecting elements were made from cardboard tubes (Figure 6.5b). The post-tensioning system was been achieved with stripes (Figure 6.5c), a relatively strong and stiff material that can be cut and connected with low-tech tools.

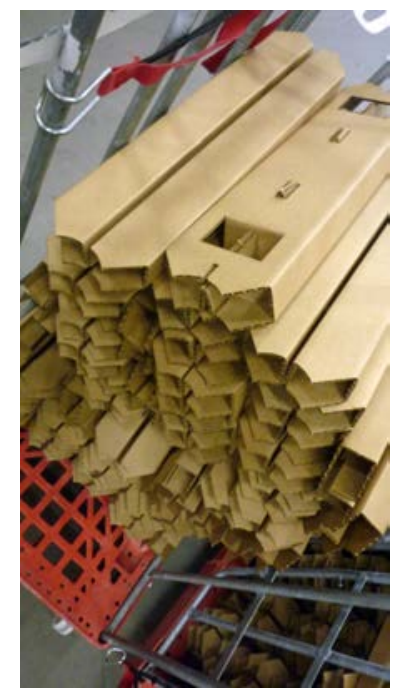

(a)

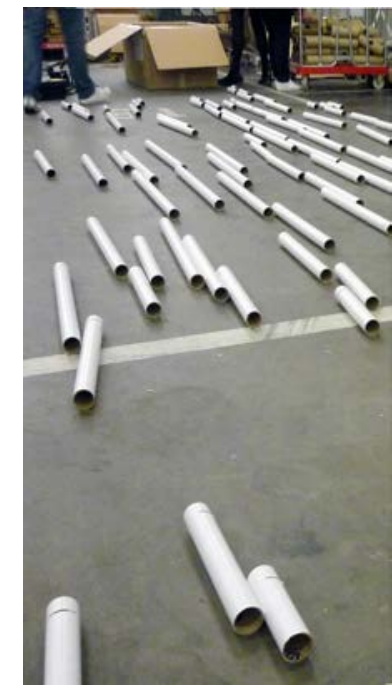

(b)

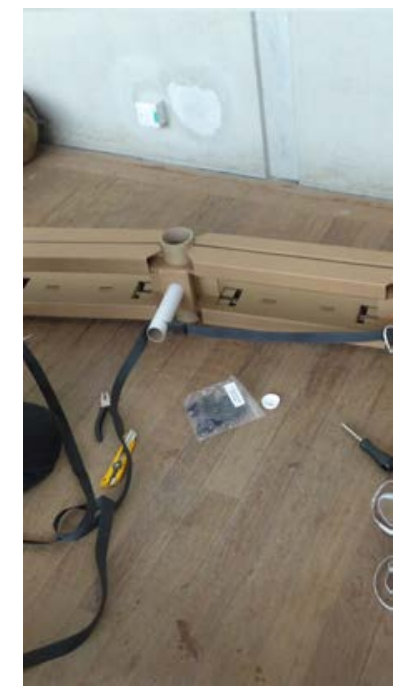

(c)

Figure 6.5: Materials employed for building the pavilion.

These materials have several advantages. First, they are planar/linear, and can easily be stacked, folded, and packed in disassembled form into the allowed suitcases. Second, they easily accommodate construction tolerance issues, since they can be cut, tied, folded, etc. on site as needed to make up for unexpected geometric shifts.

The use of unconventional and low cost materials has been made possible by the efficiency of the geometric design.

\subsubsection{Design}

The pavilion serves as both a validation and demonstration of the method presented in Section 4, expressing the creative freedom and flexibility of 
designers.

The proposed design was an array of nine two-dimensional waves, starting with a funicular parabolic arch. Progressing from this rational starting point, the subsequent shapes undulate increasingly toward an expressive but structurally arbitrary shape that is impossible to achieve in pure compression. The external post-tensioning system contributes increasingly from one curve to the next, finally allowing the terminal free-form shape to be achieved with axial forces only. The result is visually exuberant but also didactic, illustrating the possibilities and trade-offs in funicular explorations for architectural design. Figure 6.6 shows the design proposal from different views.
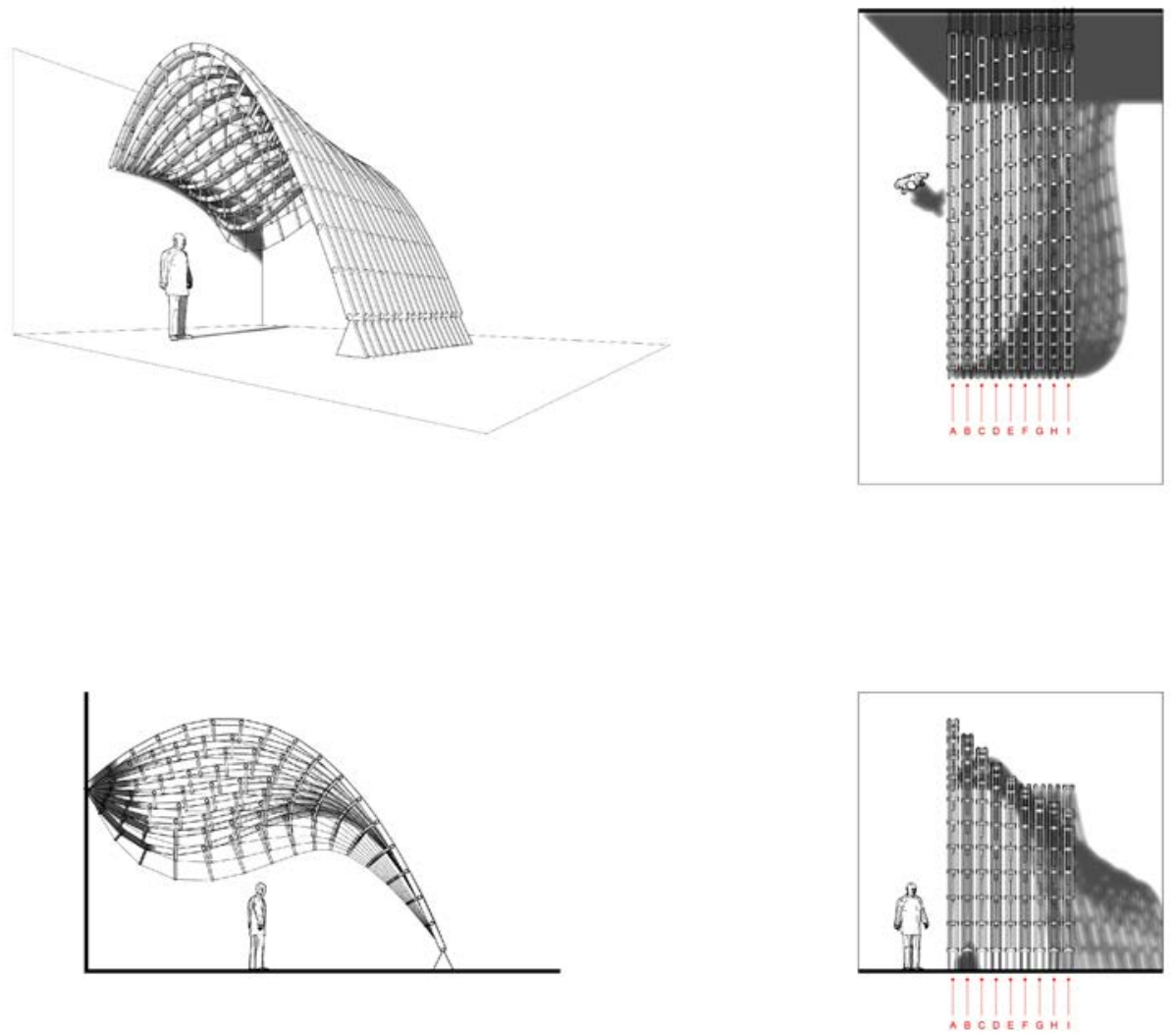

Figure 6.6: Design proposal. Image courtesy of Juney Lee.

As explained in detail before, to one non-antifunicular shape correspond infinite positions of the external post-tensioned cable that transforms the 
geometry into an antifunicular one. Among the infinite possibilities there is one option that guarantees no net horizontal reaction. This solution has been adopted in the pavilion for finding the position of the prestressed cable. Figures 6.7, 6.8 and 6.9 illustrate the graphical construction adopted for finding the layout of the external post-tensioned stripes and the forces within the structure. 


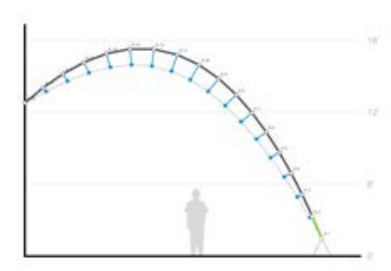

A

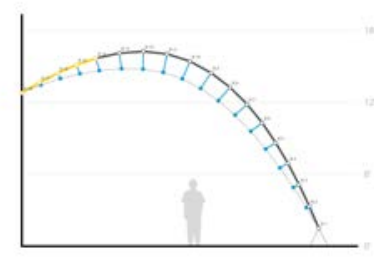

B

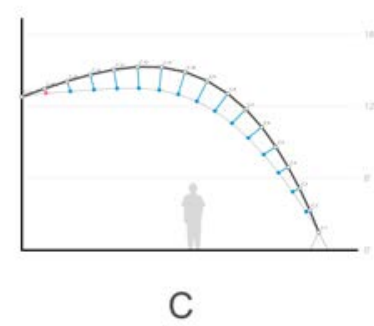

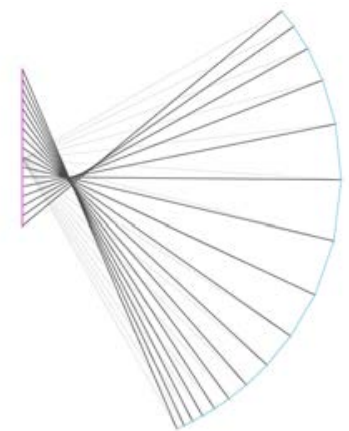
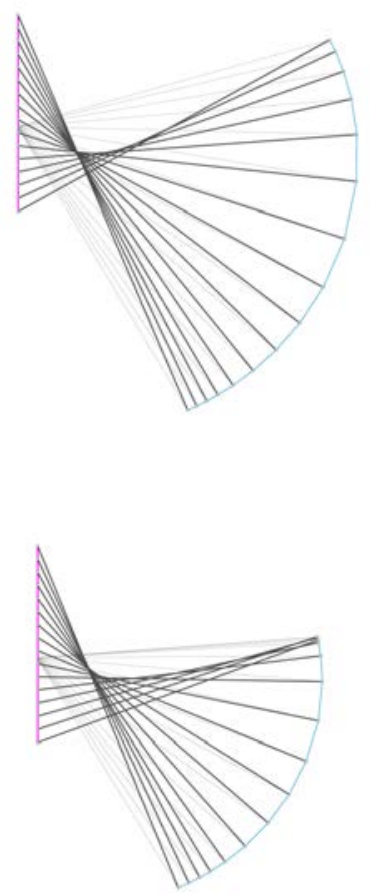

Figure 6.7: Graphical construction ( 1 of 3 ). Image courtesy of Juney Lee. 


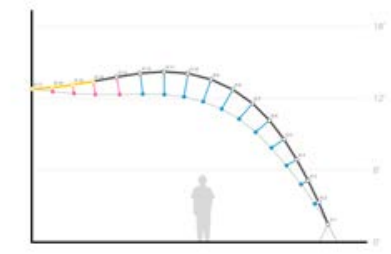

$\mathrm{D}$

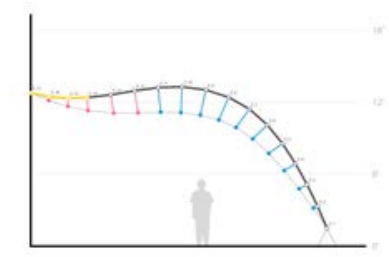

E

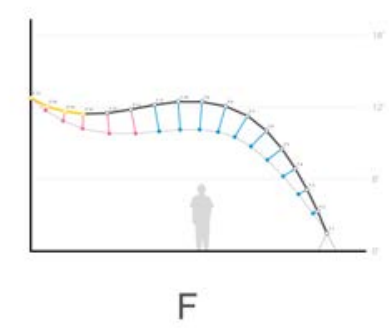

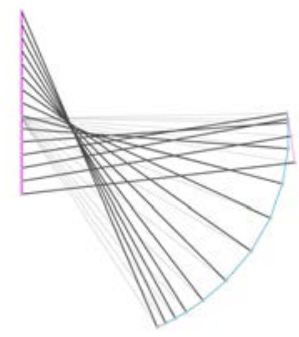
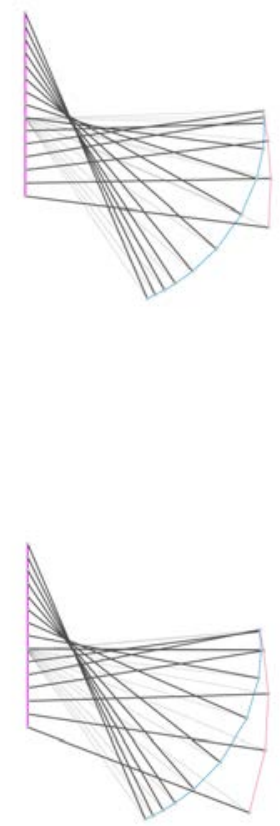

Figure 6.8: Graphical construction ( 2 of 3 ). Image courtesy of Juney Lee. 


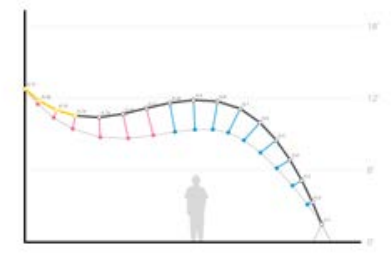

G

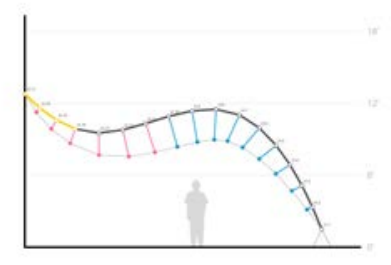

$\mathrm{H}$

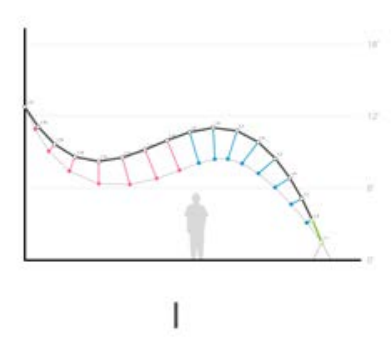

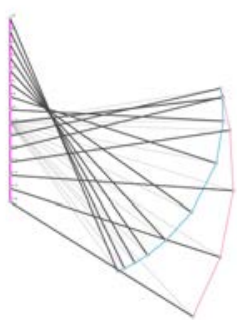
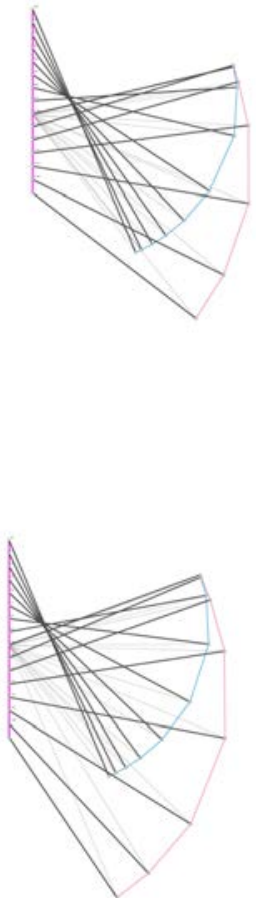

Figure 6.9: Graphical construction ( 3 of 3 ). Image courtesy of Juney Lee. 


\subsubsection{FABRICATION AND CONSTRUCTION PROCESS}

The fabrication process (Figure 6.10) was based on the following assembly line: laser-cutting, creasing and fireproofing with fire retardant spray. The Pavilion has been designed with 9 diverse waves, each one of them has 15 different joint. Around 150 joints, 150 pipes and 160 compressive elements have been packed in four boxes and shipped to Amsterdam.

Once arrived at the final destination, the construction process started (Figure 6.11): all the pieces have been folded and the waves have been built on the ground. Next, they have been rotated and placed in their final position (Figure 6.12) using cables from the roof and a crane. Finally, some lightening has been added to the pavilion.

The folding process required more time that the expected and due to the very short time available for the construction only three of nine waves have been placed in their final position.

\subsubsection{Acknowledgments to the Project Team}

The author's personal involvement included theoretical development beyond the project and collaboration in the final construction of the pavilion.

The Paperwave Project has been only possible with the great work provided by a large number of people, many of them are part of the Digital Structures Research Group at MIT led by Professor Caitlin Mueller.

This team was composed by: Prof. Caitlin Mueller (responsible for the scientific development of the pavilion), Juney Lee, Leonardo Todisco, Ornella Iuorio, Catherine De Wolf, Corentin Fivet, Andrew Smith, Samuel Schneider, Mark Tam, Stavros Tserandins, Chrystal Chern, Mitchell Gu, Jonathan Felipe and Nathan Brown. 

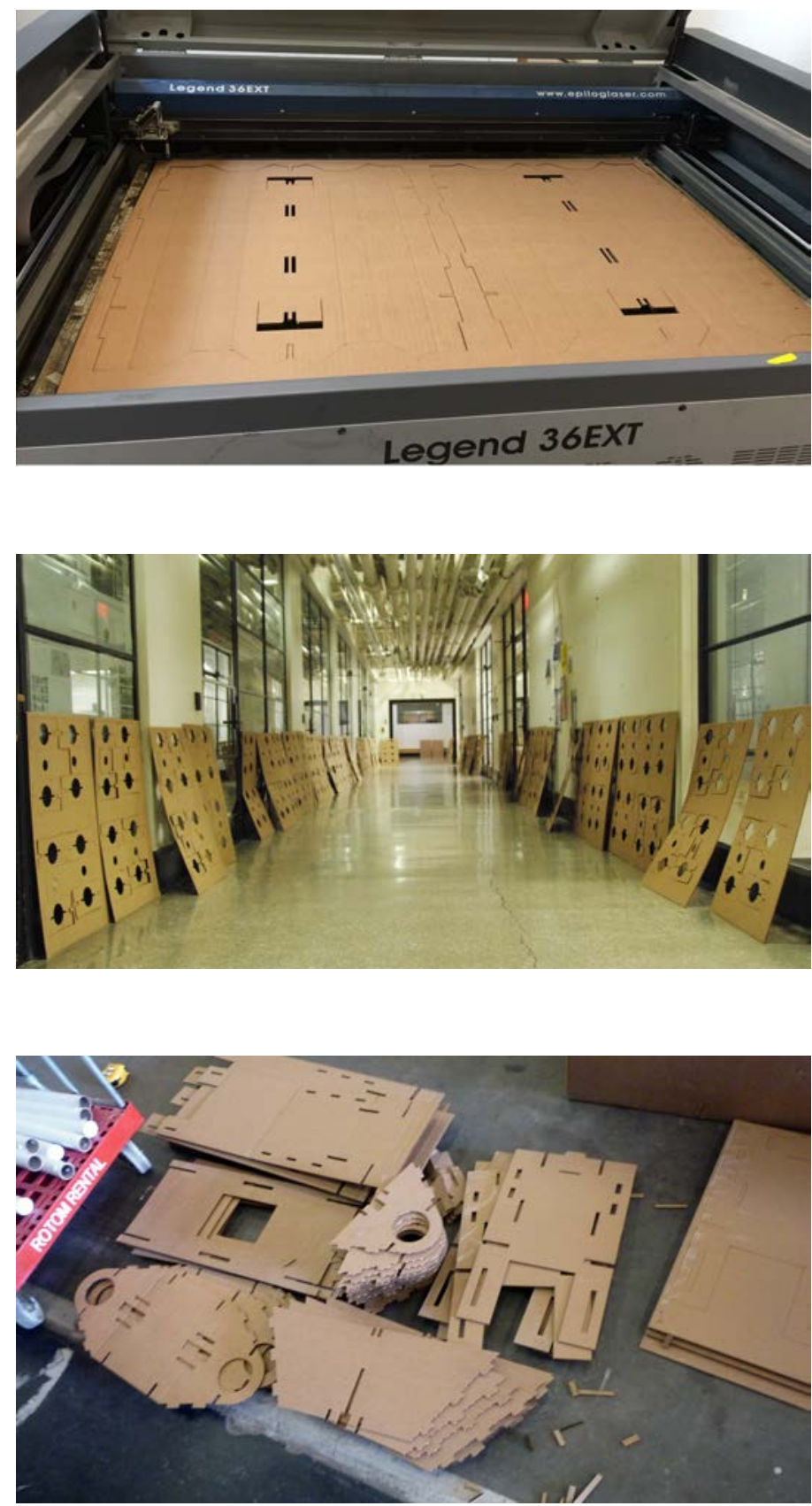

Figure 6.10: Fabrication process. 

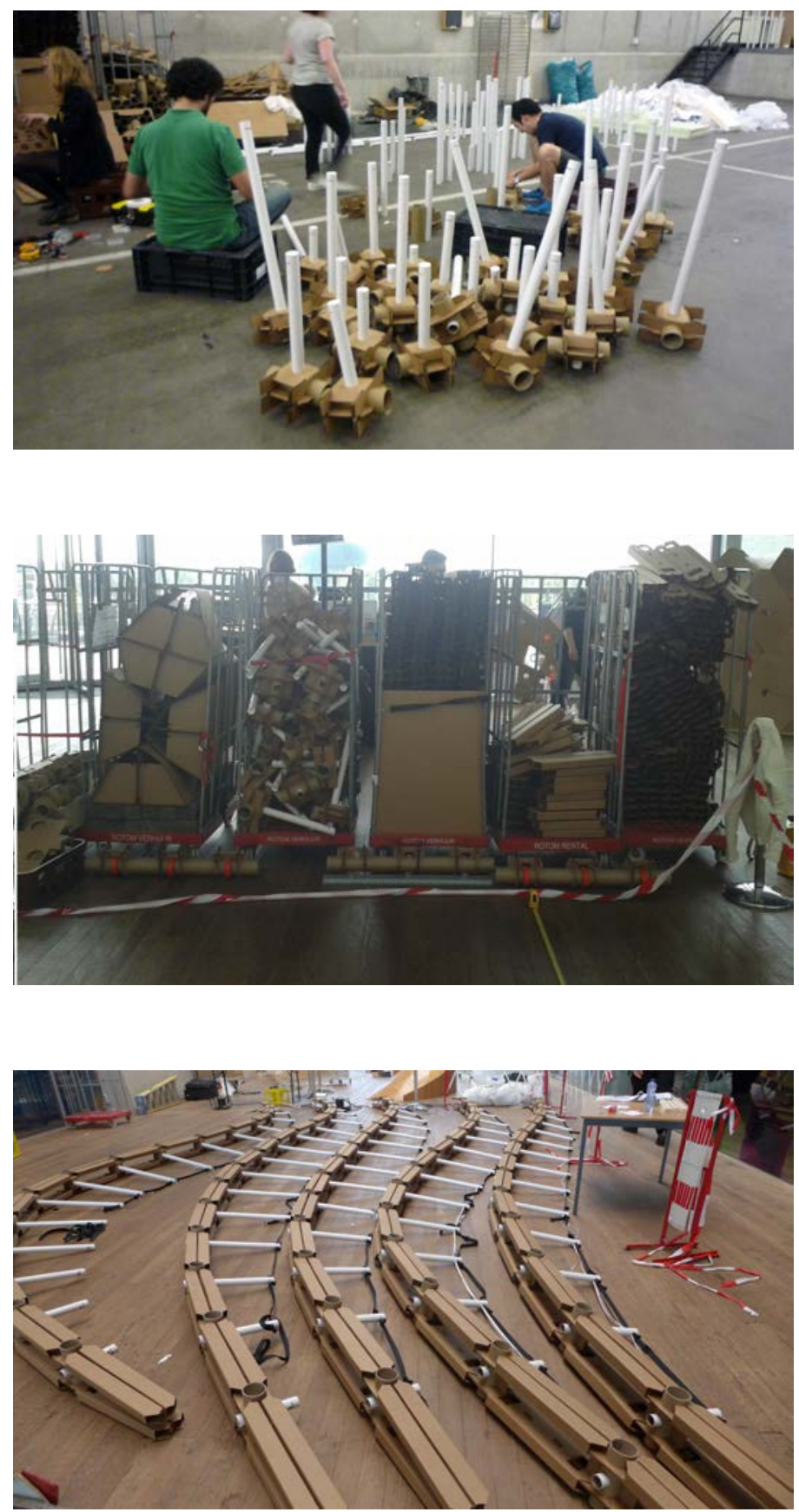

Figure 6.1 1: Construction Process. 

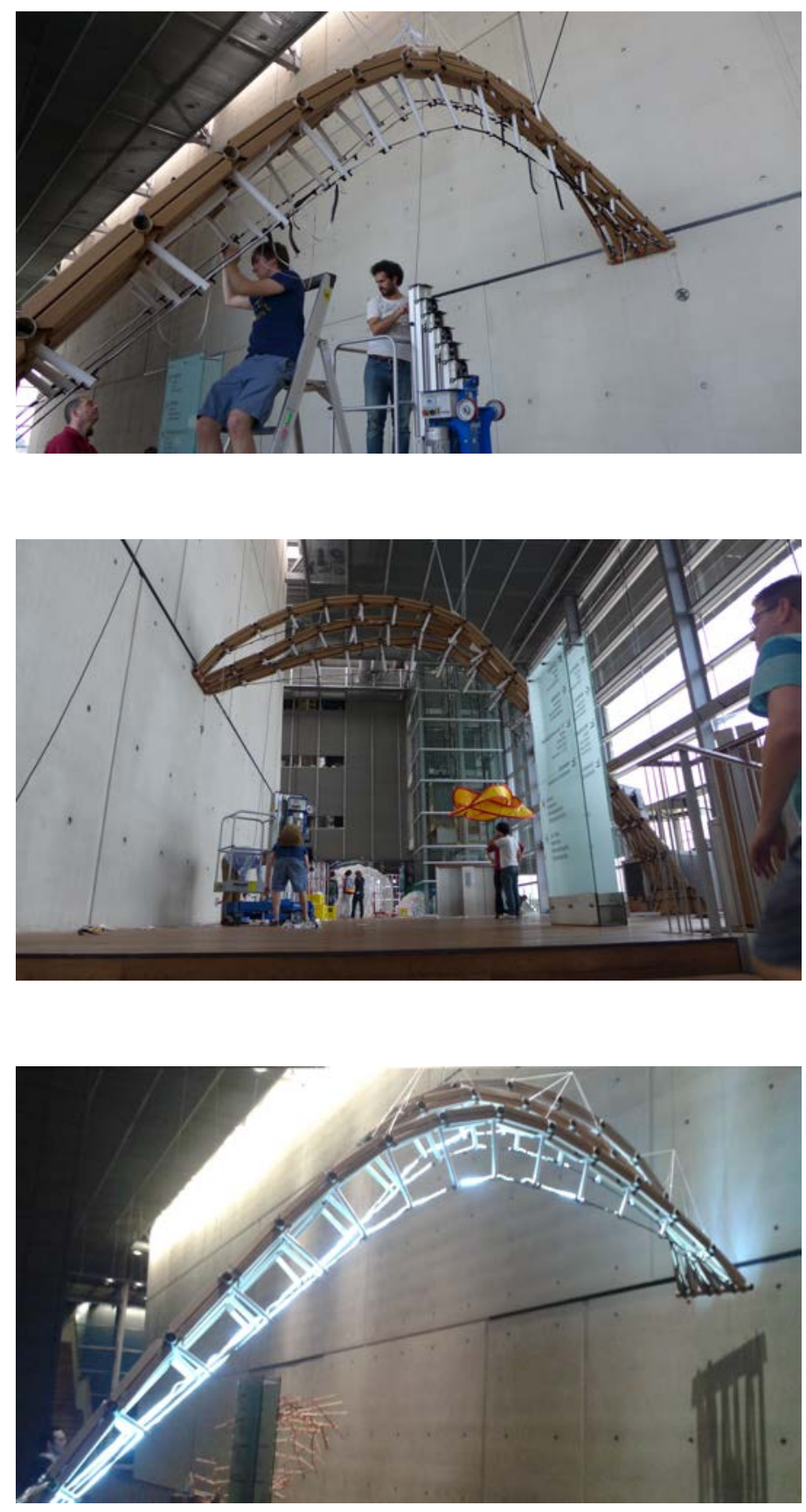

Figure 6.12: After construction. 


\subsubsection{CONCLUSIONS}

Structural behaviour: The overall structural behaviour of the pavilion was good and the application of external forces was very favorable. All the calculations were performed for a two-dimensional behaviour of the wave because the restrain provided by the contiguous structures was taken into account. However, the fact that the waves had slightly different shapes did not allow for this collaboration. For this reason the structure suffered out-of-plane buckling. In the future this aspect should be carefully taken into account.

Material: The construction of a pavilion with unconventional materials faced new and unexpected problems. The structure resulted too much deformable. In the future, probably, the use of more stiff joints would be advisable. Existing examples, such as the cardboard geodetic dome by Mixuro and the bridge across the Gardon River by Shigeru Ban, employed, respectively, wood and steel for the joints.

Construction: The construction of nine waves was a too much ambitious goal to be achieved in the very limited available time for the building process. Furthermore, the structural behaviour during the construction process was not studied enough and more attention has to be paid on that topic in the future. Finally, the application of the prestress forces, based on a trial/error method, was complicated to achieve with low-tech technologies.

\subsection{SUMMARY}

This Chapter has described the construction of reduced-scale models and a temporary pavilion for illustrating the possibilities given by the methodology developed in Chapter 4 for the design of versatile and material-efficient structures.

First, this Chapter has presented the production of stable reduced-scale models made of discrete elements with non-antifunicular shapes. This represents a further physical validation of the theory. The beneficial role of physical models has been pointed out especially in early stage design and for teaching purposes. Small-scale models, less expensive and invasive compared to the real scale ones, 
are able to provide the same feedback if the structural behaviour is independent of scale.

Next, the conceptual and material design of a pavilion (Paperwave) built entirely with cardboard has been in-depth described. It visually demonstrates the possibility of combining low-cost material with high-performance design.

In summary, this Chapter has presented the materialization of the methodology proposed in Chapter 4 in a research which aim consists in allowing architects and structural engineers a way to achieve high-performance, efficient and versatile designs, even when the global geometry departs from classical antifunicular shapes. 



\section{Part III}

\section{Conclusions}



The most powerful way that an engineer can contribute to the

work of architects is by exploring the nature of the materials

and using that knowledge to produce a special quality (...).

Exploration and innovation are the keys.

Peter Rice

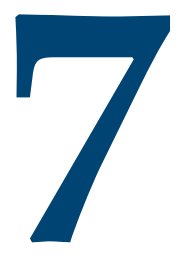

Conclusions and future studies

\subsection{SUMmary OF RESULTS}

The choice of an appropriate shape in curved geometries is an important decision for designing materially efficient structures. However, engineers often face the challenge of designing shapes that reflect a broad range of requirements; frequently, these geometries are optimal shapes from a functional point of view, but less efficient in terms of structural performance.

The main contribution of this research has been to address this problem, by introducing a new methodology for transforming the load internal distribution of general geometries, and to make them act in pure compression. Bending moments, which would otherwise occur, are eliminated by applying additional forces through the rational design of a post-tensioning system.

The developed approach, based on graphic statics, has been implemented in an interactive and integrated tool (EXOEQUILIBRIUM). This allows users to explore different alternatives and design-criteria for any two-dimensional 
geometry.

In addition, the employment of reduced-scale physical models has provided further validations of the effectiveness of the method and, at the same time, tools for didactic purposes.

Finally, the construction of a temporary pavilion has demonstrated that low-cost materials in combination with basic structural concepts can provide creative, inexpensive and high-performing designs.

The following specific conclusions can be drawn:

1. Any base non-antifunicular geometry can be converted into a bendingfree shape by adding external loads. The proposed graphical procedure can be applied to a great number of problems, without limitations related to starting geometry, loads and support positions. Furthermore, the approach can be employed for structures contained in different planes.

2. Given an initial shape and its related loads, the problem is indeterminate: an infinite number of solutions exist to make the starting geometry bending-free.

3. The employment of a graphical-based design technique embedded in an interactive environment provides a well-suited environment for the computational exploration of equilibrate solutions for buildings and spatial structures.

4. A preliminary structural analysis points out the great efficiency of this system in terms of mass saving, by reducing the required mass compared to the bending solution in which axial and bending coexist.

5. Any change of acting loads after construction inevitably generate bending moments that decrease the structural efficiency of the system.

6. The distance between the base geometry and the prestressed cable plays a key role for optimizing the material-efficiency of the whole structure. Higher offsets correspond to lower material volumes, thus, greater structural efficiency. 
7. The need of no net horizontal thrusts or a cable always placed above the compressive geometry requires high amount of forces.

8. If there are no constrains with regards to the cable position, a design criterion for achieving mass optimization has to be adopted. It can be based on minimizing the energy of deformation. Generally, this would result in a cable that crosses the base structure.

9. The employment of reduced-scale physical models has provided a further experimental validation of the theory by producing stable models of discrete elements with non-antifunicular base shapes. Furthermore, reduced physical models have offered new insights about the structural behaviour of such forms.

10. The construction of a temporary pavilion served as a demonstration of the method by using low-cost materials. Despite the good results on the global structural behaviour, lessons learned include the importance of 3 d-behaviour (when lateral stiffness is missing), unexpected problems (deformability) related to the choice of unconventional materials and construction issues.

\subsection{FutUre STUdies}

This research has introduced a generalized theory for designing bending-free external post-tensioning structures and provided a number of case studies, but there are several important directions for further research in this area.

\section{ANALYTIC AND EXPERIMENTAL RESEARCH}

There is significant research to be carried out for identifying and analyzing (analytically and experimentally) the gaps in knowledge that can prevent the utilization of externally post-tensioned structures.

First, more detailed evaluations of the whole system performance should be performed in order to find limitations of the described design philosophy. In these analyses asymmetrical loads, different materials, support displacements 
should be taken into account. Not only the mass, but the global cost of the structure (including post-tensioning system and connecting struts) should be computed for a more precise performance evaluation of the whole system. More refined comparisons between classical solutions and the new structural system have to be performed.

Second, the passive and active effects of the cable (e.g., in-plane stiffening, control of displacements, etc...) have to be analyzed, with special focus for asymmetrical loads.

Furthermore, the performance of these structures have to studied to take into account many other requirements (e.g., robustness, resiliency, ductility), which have not been included in this work.

In addition, effects of creep on delayed deformations have not been considered, but some materials are strongly characterized by rheological behaviour which implies long-term delayed deformations. These phenomena have to be investigated because they can play a fundamental role in prestressed structures, influencing structural behavior and durability for a long time in service life.

Finally, constructability challenges related to the introduction of different post-tensioning forces in varied sections of the cable should be studied following the preliminary research by Saitoh [97]. The construction of full-scale structures have to be planned for validating the design concepts through construction, monitoring and testing.

\section{ENVIRONMENTAL RESPONSIVE HYBRID STRUCTURES}

The methodology illustrated in this thesis guarantees a bending-free behaviour only for one distribution of loads. Thus, the structure has to be sized for ensuring that strength and deformations meet the required limits to cope with the worst load cases.

However, a new design approach, that could take advantage of a responsive post-tensioning system, can be studied. It is based on structures that are able to sense and respond appropriately to changing loads for always guaranteeing material-efficiency (i.e., bending-free behaviour), independently on the external 
load conditions. This can be achieved by varying the internal stress distribution with a responsive externally post-tensioned structure (Figure 7.1) that combines rigid members (that work in compression), active prestressed members (that work in tension) and active connecting elements (that can work in tension or in compression). Figure 7.1 shows how the responsive externally post-tensioning system would change its geometry in case of an asymmetrical distribution of loads.

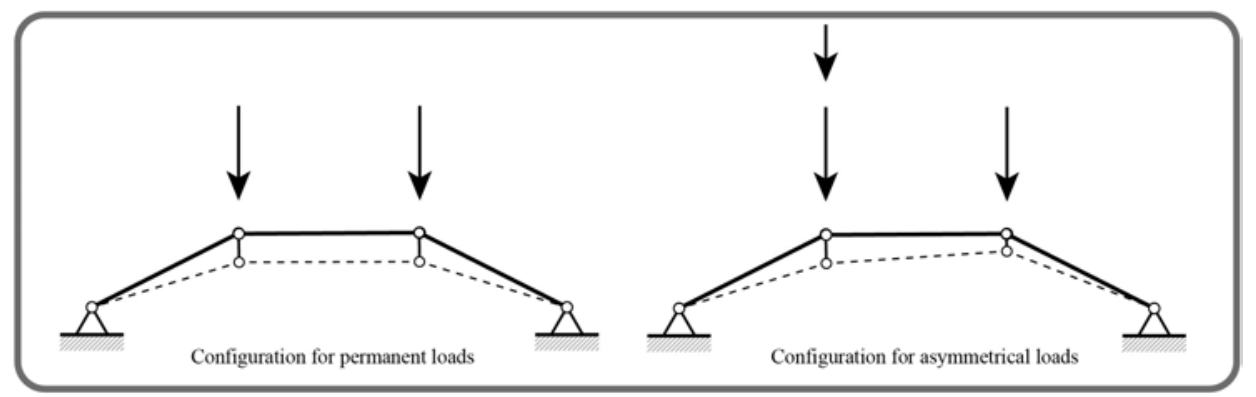

Figure 7.1: Optimal shapes for symmetrical and asymmetrical loading.

To date, within all the attempts that have been performed to design adaptive structures, adaptability involves changes in the base shape with relation to the applied loads. The proposed approach for future studies would guarantee to keep the original shape, avoiding functionality issues, and, at the same time, achieving material-efficiency. The adoption of this innovative alternative poses many theoretical and practical challenges to which future research has to be addressed.

In summary, future studies would explore the application of responsive hybrid structures, as smart systems that act as living organisms for always guaranteeing a bending-free behaviour independently on the external load conditions. This is not achieved by changing the structural shape, but varying the internal stress distribution.

The elongation/shortening of actuators and cables would allow the internal flow of forces to be redistributed in an appropriate way in order to get always an axial-only behaviour. The result would be a lightweight efficient structure that harmoniously combine functionality, smart technology and material-efficiency. 
Figure 7.2 provides a graphical overview of the whole process. Sensors embedded in the externally post-tensioned structure measure strains, and transfer data through gateways and wireless connection to an adaptive control centre. Here, based on input from the sensors, the adaptive control software makes an optimized decision on the movement of the structure to be actuated and sends this information back to the structure. Next, the actuators, by changing their lengths, are able to manipulate the force in the cables and to achieve the required internal stress distribution without changing the main structural shape.

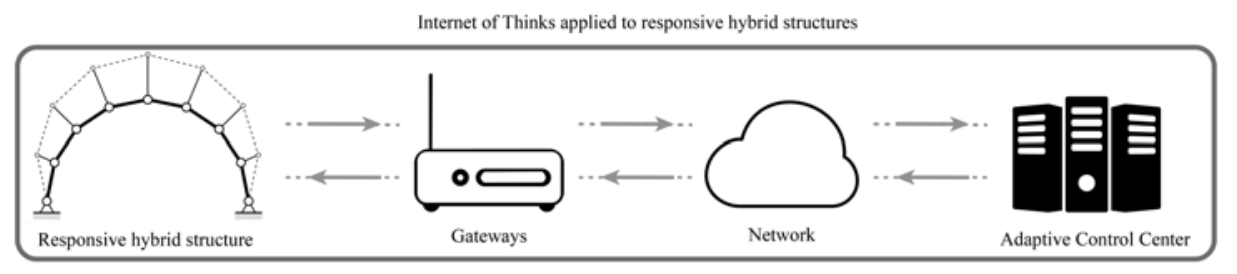

Figure 7.2: Graphical overview of the process.

The overall aim of this research would be to design more material-efficient buildings by taking advantage of smart technologies. Built-in actuators, sensors and internet connection make responsive structures a very attractive alternative to conventional structural systems.

In this scenario, the ongoing revolution of the Internet of Things (IoT) would be exploited for a dialogue between structures and their surroundings creating unexpected opportunities for increasing the structural efficiency of buildings.

\section{Application to EXISTING STRUCTURES}

The methodology described in Chapter 4 has been mostly oriented to the design of new material-efficient structures. In spite of that, the same approach can be employed for improving the structural behaviour of existing masonry. This idea is not new, in fact, some researchers $[54,55]$ have employed similar techniques for strengthening vaults and arches.

Future research would be focused on an approach for the reduction of the thrust line eccentricity by applying external forces through post-tensioning. Furthermore, the increment of axial forces would have a positive effect on 
masonry behaviour against asymmetric loads. In addition, the interventions on masonry based on the use of external systems would provide several advantages with respect to more traditional techniques:

- The seismic behaviour is strongly improved by a stiffer structure with a negligible increment of weight.

- The masonry (if it has good quality) does not need to be replaced.

- The strengthening would provide a double positive effect for both, static and seismic loads.

- The strengthening techniques, based on post-tensioning, would be replaceable, reversible and not invasive.

\section{EXTENSION TO 3D}

The design methodology has been described for two-dimensional geometries, but it can be extended to the three-dimensional space. This would allow to transform non-antifunicular surfaces into antifunicular ones.

The complexity of the methodology to be studied is related to the development of graphic statics in $3 \mathrm{~d}$, which provides more difficulties with respect to the $2 \mathrm{~d}$ one $[10,51]$. An alternative approach would follow the studies carried out by Galafel [37]. 


\subsection{FinAL REMARKS}

Novel developments in material science, computing and industrial processes have the potential to radically change the construction sector, leading to more material-efficient structures. Nevertheless, these achievements have been only partially transferred to the practice of structural design. This results in standard constructions that do not clearly exploit the technological improvements.

Differently, this thesis promotes innovation in structural design by taking advantage of recent developments in material technology (post-tensioning) and computation (design-driven tools) for the conceptual design of a structural typology that combine functionality and structural optimization.

This work strongly expands the range of possible forms that exhibit a bendingfree behaviour and, de facto, opens up new possibilities for designs that combine high-performing solutions with architectural freedom. 


\section{A \\ Appendix 1}

\section{A.1 Timeline}

This Appendix presents an attempt from the author to summarize the information described in Chapter 2, and other data collected during this research that are not reported in this thesis.

This is achieved by sketching a timeline of the historical analysis of the equilibrium concept and its prominent employers. The review is not comprehensive, but it aims to historically contextualize the evolution of the funicularity concept and its main employers. 




\section{References}

[1] Website of forces frozen. http://monograph.io/caitlinm/ forces-frozen. Accessed: 2016-04-02.

[2] Website of schlaich bergermann und partner. http://sbp.de, 2014. Accessed: 2014-07-12.

[3] Website of the block research group. http://block. arch . ethz.ch/, 2014. Accessed: 2014-05-05.

[4] Website of the structural concrete research group at upm. www . he-upm . com, 2015. Accessed: 2015-08-10.

[5] ACI-Commitree-347. SP-120: External Prestressing in Bridges. American Concrete Institute, Michigan, USA, 1990.

[6] Adams, E., Connor, J., Ochsendorf, J., And Nicolin, R. 1.964 design for sustainability, fall 2006. http://ocw.mit. edu, 2006. Accessed: 2014-03-12.

[7] AdDis, W. Structural and civil engineering design. Ashgate, Aldershot, 1999.

[8] AdDIs, W. Building: 3000 years of design engineering and construction. Phaidon Press, London, 2007.

[9] Adriaenssens, S., Block, P., Veenendaal, D., and Williams, C. Shell structures for architecture: form finding and optimization. Routledge, London, 2014.

[10] Akbarzadeh, M., Van Mele, T., and Block, P. On the equilibrium of funicular polyhedral frames and convex polyhedral force diagrams. Computer-Aided Design 63 (2015), 118-128.

[11] Allen, E., And Zalewski, W. Form and Forces Designing Efficient, Expressive Structures. John Wiley and Sons, New York, 2009. 
[12] Baker, W. F., Beghini, L. L., Mazurek, A., Carrion, J., ANd Beghini, A. Maxwell's reciprocal diagrams and discrete michell frames. Structural and Multidisciplinary Optimization 48, 2 (2013), 267-277.

[13] Barnes, M. R. Dynamic relaxation analysis of tension networks. In Proceedings of the International Conference Tension Roof Structures (London, 1974).

[14] Bauschinger, J. Elemente der graphischen Statik. Oldenbourg, München, 1871.

[15] BeChтноLD, M. Innovative surface structures: technology and applications. Taylor and Francis, New York, 2008.

[16] Beghini, A., Beghini, L. L., ANd BAker, W. F. On the layout of a least weight single span structure with uniform load. Structural and Multidisciplinary Optimization 5o, 1 (2014), 49-64.

[17] Beghini, L. L., Carrion, J., Beghini, A., Mazurek, A., ANd Baker, W. F. Structural optimization using graphic statics. Structural and Multidisciplinary Optimization 49, 3 (2014), 351-366.

[18] Block, P., Dejong, M., And Ochsendorf, J. As hangs the flexible line: Equilibrium of masonry arches. Nexus Network Journal 8, 2 (2006), 1324.

[19] Block, P., Lachauer, L., and Rippmann, M. Validating thrust network analysis using $3 \mathrm{~d}$-printed, structural models. In Proceedings of the International Association for Shell and Spatial Structures (IASS) Symposium (2010), pp. 1-10.

[20] Casado, C. F. La arquitectura del ingeniero. Colegio de Ingenieros de Caminos, Canales y Puertos, Madrid, 2006.

[21] Casquero, A. R. Caracterización estructural de los rellenos situados en el trasdós de bóvedas de edificios históricos. $\mathrm{PhD}$ thesis, Technical University of Madrid, Spain, 2015.

[22] Chaudhary, T., P.-A. Examining the role of structural engineers in green building ratings and sustainable development. Australian Journal of Structural Engineering 14, 3 (2013), 217-228.

[23] Chías-Navarro, P., And Abad-Balboa, T. Eduardo Torroja: obras $y$ proyectos. Instituto de Ciencias de la Construcción Eduardo Torroja, Madrid, 2005. 
[24] Clune, R., Connor, J. J., Ochsendorf, J. A., And Kelliher, D. An object-oriented architecture for extensible structural design software. Computers and Structures 100-101 (2012), 1-17.

[25] Clune, R. P. Explorative structural design. PhD thesis, Massachusetts Institute of Technology, Cambridge, USA, 2010.

[26] Conzetr, J., And Mostafavi, M. Structure as space: engineering and architecture in the works of Jürg Conzett and his partners, vol. 3. AA Publications, London, 2006.

[27] Corres-Peiretit, H. Conceptual design. the only way to create sound structural concrete solutions. Structural Concrete 10, 3 (2009), 107-108.

[28] Corres-Peiretti, H. Sound engineering through conceptual design according to the fib model code 2010. Structural Concrete 14, 2 (2013), 89-98.

[29] Culmann, K. Die graphische Statik. Verlag von Meyer and Zeller, Zürich, 1864 .

[30] DaVinci, L., And Richter, J. P. The notebooks of Leonardo da Vinci. Dover Publications, New York, 1970.

[31] DAY, A. S. An introduction to dynamic relaxation. The Engineer 219 (1965), 220-221.

[32] DeJong, M. J. Seismic Assessment Strategies for Masonry Structures. PhD thesis, Massachusetts Institute of Technology, Cambridge, MA, 2009.

[33] Fernández-Casado, C. Cálculo de arcos. Dossat, Madrid, 1955.

[34] FIP. Prestressed concrete : safety precautions in post-tensioning. Telford, London, 1989.

[35] Fivet, C., And Zastavni, D. Robert maillart's key methods from the salginatobel bridge design process (1928). Journal of the International Association for Shell and Spatial Structures 53, 171 (2012), 39-47.

[36] Fivet, C., ANd Zastavni, D. A fully geometric approach for interactive constraint-based structural equilibrium design. CAD Computer Aided Design 61 (2015), 42-57. 
[37] Galafel-González, J. Estudio de elementos de fábrica por superficies antifuniculares. Master's thesis, Technical University of Madrid, Spain, 2011.

[38] GaliLei, G. Discorsi e dimostrazioni matematiche intorno à due nuoue scienze attenenti alla mecanica i movimenti locali. Appresso gli Elsevirii, Leida, 1638 .

[39] GeoGebra. Geogebra: Computer software. Www.geogebra.org, 2013. Version 5.0.166.0.

[40] Georgiou, O. Interactive structural analysis and form finding. In Proceedings of the IASS Annual Symposium (2011), IASS.

[41] Georgiou, O., Richens, P., And Shepherd, P. Performance based interactive analysis. In Design Modelling Symposium Berlin (Berlin, 201 1).

[42] Gregory, D. Catenaria. Philosophical Transaction of the Royal Society 19, 231 (1697), 637-652.

[43] Heyman, J. The stone skeleton : structural engineering of masonry architecture. Cambridge University Press, Cambridge; New York, 1995.

[44] Heyman, J. Structural analysis: a historical approach. Cambridge University Press, Cambridge; New York, 1998.

[45] Honnecourt, V. D. Album de dessins et croquis. Bibliothèque nationale de France, Paris, 1300.

[46] Hooke, R. A description of helioscopes and some other instruments. T.R. for John Martyn, London, 1676.

[47] Huerta-Fernandéz, S. Structural design in the work of gaudí. Architectural Science Review 49, 4 (2006), 324-339.

[48] Huerta-Fernandéz, S. The analysis of masonry architecture: A historical approach. Architectural Science Review 51, 4 (2008), 297-328.

[49] Huerta-Fernández, S. Arcos, bóvedas y cúpulas : geometría y equilibrio en el cálculo tradicional de estructuras de fábrica. Instituto Juan de Herrera, Madrid, 2004.

[50] IASS. Website of the hangai prize. http://www. iass-structures . org/index.cfm/page/HA/HP . htm, 2016. Accessed: 2016-02-02. 
[51] Jasienski, J., Fivet, C., And Zastavni, D. Various perspectives on the extension of graphic statics to the third dimension. In Proceedings of the IASS-SLTE 2014 Symposium (2014).

[52] Jorquera-LuCERGA, J. J. Estudio del comportamiento resistente de los puentes de arco espaciales. PhD thesis, Technical University of Madrid, Spain, 2007.

[53] Jorquera-Lucerga, J. J., and Manterola-Armisen, J. An iterative form-finding method for antifunicular shapes in spatial arch bridges. Computers and Structures 108-109 (2012), 42-60.

[54] JURINA, L. Strengthening of masonry arch bridges with "ram" - reinforced arch method. In Proceedings of the Sixth International Conference on Bridge Maintenance, Safety and Management (2012), pp. 1063-1070.

[55] Jurina, L., Mantegazza, G., and Radaelli, E. O. Frcm strenghtening of masonry vaults: The "duomo di colorno" and "braidense library" cases in italy. Key Engineering Materials 624 (2015), 494-501.

[56] Kilian, A., And Ochsendorf, J. Particle-spring systems for structural form finding. Journal of the International Association for Shell and Spatial Structures, 148 (2005), 77-84.

[57] KURRER, K.-E. The history of the theory of structures from arch analysis to computational mechanics. Ernst and Sohn, Berlin, 2008.

[58] Lachauer, L., AND Block, P. Interactive equilibrium modelling. International Journal of Space Structures 29, 1 (2014), 25-38.

[59] Lachauer, L., ANd Kotnik, T. Geometry of structural form. In Advances in Architectural Geometry 2010 (2010), Springer, pp. 193-203.

[6o] Lachauer, L., ANd Kotnik, T. Curved bridge design. In Computational Design Modelling (2012), Springer, pp. 145-152.

[61] LAfFranchi, M., AND Marti, P. Robert maillart's curved concrete arch bridges. Journal of Structural Engineering 123, 10 (1997), 1280-1286.

[62] Lancaster, L. C. Concrete Vaulted Construction in Imperial Rome. Cambridge University Press, New York, 2005.

[63] LaRsen, O. P., AND Tyas, A. Conceptual structural design: bridging the gap between architects and engineers. Thomas Telford, London, 2003. 
[64] LENCZnER, E. The design of the stone facade to the pavilion of the future, expo' 92, seville. The Structural Engineer 72, 11 (1994).

[65] Leonhardt, F. Prestressed concrete; design and construction. Translated by C. van Amerongen. W. Ernst, Berlin, 1964.

[66] Lewis, W. J. Tension structures: form and behaviour. Thomas Telford, London, 2003.

[67] LIN, T. Revolution in concrete. Architectural Forum May (1961), 121127.

[68] LIN, T. Revolution in concrete. Architectural Forum June (1961), 116-122.

[69] Linkwitz, K., AND ScheK, H. J. Einige bemerkungen zur berechnung von vorgespannten seilnetzkonstruktionen. Ingenieur-Archiv 40, 3 (1971), $145-158$.

[7o] Llorente-Zurdo, M. P. El Pretensado. La disolución de las tipologías constructivas en la arquitectura del SXX. PhD thesis, Technical University of Madrid, Spain, 2016.

[71] Manterola-Armisen, J. Puentes: apuntes para su diseño, cálculo y construcción. Colegio de Ingenieros de Caminos, Canales y Puertos, Madrid, 2006.

[72] Maxwell, J. On reciprocal figures and diagrams of forces. Philosophy Magazine 26 (1864), 250-261.

[73] Maxwell, J. On reciprocal figures, frames, and diagrams of forces. Edinburgh Royal Society Proceedings 7 (1870), 160-208.

[74] McNeel, R. Grasshopper generative modeling for rhino. computer software. Www.rhino3d.com, 2014. Version 0.9.0076.

[75] McNeel, R. Rhinoceros nurbs modeling for windows. computer software. www. rhino3d. com, 2014. Version 5.12.

[76] Menn, C. Prestressed concrete bridges. Birkhäuser Verlag, Basel, Switzerland; Boston, 1990.

[77] Misiunaite, I. Structural Behaviour and Stability of Steel Beam-Column Elements in Under-Deck Cable-Stayed Bridge. PhD thesis, VGTU leidykla Technika, Vilnius, 2013. 
[78] Mueller, C. Computational exploration of the structural design space. $\mathrm{PhD}$ thesis, Massachusetts Institute of Technology, Cambridge, USA, 2014.

[79] Mueller, C., Fivet, C., And Ochsendorf, J. Graphic statics and interactive optimization for engineering education. In Proceedings of the 2015 Structures Congress (2015), American Society of Civil Engineers.

[8o] Mueller, C. T., and Ochsendorf, J. A. Combining structural performance and designer preferences in evolutionary design space exploration. Automation in Construction 52 (2015), 70-82.

[81] Mutroni, A. Brücken mit einem innovativen statischen system. Schweizer Ingenieur und Architekten 26 (1997), 28 - 31.

[82] Mutroni, A. The art of structures ; introduction to the functioning of structures in architecture. EPFL Press/Routledge, Abingdon, Oxford, UK; New York, NY, 2011.

[83] Muttoni, A., Lurati, F., And Fernández-Ruiz, M. Concrete shells towards efficient structures: Construction of an ellipsoidal concrete shell in switzerland. Structural Concrete 14, 1 (2013), 43-50.

[84] Ninino, B. Optimal shape of arch bridges by using graphic statics. Internship report, Technical University of Madrid, Spain, 2015.

[85] Ochsendorf, J. A., And Freeman, M. Guastavino vaulting: the art of structural tile. Princeton Architectural Press, New York, 2010.

[86] Oтto, F., And Rasch, B. Frei Otto, Bodo Rasch: finding form: towards an architecture of the minimal. Edition of Axel Menges, 1995.

[87] Perez-Fadon, S., Herrero-Benéitez, J. E., Sanchéz-Ramírez, J. J., AND SANChÉz, M. S. El arco de los tilos en la isla de la palma (canarias). Cemento Hormigón 886 (2006), 76-92.

[88] Post-Tensioning-Institute. Post-Tensioning Manual, sixth edition ed. Post-Tensioning Institute, Farmington Hills, MI, 2006.

[89] Preisinger, C., And Heimrath, M. Karamba - a toolkit for parametric structural design. Structural Engineering International 24, 2 (2014), 217221.

[90] Quinonez, A., Zessin, J., Nutzel, A., And Ochsendorf, J. Small-scale models for testing masonry structures. Advanced Materials Research 133134 (2010), 497-502. 
[91] RAMM, E. Shape finding of concrete shell roofs. Journal of the International Association for Shell and Spatial Structures, 144 (2004), 29-40.

[92] Rankine, W. A Manual of Applied Mechanics. Griffin, London, 1958.

[93] Rankine, W. A Manual of Civil Engineering. Griffin, London, 1962.

[94] Robert, M., And Hutchinson, P. On the structure of the roman pantheon. The Art Bulletin 68, 1 (1986), 24-34.

[95] Ruiz-Teran, A. M. Unconventional cable-stayed bridges: structural behaviour and design criteria. Structural Concrete 11, 1 (2010), 25-34.

[96] Ruiz-Teran, A. M., And Aparicio, A. C. Two new types of bridges: under-deck cable-stayed bridges and combined cable-stayed bridges - the state of the art. Canadian Journal of Civil Engineering 34, 8 (2007), 10031015 .

[97] Saitoh, M., and OKada, A. The role of string in hybrid string structure. Engineering Structures 21, 8 (1999), 756-769.

[98] Sarmiento-Comesias, M., Aparicio, A. C., and Ruiz-Teran, A. M. State-of-the-art of spatial arch bridges. Proceedings of the Institution of Civil Engineers: Bridge Engineering 166, 3 (2013), 163-176.

[99] Schek, H.J. The force density method for form finding and computation of general networks. Computer Methods in Applied Mechanics and Engineering 3, 1 (1974), 115-134.

[100] Schlaich, J., Schafer, K., And Jennewein, M. Toward a consistent design of structural concrete. Journal of the Prestressed Concrete Institute 32 (1987), 74-150.

[101] SQUIER, E. G. Peru; incidents of travel and exploration in the land of the Incas,. Harper and Brothers, New York, 1877.

[102] Strasky, J. The power of prestressing. Structural Concrete 4, 1 (2003), $25-43$.

[103] Strasky, J. Stress ribbon and cable-supported pedestrian bridges. Thomas Telford, London, 2005.

[104] Thrall, A. P., Billington, D. P., ANd BrÉA, K. L. The maria pia bridge: A major work of structural art. Engineering Structures 40 (2012), 479-486. 
[105] Timoshenko, S. History of strength of materials: with a brief account of the history of theory of elasticity and theory of structures. McGraw-Hill, New York, 1953.

[106] Timoshenko, S., And Young, D. H. Theory of structures. McGraw-Hill, New York, 1965.

[107] Todisco, L. An integrated approach to conceptual design of arch bridges with curved deck. Master's thesis, Technical University of Madrid, Spain, 2014.

[108] Todisco, L., ANd Corres-Peiretti, H. Il concetto di funicolarità. l'applicazione per il conceptual design di strutture efficienti e versatili. Magazine 201, 1 (2016), 1-10.

[109] Todisco, L., Corres-Peiretti, H., ANd Mueller, C. Funicularity through external posttensioning: Design philosophy and computational tool. Journal of Structural Engineering (ASCE) 142, 2 (2015).

[1 10] Todisco, L., Fivet, C., Corres-Peiretti, H., And Mueller, C. Design and exploration of externally post-tensioned structures using graphic statics. Journal of the International Association for Shell and Spatial Structures 56, 4 (2015), 249-258.

[1 11 1 ] Todisco, L., Fivet, C., Corres-Peiretti, H., And Mueller, C. Design and exploration of externally post-tensioned structures using graphic statics. In Proceedings of the IASS Symposium (2015).

[112] Todisco, L., AND Mueller, C. Externally post-tensioned structures: validation through physical models. In Proceedings of the ICSA Symposium (2016). Article accepted.

[113] UnGEWITTER, K. Lehrbuch der gotischen konstruktionen. Weigel, Leipzig, 1890.

[114] United-Nations. World Urbanization Prospects: The 2014 Revision, vol. ST/ESA/SER.A/352. 2014.

[115] Van Mele, T., McInerney, J., DeJong, M., And Block, P. Physical and computational discrete modeling of masonry vault collapse. In Proceedings of the 8th International Conference on Structural Analysis of Historical Constructions (2012).

[116] VARIgnON, P. Nouvelle mécanique ou statique 1. Jombert, Paris, 1725. 


\section{REFERENCES}

[117] VeenendaAL, D., AND Block, P. Design process for prototype concrete shells using a hybrid cable-net and fabric formwork. Engineering Structures 75 (2014), 39-50.

[1 18 ] VSL. External post-tensioning. VSL Rep. Series, Switzerland, 1992.

[119] Wolfe, W. S. Graphical analysis; a text book on graphic statics. McGrawHill, New York, 1921. 


\title{
Colophon
}

\author{
7 HIS THESIS WAS TYPESET using \\ ${ }^{\mathrm{E}} \mathrm{T}_{\mathrm{E}} \mathrm{X}$, originally developed by Leslie \\ 1 Lamport and based on Donald Knuth's \\ $\mathrm{T}_{\mathrm{E}} \mathrm{X}$. The body text is set in 11 point Arno \\ Pro, designed by Robert Slimbach in the \\ style of book types from the Aldine Press in \\ Venice, and issued by Adobe in 2007. A \\ template, which can be used to format a $\mathrm{PhD}$ \\ thesis with this look and feel, has been \\ released under the permissive MIT (X1 1) \\ license, and can be found online at \\ github.com/suchow/ or from the author at \\ suchow@post.harvard.edu.
}

